\title{
Genetics in the news : studying the effects of mass media genetic health messages on health cognitions and behaviour
}

Citation for published version (APA):

Smerecnik, C. M. R. (2010). Genetics in the news : studying the effects of mass media genetic health messages on health cognitions and behaviour. [Doctoral Thesis, Maastricht University]. Universitaire Pers Maastricht. https://doi.org/10.26481/dis.20100204cs

Document status and date:

Published: 01/01/2010

DOI:

10.26481/dis.20100204cs

Document Version:

Publisher's PDF, also known as Version of record

\section{Please check the document version of this publication:}

- A submitted manuscript is the version of the article upon submission and before peer-review. There can be important differences between the submitted version and the official published version of record. People interested in the research are advised to contact the author for the final version of the publication, or visit the DOI to the publisher's website.

- The final author version and the galley proof are versions of the publication after peer review.

- The final published version features the final layout of the paper including the volume, issue and page numbers.

Link to publication

\footnotetext{
General rights rights.

- You may freely distribute the URL identifying the publication in the public portal. please follow below link for the End User Agreement:

www.umlib.nl/taverne-license

Take down policy

If you believe that this document breaches copyright please contact us at:

repository@maastrichtuniversity.nl

providing details and we will investigate your claim.
}

Copyright and moral rights for the publications made accessible in the public portal are retained by the authors and/or other copyright owners and it is a condition of accessing publications that users recognise and abide by the legal requirements associated with these

- Users may download and print one copy of any publication from the public portal for the purpose of private study or research.

- You may not further distribute the material or use it for any profit-making activity or commercial gain

If the publication is distributed under the terms of Article $25 \mathrm{fa}$ of the Dutch Copyright Act, indicated by the "Taverne" license above, 


\title{
Genetics in the news \\ Studying the effects of mass media genetic health messages on health cognitions and behaviour.
}

\author{
PROEFSCHRIFT \\ ter verkrijging van de graad van doctor \\ aan de Universiteit Maastricht, \\ op gezag van de Rector Magnificus, \\ prof. mr. G. P. M. F. Mols \\ volgens besluit van het College van Decanen, \\ in het openbaar te verdedigen \\ op donderdag 4 februari 2010 om 12:00 uur \\ door \\ Chris Martinus Robertus Smerecnik
}




\section{Promotores}

Prof. dr. N. K. de Vries

Prof. dr. H. de Vries

\section{Co-promotor}

Dr. I. Mesters

\section{Beoordelingscommissie}

Prof. dr. B. van den Borne (voorzitter)

Prof. dr. G. Kok

Prof. dr. T. Marteau (King's College, London)

Prof. dr. A. Brand

Dr. R. Meertens

Colophon

Printed by Datawyse / Universitaire Pers Maastricht

Lay-out by Bilbo Schickenberg

(c) Chris Smerecnik, 2009

ISBN:

The studies presented in this dissertation were financially supported by Maastricht University and performed under the auspices of the School for Public Health and Primary Care (Caphri), a part of the Netherlands School of Primary Care Research (CaRe), which was acknowledged by the Royal Netherlands Academy of Arts and Sciences (KNAW) in 1995. 
Live.Love.Burn.Die. 


\section{Content}

$\begin{array}{lll}\text { Chapter } 1 & \text { General introduction } & 7\end{array}$

Chapter 2 Educating the general public about 19

multifactorial genetic disease: Applying a theory-based framework to understand current public knowledge

Chapter 3 Applying a theory-based framework to understand public knowledge of genetic risk factors: A case for the distinction between howto and principles knowledge

Chapter 4 Alerting the general population to genetic risks: The value of health messages communicating the existence of genetic risk factors for public health promotion

Chapter 5 Genetic health messages and preventive action: Do the general public perceive genetic health message as personally relevant?

Chapter 6 An empirical test of the materialist framework 101 for understanding the general population's reaction to genetic health messages

Chapter 7 General discussion 


\section{Chapter 1}

General introduction 


\section{Introduction}

Imagine you are being told that the amount of salt you consume affects your blood pressure. This may or may not come as a shock to you; you may already be familiar with this fact. But imagine you are also told that the extent to which salt affects the blood pressure differs between people. How does this information affect you? Do you think you are one of the people for whom salt greatly affects the blood pressure or rather one for whom it hardly has an effect on the blood pressure? Now imagine you are being told that individual differences in the extent to which salt affects the blood pressure are genetically determined. There is a genetic variant that causes the blood pressure to greatly respond to salt consumption or not. How does this information influence your belief about whether or not your blood pressure is likely to respond to salt consumption? Does this information motivate you to restrict your salt consumption? In this dissertation, I will present several studies that examined these and similar questions. In particular, these studies will focus on how communicating the existence of genetic risk factors for a given disease affects people's belief of personal susceptibility to that disease, their intention to engage in preventive behaviour and preventive action itself.

\section{The history of genetics in a nutshell}

It is important to note at this point that this dissertation is not concerned with genetics per se, but, instead, focuses on communication about genetic risks to the general population. In particular, the research presented in this dissertation concerns the effects of mass media messages about the role of genes in health and disease on health cognitions and preventive behaviour among the general population. However, a short history of professional knowledge of genetics may illustrate the difficulties encountered by geneticists throughout the years. As such, it illustrates the difficulty lay people may experience when confronted with genetic information.

In 1865, Mendel presented his Laws of Segregation and of Independent Assortment at two meetings of the Natural History Society of Brünn (Mendel, 1865). At that time, however, Mendel's 'laws of inheritance' were largely ignored. Mendel's laws were rediscovered at the beginning of the twentieth century and the term 'gene' (which he derived from the Latin word genese) was introduced to refer to individual 'units' of inheritance. The underlying structure and working mechanisms of genes, however, remained largely unknown. Initially, geneticists were convinced that the deoxyribonucleic acid (DNA) consisted of a triple helix structure. 
However in 1953, Watson and Crick (1953; 1953) definitively suggested the double helix structure which we know today to be the underlying structure of DNA. Since then, molecular genetics has undergone a revolution which culminated in the initiation of the Human Genome Project in 1990 (National Institutes for Health, 2009). The Human Genome Project aimed at a complete sequencing of the three billion base pairs in the human genome. Since the completion of the Human Genome Project in 2003 nearly two thousand disease genes have been identified and over 350 genetic tests have become available for a variety of diseases (National Institutes for Health, 2009). Advances in genetic science are enormous and may prove hard to keep up with, even for experts.

\section{Genetics and public health}

The availability of technological (e.g., genetic testing) and biochemical (e.g., pharmacogenetics) applications of genomics has incited a debate of whether and how to integrate professional knowledge of genetics into public health efforts. The value of genomics for public health, it seems, is not beyond doubt. Professional opinions about the role of genomics in public health are quite diverse, ranging from scepticism to euphoria. For instance, Holtzman and Marteau (2000, p. 144) write that "In our rush to fit medicine with the genetic mantle, we are losing sight of other possibilities for improving the public health. Differences in social structure, lifestyle, and environment account for much larger proportions of disease than genetic differences. Although we do not contend that the genetic mantle is as imperceptible as the emperor's new clothes were, it is not made of the silks and ermines that some claim it to be. Those who make medical and science policies in the next decadewould do well to see beyond the hype."

On the other hand, Zimmern and colleagues (2001, p. 1005) assert that "In time, health promotion programmes may take into account individual susceptibility to disease and provide more individualised approaches to behavioural change. Public health professionals will need to explore how genetic factors influence health and disease in populations and target interventions, such as screening programmes, at genetically defined subpopulations to improve their efficiency."

Recently a more nuanced picture has been painted in which both the difficulties and the value of integrating genomics into public health efforts have been recognized (Brand, Brand, \& Schulte in den Baumen, 2007). This perspective also recognizes the need to educate the general public about genomics and its value for disease prevention and health promotion. That is, if technological and 
biochemical applications are to be successfully implemented in public health programmes, the general public needs to be educated about their existence and about genetics in general (Kardia \& Wang, 2005). Indeed, "health literacy, health communication and empowerment in managing risks are the key for opening the doors to a truly beneficial public health genetics" (Brand, 2005, p. 116). As such, public education of genetics is one important facilitator of the integration of genomics into public health efforts.

\section{Genetics and health in the mass media}

The ultimate value of genetic information has been suggested to lie in its ability to personalize risks for individual members of the general population by referring to interpersonal differences in DNA structure (Guttmacher \& Collins, 2005; Janssens \& Van Duijn, 2008). Recent research suggests that personalized DNA risk information on obesity (Frosch, Mello, \& Lerman, 2005), smoking (Sanderson, Humphries, Hubbart, Hughes, J arvis, \& Wardle, 2008), and hypercholesterolemia (Marteau et al., 2004) may result in enhanced preventive behaviour. Health messages directed at the general population, however, inevitably lack such personalization. That is, mass media messages are unable to definitively show whether or not the predisposing gene is present for a given individual member of the general public.

One popular outlet for scientific discoveries in general and of genetics in particular is the mass media. Moreover, public health campaigns often use the mass media to reach the general population. Consequently, for a large majority of the general population knowledge of genetics is primarily acquired through the mass media (Conrad, 1997; Geller, Bernhardt, \& Holtzman, 2002; Ikeda, 2008). Although the mass media have been used to communicate the role of genes in health and disease, the mass media may not necessarily be an effective means to enhance preventive behaviour by communicating about the existence of individual differences in DNA structure (Smerecnik, Mesters, De Vries, \& De Vries, 2008).

The mass media have eagerly reported on the announcement of the Human Genome Project (Tambor, Bernhardt, Rodgers, Holtzman, \& Geller, 2002) and resulting discoveries of disease genes (Bubela \& Caulfield, 2004). 'Gene defect explains high blood pressure' (BBC News, 2003), 'Blood pressure gene affects 20\%' (BBC News, 2008) and 'Single gene link to heart health' (BBC News, 2004) are relatively common expressions found in the mass media. Research has shown that certain genetic terms (such as mutation) may often carry negative connotations and associations among a large majority of the general public (Condit, Achter, Lauer, \& Sefcovic, 2002; Condit, Dubriwny, Lynch, \& Parrott, 2004). Several authors 
have suggested that mass media messages that employed words with negative connotations may have adverse effects on persuasion (Condit et al., 2002; Condit et al., 2004). Other authors have also warned against the use of genetic health messages in the media or in public health campaigns but for different reasons. For instance, it has been suggested that genetic health messages lead to an overestimation of the influence of genes and an underestimation of the influence of lifestyle factors on disease development (De Vries, Mesters, Van de Steeg, \& Honing, 2005). However, these objections to the use or efficacy of genetic health messages are based primarily on assumptions or on theoretical grounds. Little or no research has examined the effects of mass media genetic health messages on preventive behaviour and its socio-cognitive determinants. Without such insight, genetic-based public health campaigns may 'do more harm than good' (Condit, 2001; Khoury, Thrasher, Burke, Gettig, Fridinger, \&J ackson, 2000).

Research into the impact of genetic health messages, however, is scarce and a closer examination of how these messages affect behaviour change is warranted (Saab et al., 2004). Health messages communicating the role of genetic polymorphisms (i.e. variants) in health and disease are increasingly prevalent in our society. It is thus imperative that we investigate the effect of genetic health messages in the mass media on relevant health cognitions and preventive behaviour and its psycho-social determinants.

\section{Mass communication}

Mass media communications have received a considerable amount of attention in the second half of the twentieth century. Several mass communication models or theories have been proposed. One theory, the Theory of Consonance and Dissonance (Van Cuilenberg \& Noomen, 1984), seems especially relevant to the research presented in this dissertation. This model is especially suited to situations in which communication may lead to disagreement or conflict between the message and a person's opinions or beliefs rather than situations in which communications aim at potential agreement or increasing consensus and consonance (McQuail \&Windahl, 1993).

\section{The Theory of Consonance and Dissonance}

According to the Theory of Consonance and Dissonance, people screen all incoming messages with the aim of reducing potential dissonance (i.e. selective perception). As such, people tend to avoid exposure to messages that conflict with their current knowledge, opinions, goals and motivations (i.e., selective reception). However, due to inefficiency of this process or a changing context, conflicting 
messages with new or contrary information are received which may result in dissonance. The Theory of Consonance and Dissonance posits the two main possibilities for restoring consonance or balance: (1) change the perceptions of the source (e.g., perceiving the source as less credible or attractive) or (2) change the existing opinion, goal or motivation. Cognitive Dissonance Theory (Festinger, 1962) provides a more detailed list of possible reactions to decrease dissonance. According to this theory, a person can (1) add consonant cognitions, (2) remove dissonant cognitions (e.g., suppress or ignore them), (3) replace existing cognitions with others by subtracting dissonant cognitions and replacing them with consonant ones, (4) increase the importance of consonant cognitions, or (5) reduce the importance of dissonant cognitions. Notwithstanding, low levels of dissonance are unlikely to result in any changes (of the perception of the source or of people current opinions), medium levels of dissonance are likely to result in revision of people's opinions, while high levels of dissonance are likely to result in a rejection of the message and the source (McQuail \& Windahl, 1993; for a similar discussion see Social Judgment Theory: Sherif \& Hovland, 1961).

The Theory of Consonance and Dissonance highlights two issues that are relevant for this dissertation. First, this theory assumes that mass media messages are either consonant or dissonant with existing knowledge, opinions, goals and motivations and that whether a message is consonant or dissonant determines its effect on the message recipient. As such, when examining the effects of genetic health messages among the general population, it is important to take into account people's current level of genetic knowledge and relevant opinions and beliefs.

Second, genetic health messages would only be expected to result in changes if these messages create some degree of dissonance. Thus, people who were not aware of the genetic risk factors of a given disease at the moment of information exposure are likely to experience dissonance since the information is new and is perceived as conflicting with their current knowledge. In contrast, people who were aware at the moment of information exposure are not likely to experience dissonance and thus no changes are necessary. This reasoning is consistent with argumentation theory, which posits that an argument will only lead to persuasion if it is correct, new, and relevant to the topic under consideration (Vinokur \& Burnstein, 1978).

\section{Mass media effects}

One prominent goal of mass media communications is to encourage the adoption of an innovation (McQuail \& Windahl, 1993). E. M. 
Rogers (2003) argues that, at the individual level, this process involves five distinct steps: knowledge, persuasion, decision, implementation and confirmation. During the knowledge phase, people are exposed to messages communicating the existence of the innovation and gain understanding of how it functions. Rogers (2003) distinguishes three types of increasingly complex types of knowledge: awareness knowledge, how-to knowledge and principles knowledge (see Chapter 2 for a more detailed description of this framework). After people have acquired the necessary knowledge of the innovation (where 'necessary' is a subjective interpretation), people should be persuaded about the merits and advantages of the innovation. In the decision phase, people engage in activities which lead to the decision to adopt or reject the innovation. People may thus decide to reject the innovation, but once they decided to adopt it, they will start to use the innovation (the implementation phase). Finally, in the confirmation phase, people seek reinforcement for the decision they made. They may reverse their decision if they are exposed to conflicting messages. The primary reasons for discontinuance are dissatisfaction with the innovation or finding a better alternative to the innovation. Rogers (2003) assumes that the diffusion of innovations normally involves different communication sources. For instance, while the mass media are probably superior sources when imparting knowledge, experience of use may be an important source in the confirmation phase (McQuail \&Windahl, 1993).

For the present purpose, this framework suggests that knowledge, and especially awareness knowledge, is a first step in behaviour change based on genetic information. Mass media communications are particularly suited for the task of communicating awareness knowledge of genetic risk factors because of their reach. After the general population is aware of the existence of genetic risk factors for a given disease and possess more detailed knowledge of genetics and health, they need to be persuaded that genetic risk factors are an important aspect of disease development. Moreover, they should be persuaded that these genetic risk factors are relevant for their personal situation. However, as McQuail \& Windahl (1993) argue, the mass media may not be the ideal source for this phase. Indeed, the mass media lack the ability to personalize communications (i.e. to definitively argue whether or not the predisposing gene is present). As such, people may not accept genetic health messages as credible and / or may not consider these messages to be personally relevant.

In this dissertation, Rogers' knowledge framework is discussed in Chapter 2 and applied to understand the Dutch general public's knowledge of genetics in Chapter 3. The effects of mass media genetic 
health messages will be examined on risk perception (Chapters 4,5 and 6), intention (Chapters 4, 5, and 6), and preventive behaviour (Chapter 6). In all these studies, the moderating role of awareness status was also investigated. As such, all five phases of Rogers model will be studied: 'knowledge' by examining the role of awareness, howto and principles knowledge; 'persuasion' by looking at effects on risk perception; 'decision' by investigating intention to engage in preventive behaviour; and, finally, 'implementation' and 'confirmation' by examining preventive behaviour.

\section{Salt sensitivity}

Examining effects of genetic health messages necessarily implies alerting the general population to the genetic risk factors for some specific disease. The previous example of salt sensitivity of the blood pressure will be used for the studies presented in this dissertation. Salt sensitivity refers to the fact that some individuals show a greater increase in blood pressure following similar amounts of salt intake compared to others (Weinberger, 1991). A number of different polymorphisms seem to be causally involved in this phenomenon (Beeks, Kessels, Kroon, Van der Klauw, \& De Leeuw, 2004; Sanada et al., 2006). The alpha-adducin polymorphism Gly 460 Trp has been suggested to be the most important of these (Beeks et al., 2004; Cusi, Barlassina, Azzani, Casari, Citterio, \&Devoto, 1997).

We chose to investigate the effects of alerting the general population to the existence of genetic risk factors for salt sensitivity for several reasons. First, the general population is already largely aware of the relationship between salt consumption and increased blood pressure and the risk this carries for cardiovascular disease. Second, and related, the genetic polymorphism for salt sensitivity has been discovered fairly recently. Consequently, the genetic risk factors for salt sensitivity are relatively unknown among the general population. As such, using salt sensitivity in our studies may provide a good approximation to mass media messages reporting the discovery of new disease genes. Third, the Dutch general population has been shown to consume approximately 9 grams of salt each day, which is about $50 \%$ over the recommended 6 grams (Van den Hooven, Fransen, Jansen, \& Ocke, 2007). Fourth, an estimated 40\% of the population has the alpha-adducin polymorphism which predisposes for salt sensitivity. As such, a large portion of the general population may gain additional benefits from this knowledge.

\section{Aims of this dissertation}

Although genetic health messages are increasingly prevalent in our society, their ability to enhance preventive behaviour among the 
general population has received little attention in the empirical literature (Saab et al., 2004). Following the Theory of Consonance and Dissonance, prior knowledge is crucial in determining whether genetic health messages result in dissonance and, as such, have an impact on the message recipient. Indeed, research has consistently shown that individual responses to genetic health message are, at least partly, determined by prior knowledge (Marteau \& Weinman, 2006; Morgan, Fischhoff, Bostrom, \& Atman, 2002). Any investigation into the effects of genetic health messages on preventive behaviour among the general population should thus begin with examining the public's current level of genetic knowledge. The first aim of this dissertation is therefore to examine the current level of genetic knowledge among the Dutch general population.

Although research has shown that personalised DNA risk information on, for instance, obesity (Frosch et al., 2005), smoking (Sanderson et al., 2008), and hypercholesterolemia (Marteau et al., 2004) may result in enhanced preventive behaviour, little research has examined whether genetic health messages in the mass media can effectively improve healthy behaviour. The second aim was therefore to examine the ability (or lack thereof) of general, non-personalised genetic health messages to enhance preventive behaviour among the general population. The Theory of Consonance and Dissonance argues that genetic health messages would only be expected to result in changes if these messages create dissonance. In line with this argument, argumentation theory posits that an argument will only lead to persuasion if it is correct, new, and relevant to the topic under consideration (Vinokur \& Burnstein, 1978). Therefore, information about the existence of genetic risk factors may be expected to only affect individuals who were unaware of the existence of genetic risk factors for salt sensitivity at the moment of information exposure (i.e., for whom the information is new). However, information about the existence of genetic risk factors could also influence previously aware individuals by enhancing accessibility. The discrepancy between prior knowledge and information is, however, likely to be larger among the previously unaware individuals. Moreover, a health message's impact on preventive behaviour is probably related to individuals' confidence in reaching a decision in accordance with their current motivational concerns (Eagly \& Chaiken, 1993). The third aim of this dissertation was therefore to examine whether or not the effects of genetic health messages on health cognitions and behaviour differ according to whether message recipients are aware or unaware of the existence of these genetic risk factors at the moment of information exposure. 
The strength of genetic information to improve preventive behaviour has been argued to lie in its ability to personalise risks for individual members of the general population by refrerring to individual differences in DNA (Guttmacher \& Collins, 2005; J anssens $\&$ Van Duijn, 2008). However, since the mass media may lack the ability to individualise risks (i.e. definitively show whether or not the gene is present), genetic health messages in the mass media may not prove to be effective in improving relevant health cognitions and preventive behaviour because these messages may not be accepted or viewed as personally relevant. Indeed, the Theory of Consonance and Dissonance and the Cognitive Dissonance Theory suggest that a revision of the message or the source is one strategy people may use to reduce dissonance as a result of conflicting messages. The fourth aim was therefore to examine whether the general public accepts genetic health messages and whether they perceive such messages as personally relevant. Moreover, the potentially mediating or moderating effects of message acceptance and personal relevance in explaining the effects of genetic health messages on relevant health cognitions and preventive behaviour were examined.

Finally, a recently developed framework for understanding laypeople's responses to genetic information (Condit, Gronnwoll, Landau, Shen, Wright, \& Harris, 2009) provided an alternative explanation for the effects of genetic health messages on health cognitions and behaviour. According to this framework, when people are primed with a genetic health message in the mass media, they may use the so-called genetic causation model to determine their reaction to the message. This genetic causation model is highly deterministic and may therefore have resulted in defensive strategies such as underestimating personal susceptibility. Examining this possible explanation for the effects of genetic health messages was the fifth and final aim of this dissertation.

\section{Outline of this dissertation}

The present dissertation is based on the observation that health messages communicating the role of genes in health and disease are increasingly prevalent in the mass media. Research into the impact of genetic health messages, however, is scarce and a closer examination of whether and how these messages affect health cognitions and behaviour change is warranted (Saab et al., 2004). This dissertation first describes a systematic review of the general public's knowledge of genetics adopting Roger's knowledge framework to distinguish genetic knowledge types (Chapter 2). In Chapter 3, this knowledge framework is used to present an in-depth overview of the Dutch general public's knowledge of genetics. Based on the findings 
presented in these two chapters, three experimental studies were designed and conducted to examine the impact of genetic health messages on risk perception and the intention to engage in preventive behaviour. These studies are described in Chapter 4. Next, Chapter 5 describes a large-scale study to replicate the results from the studies in Chapter 4 among a sample representative of the Dutch general population. Additionally, this study corrects several limitations of the previous studies (e.g., pre-test assessments of the outcome variable) and examines the possible role of information acceptance and perceived personal relevance. Finally, a test of the materialist framework of laypeople's knowledge of genetics was conducted and described in Chapter 6. The results of these studies are discussed in the General discussion. In this final chapter the findings of the present studies will be integrated and a theoretical framework is proposed that may explain the findings and anchor them in a theoretical basis. At the same time, this theoretical framework leads to the development of implications for future research and practice. 


\section{Chapter 2}

Educating the general public about multifactorial genetic disease: Applying a theory-based framework to understand current public knowledge

Published as: Smerecnik, C. M. R., Mesters, I., DeVries, N. K. \&De Vries, H. (2008). Educating the general public about multifactorial genetic disease: Applying a theory-based framework to understand current public knowledge. Genetics in Medicine, 10, 251-258. 


\begin{abstract}
The present paper describes the application of a theory-based framework to understand current public knowledge of genetic risk factors of multifactorial diseases. The main innovative aspect is the application of E. M. Rogers' knowledge framework which distinguishes three types of knowledge: "awareness knowledge," "how-to knowledge," and "principles knowledge." We argue that distinguishing these types of knowledge allows for a more sophisticated overview of that of the general public. To illustrate the application of Rogers' framework, we performed a literature review of current public knowledge of genetic risk factors of multifactorial genetic diseases. Relevant papers were identified by searching the Pubmed, Web of Science, Embase, CINAHL, ERIC and PsycINFO databases from J anuary 1990 until J anuary 2007 and by performing reference list and author searches. While this review showed that current public knowledge is limited, it also showed that the knowledge framework may be a useful tool for assessing different types of public knowledge and pinpointing flaws or caveats in public knowledge with more precision and subsequently develop public health campaigns to remedy such flaws. Implications for genetic education are discussed.
\end{abstract}




\section{Introduction}

As genetic science evolves, genetic predispositions to medical conditions are increasingly better understood. The completion of the Human Genome Project in 2003 has vastly increased professional knowledge of genetics (Collins, Green, Guttmacher, \& Guyer, 2003). The discovery of so-called polymorphisms (i.e. genetic variants) has broadened the scope of genetic risks from single-gene disorders to multifactorial diseases (World Health Organization, 2002). These advances in the understanding of genetic predispositions to disease have several implications for public health promotion (Center for Disease Control, 2006); the most obvious being whether and how to use genetic information to promote public health (Khoury et al., 2000). Investigating public understanding of genetic information is therefore an important dimension of the translation of professional genetic knowledge into public health benefits (Kardia \& Wang, 2005).

Since knowledge is considered one of the prerequisites of health behaviour (Prochaska \& DiClemente, 1984; 1992; Weinstein, 1988), a necessary first step in public health promotion involves increasing the general public's knowledge of the genetic risk factors of multifactorial diseases (Collins et al., 2003). E.M. Rogers' conceptualization of knowledge distinguishes three types of increasingly complex knowledge: "awareness knowledge", which refers to knowledge about the existence of an innovation; "how-to knowledge", which is practical knowledge concerning the proper use of innovation; and "principles knowledge", or knowledge of the underlying theoretical principles of the innovation (Rogers, 2003). Although increasing awareness knowledge is an important first step, public health programs should not neglect the other two forms of knowledge. Indeed, if how-to knowledge is not acquired before or during the adoption of the innovation, discontinuance is highly likely (Rogers, 2003).

Although a considerable body of literature has shown the value of this knowledge framework in understanding public knowledge of technical innovations (Geibert, 2006; Kautz \& Larsen, 2000), there is relatively scarce research on the value of this framework for the diffusion of new knowledge or ideas. We propose that Rogers's knowledge framework is a valuable asset to the diffusion of (professional) knowledge of genetic risk factors to the general public for two reasons. First, the distinction between awareness, how-to and principles knowledge presents a sophisticated overview of public knowledge of genetic risk factors. Second, it allows us to pinpoint caveats in the public's knowledge with more precision and adapt future public health campaigns to remedy them with appropriate strategies. 
In the case of diffusing professional knowledge of genetic risk factors, awareness knowledge refers to simply knowing that there are genetic risk factors for a particular disease. This type of knowledge may act as a motivator to acquire how-to and principles knowledge (Rogers, 2003). For instance, knowing of the existence of genetic risk factors can motivate individuals to assess their family history or opt for genetic counseling and testing (Jallinoja \& Aro, 2000). Knowing of the existence of genetic risk factors for a certain disease, however, does not guarantee adequate use of professional knowledge of genetic risk factors in decision-making concerning preventive behaviour (e.g., assessing family history or changing unhealthy lifestyles). To this end, how-to knowledge is needed. How-to knowledge refers to practical knowledge of genetic risk factors such as knowing how genetic risk factors influence the overall risk of developing the disease (e.g., knowing that there is no one-on-one relationship between genetic risk and disease development).

In contrast, principles knowledge refers to theoretical knowledge of genetic risk factors, such as knowledge of the underlying working mechanisms through which genetic risk factors affect disease development (e.g., knowing that certain polymorphisms create a genetic predisposition which interacts with other factors to develop the disease). Although adequate decision making can occur without proper principles knowledge, the risk of falsely using perceived knowledge of genetic risk factors in decision-making is substantially higher without it (Rogers, 2003). For instance, a flawed or speculative understanding of how a disease can be genetic if the disease has not yet been observed in the family (as could be the case in recessive disonders or certain polymorphisms) has been shown to adversely affect health behaviour (Chapple, May, \& Campion, 1995; Van den Nieuwenhoff, Mesters, Gielen, \& De Vries, 2007).

The general public thus needs to know that polymorphisms interact with other genes and environmental factors, such as lifestyle, to cause the development of the disease (Khoury, 2003). Understanding the complexity of gene-environment interactions (i.e., how and why genetic risk factors affect the development of multifactorial diseases) may prevent feelings of fatalism due to unchangeable genetic predispositions and increase motivation to change unhealthy lifestyles, both in the absence, but especially in the presence of a genetic predisposition. Despite the importance of such knowledge for adequate preventive behaviour, little research has focused on the general public's knowledge of genetic risk factors and how and why these factors affect health (Health Council of the Netherlands, 2003). However, future health promotion programs intended to increase public knowledge of genetic risk factors for 
multifactorial diseases are likely to be unsuccessful if they disregard the public's prior knowledge (Richards \& Ponder, 1996).

We propose in this paper that applying Rogers' knowledge framework to map current public knowledge of genetic risk factors of multifactorial diseases will provide us with valuable insights on the structure of public knowledge as well as guide and assist future research and public education about multifactorial genetic disease. To illustrate the application of Rogers' framework, we performed a literature review of the general public's current knowledge of genetic risk factors of multifactorial diseases. The value of Roger's knowledge framework will be discussed in light of the results of this review.

\section{Methods}

\section{Search Strategy}

Literature searches were conducted in the Pubmed, Web of Science, Embase, CINAHL, ERIC and PsycINFO databases from J anuary 1990 until January 2007. The following keywords were exhaustively combined: awareness, knowledge, general public, general population community, lay understanding, genetic risk, familial risk, multifactorial disease, and genetic risk factors. Further, we also performed reference list and author searches. Table 2.1 specifies the inclusion criteria used to identify relevant studies.

Table 2.1. Inclusion and exclusion criteria.

\begin{tabular}{ll}
\hline Inclusion criteria & Exclusion criteria \\
\hline $\begin{array}{l}\text { Studies should focus on awareness, how- } \\
\text { to, or principles knowledge of genetic risk } \\
\text { factors of multifactorial diseases }\end{array}$ & $\begin{array}{l}\text { Examined knowledge of inheritance and } \\
\text { genetics in general }\end{array}$ \\
\hline $\begin{array}{l}\text { Participants should be representative of } \\
\text { the general population without being } \\
\text { specifically educated about genetic risk } \\
\text { factors by professionals }\end{array}$ & $\begin{array}{l}\text { Participants are individuals who know } \\
\text { they have a genetic predisposition or have } \\
\text { attended genetic counseling or other } \\
\text { education about genetic risk factors }\end{array}$ \\
\hline $\begin{array}{l}\text { Studies should describe original articles } \\
\text { published in a peer-reviewed J ournal }\end{array}$ & $\begin{array}{l}\text { Concerned editorials, commentaries, } \\
\text { book reviews, bibliographies, resources } \\
\text { or policy documents } \\
\text { Reported secondary data analysis or only } \\
\text { reviewed other studies }\end{array}$ \\
\hline
\end{tabular}

\section{Study Selection}

The selection process was completed in three separate phases. During the first phase, papers were selected or excluded based on their titles only. Studies selected for further review and those that could not be 
excluded without doubt proceeded to the second phase of the review process. Papers judged relevant based on their abstracts were included in the present review; those deemed irrelevant were excluded. In the third and final phase of the selection process, the remaining papers were exhaustively reviewed for content.

We included papers that examined either awareness, how-to or principles knowledge of genetic risk factors of multifactorial diseases among the general public. Papers were excluded if they examined knowledge of genetics in general or knowledge of genetic risk factors among individuals attending genetic counselling clinics. From an initial sample of 1174 eligible papers, we selected 20 for the present review. Due to the heterogeneity of the studies, we opted against pooling the data and thus against a meta-analysis of these studies. Relevant data were abstracted and summarized in Tables 2.2 and 2.3.

\section{Results}

Awareness Knowledge of Genetic Risk Factors

According to Rogers' suggestion, the first phase of public health education should focus on increasing awareness of the existence of the genetic risk factors of multifactorial diseases. Several studies have examined public awareness of the genetic risk factors of many multifactorial diseases in a wide variety of countries (see Table 2.2). Overall, these studies suggest that the general public is reasonably aware of the genetic risk factors of multifactorial diseases, with approximately 59\% (range: 17.6-93.3\%) of the sample being aware of the existence of genetic risk factors, although much lower (Waller, McCaffery, \& Wardle, 2004) and much higher (Ackermann, Renner, Fasching, Poehls, Bender, \& Beckmann, 2005) proportions have also been observed.

Most studies, however, showed differences in public awareness of the genetic risk factors for different types of cancer. For instance, on average approximately $60 \%$ was aware of the genetic risk factors for breast cancer, whereas some studies observed that only approximately $20 \%$ was aware of the genetic risk factors of cervical cancer. Since we were not able to identify more than one study examining public awareness of heart disease, environmentally induced conditions and hypercholesterolemia, we were unable to draw any conclusions regarding public awareness of these conditions.

Several studies observed that awareness of genetic risk factors of multifactorial diseases is highly dependent on socio-demographic factors. For instance, individuals with low educational levels were less aware of genetic risk factors compared with highly educated individuals (Mogilner, Otten, Cunningham, \& Brower, 1998; Tambor, 
Rimer, \& Strigo, 1997; Van den Nieuwenhoff, Mesters, \& De Vries, 2006; Waller et al., 2004). African Americans were less likely to be aware of genetic risk factors than Caucasians (Mogilner et al., 1998), and women were more aware than men (Van den Nieuwenhoff et al., 2006; Waller et al., 2004).

The studies reviewed here show a mixed view of public awareness of genetic risk factors of multifactorial diseases, with little over half the population being aware of the existence of such risk factors. The overall picture may, however, be somewhat poorer, since being aware of genetic risks factors does not guarantee a clear understanding of how they influence health.

\section{How-to Knowledge of Genetic Risk Factors}

Although public knowledge of genetics has been relatively little investigated (Health Council of the Netherlands, 2003), a few studies have examined the public's knowledge of the genetic risk factors of multifactorial diseases (see Table 2.3). With regards to how-to knowledge, the central question concerns whether the general public has practical knowledge of genetic risk factors and how they influence the risk of development of multifactorial disease. The few studies examining this type of knowledge show that the general public's knowledge seems limited. For instance, Donovan and Tucker (2000) observed that the public has limited knowledge on how genetic risk factors influence health, especially when compared to other risk factors. However, the general public does seem to understand that having a genetic predisposition implies heightened, but not absolute risk (Bates, Templeton, Achter, Harris, \& Condit, 2003; Inoue, Iwasaki, Otani, Sasazuki, \&Tsugane, 2006; McMenamin et al., 2005; Mesters, Ausems, \&De Vries, 2005).

In line with the studies on the general public's awareness of genetic risk factors, these studies seem to suggest that knowledge of how the genetic risk factors of multifactorial diseases affect health is largely dependent on socio-demographic factors, such as ethnicity (Donovan \& Tucker, 2000), gender (McMenamin et al., 2005), and level of education (De Vries et al., 2005; Henneman, Timmermans, \& Van der Wal, 2004). 
Chapter 2 | Theory-based framework of genetic knowledge

Table 2.2. Studies examining the general public's awareness knowledge of genetic risk factors for multifactorial diseases.

\begin{tabular}{|c|c|c|c|c|c|}
\hline Study & Country & Design & Sample & Disease & Outcome \\
\hline $\begin{array}{l}\text { Ackermann et } \\
\text { al.(2005) }\end{array}$ & Germany & Quantitative & $\begin{array}{l}2108 \text { of } 23 \text { gynaelogical } \\
\text { outpatient services }\end{array}$ & Cervical cancer & $\begin{array}{l}\text { 93.3\% identified genetic risk factors of } \\
\text { cervical cancer }\end{array}$ \\
\hline $\begin{array}{l}\text { Bottorff et al. } \\
(2002)\end{array}$ & Canada & Quantitative & $\begin{array}{l}761 \text { women without family } \\
\text { history and } 260 \text { women with a } \\
\text { family history }\end{array}$ & Breast cancer & $\begin{array}{l}\text { Approximately } 80 \% \text { of each group was } \\
\text { aware of the existence of breast cancer } \\
\text { genes }\end{array}$ \\
\hline $\begin{array}{l}\text { Bruno et al. } \\
\text { (2004) }\end{array}$ & Italy & Quantitative & $\begin{array}{l}677 \text { healthy women with or } \\
\text { without a family history }\end{array}$ & Breast cancer & $\begin{array}{l}77 \% \text { self-reported having heard about the } \\
\text { existence of breast cancer genes. Women } \\
\text { with and without a family history did not } \\
\text { differ with regards to awareness of the } \\
\text { existence of breast cancer genes }\end{array}$ \\
\hline $\begin{array}{l}\text { Hunt et al. } \\
\text { (2001) }\end{array}$ & England & Qualitative & $\begin{array}{l}61 \text { men and women from } \\
\text { middle and working class were } \\
\text { selected from a large cross- } \\
\text { sectional survey and } \\
\text { subsequently interviewed }\end{array}$ & Heart disease & $\begin{array}{l}\text { More than two-thirds spontaneously } \\
\text { mentioned genetic risk factors }\end{array}$ \\
\hline $\begin{array}{l}\text { Keighley, et al. } \\
\text { (2004) }\end{array}$ & $\begin{array}{l}21 \text { European } \\
\text { countries }\end{array}$ & Quantitative & $\begin{array}{l}20.710 \text { individuals over } 16 \\
\text { years of age representative of } \\
\text { general population in Europe }\end{array}$ & Colorectal cancer & $\begin{array}{l}54 \% \text { was aware of the genetic risk factor of } \\
\text { colorectal cancer }\end{array}$ \\
\hline $\begin{array}{l}\text { Mogliner et al. } \\
\text { (1998) }\end{array}$ & United States & Quantitative & $\begin{array}{l}354 \text { female patients of Mount } \\
\text { Sinai Medical Center }\end{array}$ & Breast cancer & $\begin{array}{l}\text { Overall, approximately 50\% was aware of } \\
\text { BRCA1/ } 2 \text { genes. Participants of African- } \\
\text { American descent (19\%) and those who } \\
\text { only completed elementary school (13\%) } \\
\text { were relatively unaware compared to }\end{array}$ \\
\hline
\end{tabular}


Chapter 2 | Theory-based framework of genetic knowledge

\begin{tabular}{|c|c|c|c|c|c|}
\hline Study & Country & Design & Sample & Disease & Outcome \\
\hline & & & & & $\begin{array}{l}\text { Caucasians (68\%) and those who } \\
\text { completed graduate school ( } 71 \%) \text {. }\end{array}$ \\
\hline $\begin{array}{l}\text { Morris et al. } \\
\text { (2003) }\end{array}$ & United States & Quantitative & $\begin{array}{l}2,353 \text { individuals contacted in } \\
\text { a national survey }\end{array}$ & $\begin{array}{l}\text { Four } \\
\text { environmentally } \\
\text { induced conditions }\end{array}$ & $\begin{array}{l}\text { Public awareness of genetic risk factors of } \\
\text { environmentally induced conditions is } \\
\text { limited; } 32 \% \text { is unaware of genetic risk } \\
\text { factors of environmentally induced } \\
\text { conditions }\end{array}$ \\
\hline $\begin{array}{l}\text { Tambor et al. } \\
\text { (1997) }\end{array}$ & United States & Quantitative & $\begin{array}{l}473 \text { women without an } \\
\text { increased risk of breast cancer }\end{array}$ & Breast cancer & $\begin{array}{l}51 \% \text { was aware of the existence of breast } \\
\text { cancer genes. Lower-educated individuals } \\
\text { (less than high school) were } 2.5 \text { times less } \\
\text { likely to be aware of genetic risk factors. }\end{array}$ \\
\hline $\begin{array}{l}\text { Van den } \\
\text { Nieuwenhoff } \\
\text { et al. (2006) }\end{array}$ & Netherlands & Quantitative & $\begin{array}{l}4117 \text { individuals } \\
\text { representative of the general } \\
\text { population }\end{array}$ & $\begin{array}{l}\text { Inherited high } \\
\text { cholesterol }\end{array}$ & $\begin{array}{l}50 \% \text { was aware of inherited high } \\
\text { cholesterol. Higher-educated individuals } \\
\text { were more aware than lower-educated } \\
\text { individuals }(\mathrm{OR}=1.73, \mathrm{p}<.001) \text {. Women } \\
\text { were more likely to be aware than men } \\
(\mathrm{OR}=1.40, \mathrm{p}<.001)\end{array}$ \\
\hline $\begin{array}{l}\text { Waller et al. } \\
\text { (2004) }\end{array}$ & Great Britain & Quantitative & $\begin{array}{l}1940 \text { individuals } \\
\text { representative of the British } \\
\text { population }\end{array}$ & Cervical cancer & $\begin{array}{l}17.6 \% \text { reported genetic factors as playing a } \\
\text { role in the development of cervical cancer. } \\
\text { Higher educated individuals were more } \\
\text { aware of genetics as a risk factor ( } 23.3 \%) \\
\text { than lower-educated individuals (11.4\%). } \\
\text { Women were also more aware than men } \\
\text { (19.9\% versus } 14.5 \%)\end{array}$ \\
\hline $\begin{array}{l}\text { Wardle et al. } \\
\text { (2001) }\end{array}$ & Great Britain & Quantitative & $\begin{array}{l}3693 \text { adults representative of } \\
\text { the British population }\end{array}$ & Cancer & $\begin{array}{l}\text { Awareness of genetic risk factor was } \\
\text { relatively low compared to awareness of } \\
\text { other risk factors: approximately } 50 \% \text { was }\end{array}$ \\
\hline
\end{tabular}


Chapter 2 | Theory-based framework of genetic knowledge

\begin{tabular}{|c|c|c|c|c|c|}
\hline Study & Country & Design & Sample & Disease & Outcome \\
\hline & & & & & $\begin{array}{l}\text { aware of the genetic risk factor of breast } \\
\text { cancer to approximately } 22 \% \text { for lung } \\
\text { cancer }\end{array}$ \\
\hline $\begin{array}{l}\text { Welkenhuyse } \\
\text { n et al. (2001) }\end{array}$ & Belgium & Quantitative & $\begin{array}{l}329 \text { women from Flemish } \\
\text { Belgium }\end{array}$ & Breast cancer & $\begin{array}{l}79 \% \text { reported being aware of hereditary } \\
\text { breast cancer }\end{array}$ \\
\hline
\end{tabular}




\section{Principles Knowledge of Genetic Risk Factors}

Principles knowledge is the most complex form of knowledge, focusing on theoretical issues such as why genetic risk factors affect the development of multifactorial diseases in the way they do. Only one study has examined the public's principles knowledge: Mesters and colleagues (2005) observed that although participants recognized the increased risk due to genetic risk factors, their knowledge of the working mechanisms of genetic factors was (highly) inadequate. Since participants associated cancer with faulty cells, they were unable to distinguish between the genetic aspect of cancer and the 'faulty cell'. Mesters and colleagues concluded that the general public's principles knowledge is largely insufficient and superficial.

\section{Discussion}

The present review shows that the general public has limited awareness knowledge of genetic risk factors as a cause of multifactorial disease and even less knowledge of how and why these factors affect health. On average, just over half the research sample was aware of the existence of genetic risk factors of multifactorial diseases (i.e. awareness knowledge). Furthermore, although the public seems to understand that having a genetic predisposition means heightened and not absolute risk, they seem to have limited how-to and principles knowledge of genetic risk factors.

We should note that the studies we reviewed were not conducted with Rogers' framework of knowledge in mind. Our analysis of the potential utility of the knowledge framework is thus limited to the pooled data. Although most studies did distinguish awareness from general knowledge, we argue that distinguishing knowledge into awareness, how-to, and principles knowledge allows for a more detailed picture of the general public's knowledge. The distinction between awareness, (practical) how-to, and (theoretical) principles knowledge depicts a knowledge continuum representing an increasingly complex form of knowledge. This continuum, ranging from being aware of the existence at one end to knowing the underlying mechanisms of genetics at the other end, allows us to better map public knowledge and enables us to set a threshold amount of knowledge the public ought to possess in order to accurately process new information. Unfortunately, we were not able to identify such a threshold, partly due to the fact that the original studies were not conducted with the Rogers framework in mind. Future research examining the general public's knowledge of genetic 
Chapter 2 | Theory-based framework of genetic knowledge

Table 2.3. Studies examining the general public's how-to and principles knowledge of genetic risk factors for multifactorial diseases.

\begin{tabular}{|c|c|c|c|c|c|}
\hline Study & Country & Design & Sample & Disease & Outcome \\
\hline $\begin{array}{l}\text { Bates et } \\
\text { al. (2003) }\end{array}$ & United States & Qualitative & $\begin{array}{l}108 \text { individuals from urban, } \\
\text { suburban and rural } \\
\text { communities in Georgia } \\
\text { were interviewed }\end{array}$ & Heart disease & $\begin{array}{l}\text { Overall, participants perceived genetic } \\
\text { predisposition to mean heightened but not } \\
\text { absolute risk and result in an increased risk } \\
\text { of becoming sick. }\end{array}$ \\
\hline $\begin{array}{l}\text { Bottorff et } \\
\text { al. (2002) }\end{array}$ & Canada & Quantitative & $\begin{array}{l}761 \text { women without family } \\
\text { history and } 260 \text { women } \\
\text { with a family history }\end{array}$ & Breast cancer & $\begin{array}{l}\text { Knowledge was relatively limited (mean }=4 \\
\text { on a } 0-7 \text { scale). Women with a family history } \\
\text { did not show superior knowledge compared } \\
\text { with women in the general public. }\end{array}$ \\
\hline $\begin{array}{l}\text { De Vries et } \\
\text { al. }(2005)\end{array}$ & Netherlands & Quantitative & 457 Dutch adults & Cancer & $\begin{array}{l}\text { Although the majority of participants } \\
\text { recognized that genetic risk factors increase, } \\
\text { but do not determine cancer development, } \\
\text { they overestimated the role of these factors } \\
\text { (52\%) and how they cause the development } \\
\text { of cancer. Higher-educated individuals had } \\
\text { more knowledge of how genetic risk factors } \\
\text { cause cancer than lower-educated } \\
\text { individuals. }\end{array}$ \\
\hline $\begin{array}{l}\text { Donovan \& } \\
\text { Tucker } \\
(2000)\end{array}$ & United States & Quantitative & $\begin{array}{l}220 \text { women awaiting } \\
\text { routine medical services }\end{array}$ & Breast cancer & $\begin{array}{l}\text { Knowledge about how genetic risk factors } \\
\text { affect risk (mean }=7 \text { on a } 0 \text { - } 14 \text { scale) was } \\
\text { less than knowledge about other risk factors } \\
\text { (mean }=12 \text { on a } 0 \text { - } 18 \text { scale). Caucasians had } \\
\text { more knowledge than African Americans ( } 7.7 \\
\text { versus } 7.0, p=.02 \text { ). }\end{array}$ \\
\hline
\end{tabular}


Chapter 2 | Theory-based framework of genetic knowledge

\begin{tabular}{|c|c|c|c|c|c|}
\hline Study & Country & Design & Sample & Disease & Outcome \\
\hline $\begin{array}{l}\text { Henneman } \\
\text { et al. (2004) }\end{array}$ & Netherlands & Quantitative & $\begin{array}{l}817 \text { individuals from a } \\
\text { Dutch consumer panel }\end{array}$ & Not specified & $\begin{array}{l}\text { The majority of the sample had adequate } \\
\text { knowledge of genetic risk factors. Higher- } \\
\text { educated individuals and men had more } \\
\text { knowledge than lower-educated individuals } \\
\text { and women. }\end{array}$ \\
\hline $\begin{array}{l}\text { Inoue et al. } \\
\text { (2006) }\end{array}$ & J apan & Quantitative & $\begin{array}{l}1355 \text { individuals } \\
\text { representative of general } \\
\text { population }\end{array}$ & Cancer & $\begin{array}{l}\text { Participants accurately perceived genetic } \\
\text { predisposition as resulting in heightened } \\
\text { risk of developing cancer. }\end{array}$ \\
\hline $\begin{array}{l}\text { McMenamin } \\
\text { et al. (2005) }\end{array}$ & Ireland & Quantitative & $\begin{array}{l}1250 \text { women and } 1105 \text { men } \\
\text { from the general population }\end{array}$ & Breast cancer & $\begin{array}{l}\text { The majority of the participants accurately } \\
\text { reported increased risk due to genetic risk } \\
\text { factors ( } 77 \% \text { of the men and } 92 \% \text { of the } \\
\text { women). }\end{array}$ \\
\hline $\begin{array}{l}\text { Mesters et } \\
\text { al. (2005) }\end{array}$ & Netherlands & Qualitative & $\begin{array}{l}40 \text { women and } 9 \text { men were } \\
\text { interviewed }\end{array}$ & Cancer & $\begin{array}{l}\text { Although participants recognized the } \\
\text { increased risk due to genetic risk factors, } \\
\text { their knowledge of the working mechanisms } \\
\text { of genetic factors was (highly) inadequate }\end{array}$ \\
\hline
\end{tabular}


risk factors using Rogers' knowledge framework will be able to do just that. Moreover, the knowledge framework will also allow us to pinpoint flaws or caveats in public knowledge with more precision and subsequently develop public health campaigns to remedy such flaws. Indeed, our results suggest that while the public's how-to knowledge is limited, the public's principles knowledge is largely insufficient; a finding that would not have been observed using only the awareness-knowledge distinction.

Moreover, recent research has shown that individuals implicitly make a distinction between practical how-to knowledge and theoretical principles knowledge (Emery, Kumar, \& Smith, 1998; Hendriks \& De Vries, 2002). Several studies have shown that individuals were only interested in the consequences of genetic risk factors and how to manage them, and were not at all interested in the underlying genetic principles (Emery et al., 1998). Similarly, the public has no need for detailed information on the working mechanism of DNA, but is interested in more practical knowledge of the role of genetics in the development of cancer (e.g., identifying the signs of a genetic predisposition to cancer, Hendriks \& De Vries, 2002). Such general lack of interest in the theoretical mechanisms of genetic risk factors until such knowledge is relevant (Mesters et al., 2005) may also explain why the general public's principles knowledge is largely insufficient. More importantly, however, these issues suggest that the knowledge framework is a useful tool to understand the general public's knowledge of genetic risk factors.

Perhaps unsurprisingly, awareness, how-to and principles knowledge appear to be largely dependent on socio-demographic factors, such as ethnicity, gender and level of education. Ethnic minorities and lower-educated individuals seem to have less knowledge than Caucasians and higher-educated individuals (Honda, 2003). Although these results do not add to the existing literature, they do highlight the resulting caveat in current public health promotion practices. More specifically, although the dissemination of genetic information to the general public has received considerable attention in the last decade (Center for Disease Control, 2006), the present results on the relationship between socio-demographics and knowledge suggest that professional knowledge on genetic predispositions may not yet have been equally disseminated. Our results suggest that the diffusion of genetic knowledge should especially focus on ethnic minorities and the lower-educated segment of the population, as it is these which seem to lag behind.

The translation of genetic knowledge from the professional to the layman, however, 'goes beyond mere dissemination and/ or diffusion' (Einsiedel, 2006, p. 433). Knowledge translation is a complex 
process, which is at least partly due to the complexity and incompleteness of genetic knowledge itself. Indeed, even among health educators (Chen \& Goodson, 2007) and medical experts (Baars, Henneman, \& ten Kate, 2005; Baars, Scherpbier et al., 2005; Wonkam, Njamnshi, \& Angwafo, 2006) knowledge of genetics is surprisingly low. Consequently, it may be argued that the observed differences in knowledge between lower- and higher-educated individuals may not only be due to incomplete dissemination, but also to the complexity of the disseminated information. Indeed, lowereducated individuals have more difficulty understanding genetic information than higher-educated individuals (Lerman et al., 1996), which can also be seen from our results. Moreover, this perceived difficulty of genetic information may discourage lower-educated individuals from even attempting to process genetic messages.

Since our review suggests that ethnic minorities and lowereducated individuals are the least knowledgeable and have more difficulties understanding genetic information, we suggest special attention be paid to both the dissemination of genetic knowledge to these segments and their abilities to understand genetic information. One possibility would be to simplify the information without changing its meaning. However, since other factors (e.g., the relevance of the information) beyond its complexity may also influence behaviour or decision making, we first need to understand the different ways by which the public processes such information (Einsiedel, 2006).

Recent research in this area suggests that the public has at least some understanding of genetics in general. For instance, Lanie and colleagues (2004) observed that the public seems to understand to some extent the gene-environment interaction underlying the development of multifactorial diseases. Alarmingly, however, they also observed general confusion about basic terms such as 'genes' and 'genetics,' and argued that such confusion may adversely impact public understanding of more complex genetic messages (also see the World Health Organization (2002) report on Genomics and world health). These misconceptions may also explain our finding that the public's how-to and principles knowledge is limited and superficial. Indeed, research has shown that misconceptions about basic genetic terms may lead to incorrect processing of new information about genetic risk factors for multifactorial diseases, especially when individuals are unaware of their misconceptions (Renner \& Renner, 2001; Richards, 1996).

These issues raise the question of whether informing the general public about genetic risk factors of multifactorial diseases is an effective strategy in promoting public health. Although knowledge of 
such factors can potentially serve as a cue to action or otherwise motivate individuals to engage in preventive behaviour, it may not contribute to preventive behaviour over and above knowledge of other risk factors in high-risk individuals (Marteau \& Lerman, 2001). Furthermore, for previously unaware individuals, information on the existence of genetic risk factors actually decreases perceived susceptibility and as a result leads to lower motivation to engage in preventive behaviour (unpublished data, 2007). In promoting public health, one should therefore not focus on increasing awareness knowledge alone, which may produce adverse effects, but at the same time increase understanding of how and why genetic risks influence the development of multifactorial diseases.

Unfortunately, our results suggest that increasing awareness knowledge is the outcome of recent public health campaigns. In other words, while the general public has reasonable awareness knowledge, they lack adequate how-to and principles knowledge. On the one hand, previous campaigns may have neglected the more complex how-to and principles knowledge. On the other hand, these campaigns may have tried to address such knowledge, but failed due to existing misconceptions about genetics. Both explanations suggest that future campaigns should first determine the target group's prior knowledge, and then build upon it to increase how-to and principles knowledge, ensuring accurate interpretation of the new information. Although the public may be primarily interested in how-to knowledge (Emery et al., 1998; Hendriks \& De Vries, 2002), we indeed suggest not neglecting principles knowledge. Indeed, Seemann (2003) suggested that education should not only focus on the know-how of a subject, but also on the know-why. For present purposes, having accurate knowledge of the underlying mechanisms or principles knowledge substantially increases, but is not necessary to, the proper use of how-to knowledge in decision-making processes and preventive behaviour (Rogers, 2003). Moreover, individuals seem interested in principles knowledge when they deem it personally relevant (Mesters et al., 2005) and should thus be available. Aocurate principles knowledge may also allow for the transfer of this knowledge to other health issues.

Advances in genetic science have provided public health promoters with information about genetic aspects of multifactorial diseases and consequently enabled them to use this information in educating the general public. However, public health promotion has a long way to go concerning public understanding of genetic risk factors and why these factors increase, but do not determine, the risk of developing multifactorial diseases. For now, we may need to mark time and ask ourselves how to effectively educate the general public 
about the genetic risk factors of multifactorial disease. On the one hand, the complexity of genetic information may lead to misunderstanding and misconceptions which, in turn, may result in the incorrect processing of new information. On the other hand, learning of the existence of genetic risk factors may not only have no effect on preventive behaviour; it may indeed have adverse effects. Furthermore, too much media attention to genetic risk factors can lead to an overestimation of the impact of such factors (De Vries et al., 2005), and consequently to an underestimation of the impact of lifestyle on disease development. Such misconceptions may reduce the public's motivation to change their lifestyles in response to information about genetic risk factors.

To conclude, the knowledge framework as suggested by E.M. Rogers proved to be a useful tool in broadening our insight into public knowledge of genetic risk factors. It allowed us to differentiate between knowledge which grows more complex by degree, in gradual stages. Future research may use this knowledge framework to provide a more detailed overview of the general public's knowledge of genetic risk factors. As genetic knowledge was lower among ethnic minorities and the lower-educated segment of the population, we suggest detailed attention be paid to both the dissemination of genetic knowledge to these segments and their abilities to understand genetic information. However, before using genetic information in public health promotion, we need to understand how such information is processed, how it influences subsequent decision-making, and whether it effectively motivates individuals to engage in preventive behaviour. Once we have identified the processes through which knowledge of genetic risk factors successfully influences preventive behaviour, information about genetic risk factors, as determined by Rogers's knowledge framework, will be a valuable asset to the public health promotion repertoire. 


\section{Chapter 3}

\section{Applying a theory-based framework to understand public knowledge of genetic risk factors: A case for the distinction between how-to and principles knowledge}

Accepted for publication as: Smerecnik, C. M. R., Mesters, I., De Vries, N. K., \&De Vries, H. (in press). Applying a theory-based framework to understand public knowledge of genetic risk factors: A case for the distinction between how-to and principles knowledge. Public Health Genomics. 


\begin{abstract}
Objective. Using E. M. Rogers' knowledge framework as presented in his seminal innovation-decision process, this paper aims to present an overview of the general public's knowledge of genetics. It also makes a first attempt to examine the statistical validity of this framework.

Methods. A sample of 2500 members of the Dutch general population was presented with a questionnaire containing measures of three increasingly complex forms of knowledge: awareness knowledge, (practical) how-to knowledge, and (theoretical) principles knowledge.

Results. The general public seems to be moderately aware of genetic risk factors for multifactorial diseases. In general, how-to knowledge seems fair, whereas principles knowledge is limited and superficial. Additional analyses provided empirical evidence for the distinction between awareness knowledge, how-to knowledge and principles knowledge.

Conclusion. The innovation-decision process, and specifically Rogers's knowledge framework, provides a useful tool for public education of genetics. Future research may build upon and extend our findings by examining the persuasion, decision, implementation, and possibly the confirmation stages of the innovation-decision process concerning genetic education.
\end{abstract}




\section{Introduction}

Five years after the completion of the Human Genome Project (Collins et al., 2003), almost 2000 disease genes have been discovered and more than 1000 genetic tests for human conditions are available (National Institutes for Health, 2009). Although such technical and biochemical applications of professional knowledge of genetics are usually considered the spearheads of genetic advancement, the ultimate and immediate value of such applications is enhanced by educating the general public about genetics (Burke et al., 2002; Wang, Bowen, \& Kardia, 2005). A recent review of the general public's knowledge of genetic risk factors for multifactorial diseases (Smerecnik et al., 2008) suggested that future efforts in education and research into public knowledge of genetics should aim to distinguish three types of increasingly complex knowledge: awareness knowledge, which refers to knowledge about the existence of an innovation; how-to knowledge, which is practical knowledge concerning the proper use of the innovation; and principles knowledge, or knowledge of the underlying theoretical principles of the innovation.

This knowledge framework was initially proposed by E. M. Rogers (2003) as a first step in the innovation-decision process. Rogers (2003) assumes that an individual's decision to adopt or reject an innovation is a process that occurs over time and consists of a series of different phases: namely, knowledge, persuasion, decision, implementation, and confirmation (see Figure 3.1). For the present purpose, an innovation could be new knowledge on the relationship between genetics and disease occurrence. In the knowledge phase, an individual comes into contact with this idea and gains some understanding of its working mechanisms. This knowledge may lead to the formation of a favorable or unfavorable attitude towards the innovation in the persuasion stage. Based on this attitude, the individual decides whether to adopt or reject the innovation (i.e., the decision phase) and starts to use the innovation (i.e., the implementation phase), which entails precautionary action, such as getting a genetic test or engaging in preventive behavior. Finally, in the confirmation phase, the individual seeks confirmation of the decision. In this phase the individual may decide to reverse the decision if and when exposed to conflicting or ambivalent messages about the innovation.

Considering the complexity of genetic communication and the relative scarcity of empirical research conducted in the public 
Chapter 3 | Public knowledge of genetic risk factors

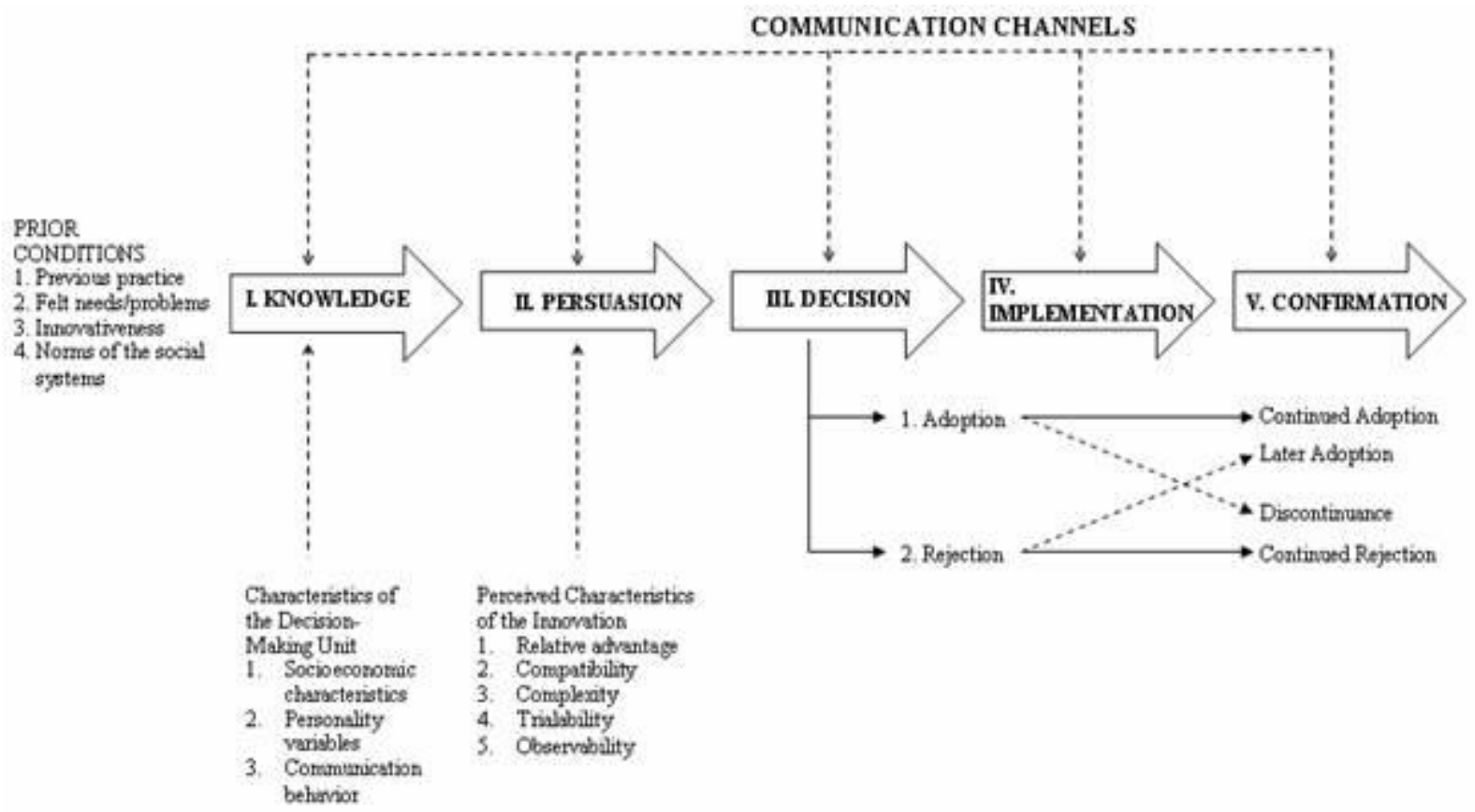

Figure 3.1. An illustration of the innovation-decision process proposed by E. M. Rogers (2003). 
health communication area, this paper will focus on the first step in the innovation-decision process. Although we recognize that the knowledge phase is only the first step in the innovation-decision process, we believe that elucidating the current general public's knowledge of genetics by using Rogers's knowledge framework may deepen our understanding of public knowledge and may simultaneously provide a solid base to examine the next stages of the innovation-decision process in future research.

A considerable body of literature has shown the value of Rogers's knowledge framework in understanding public knowledge of technical innovations (e.g., Geibert, 2006; Kautz \& Larsen, 2000). For instance, how-to knowledge has been found to be positively related to internet usage (Porter \& Donthu, 2006) and the application of theoretical guidelines in practice (Weingardt \& Villafranca, 2005). There is, however, relatively little research on the value of this framework for the diffusion of new knowledge or ideas, especially concerning genetics (cf. Smerecnik et al., 2008).

When applying Rogers's knowledge framework to genetic knowledge, awareness knowledge refers to being aware of the existence of genetic risk factors for a particular disease (i.e., knowing that a particular disease is at least partly caused by genes). Although awareness knowledge does not guarantee adequate use of professional knowledge of genetic risk factor in decision making concerning preventive behavior, it may motivate individuals to acquire more complex how-to knowledge and principles knowledge (J allinoja \& Aro, 2000; Rogers, 2003). How-to knowledge refers to practical knowledge of how genetic risk factors influence disease development, such as knowing that some multifactorial genetic diseases only manifest themselves later in adult life. In other words, how-to knowledge is essential for the adequate use of genetic information in health decision-making processes. In contrast, principles knowledge refers to more complex, theoretical knowledge of genetic risk factors, such as knowledge of the underlying working mechanisms through which genetic risk factors affect disease development (e.g., knowing that certain polymorphisms create a genetic predisposition to a given disease that interacts with other factors to develop the disease). In essence, principles knowledge deals with the theoretically complex functioning of the working mechanisms underlying how genetics works. Although Rogers (2003) suggests that adequate decision making can occur without proper principles knowledge, the risk of falsely using perceived knowledge of genetic risk factors in decision making is substantially higher without it (cf. Chapple et al., 1995; Van de Nieuwenhoff, Mesters, Gielen, \& De Vries, 2007). 
According to a recent review of the general public's knowledge of genetics that categorised existing research on public knowledge of genetics into Rogers's knowledge framework (Smerecnik et al., 2008), more than half the general population was aware of the genetic risk factors for a wide variety of multifactorial genetic diseases. The public's how-to knowledge seemed to be limited, whereas the public's principles knowledge of genetics was observed to be poor and superficial. The authors note, however, that the original studies included in their review were not conducted explicitly to reflect Rogers's knowledge framework. As such, the results may reflect an artificial pooling rather than qualitatively different forms of knowledge. The first goal of the present study was, therefore, to provide an overview of the general public's knowledge of genetics by assessing the three increasingly complex forms of knowledge: awareness knowledge, how-to knowledge, and principles knowledge.

The value of Rogers's knowledge framework for understanding the general public's knowledge of genetics has, so far, been justified on theoretical grounds only. The value and validity of the awareness, how-to and principles knowledge distinction has thus far not been investigated. In addition to our first goal, our second goal was therefore to investigate the relationship between awareness, how-to and principles knowledge and to examine the empirical evidence for the distinction of these three forms of knowledge. Rogers (2003) suggests that awareness knowledge is positively related to how-to knowledge. Thus, we expected that participants who reported having awareness knowledge were likely to have more how-to knowledge than participants who did not report having awareness knowledge (hypothesis 1). The subdivision of knowledge into practical how-to knowledge and theoretical principles knowledge has only been proposed recently - at least when applied to genetics (Smerecnik et al., 2008). Since principles knowledge is assumed to be more complex than how-to knowledge (Rogers, 2003), item response theory may be particularly suited to test whether how-to and principles knowledge are in fact distinct forms of knowledge. If principles knowledge indeed represents a distinct, more complex form of knowledge than how-to knowledge, item response theory would make the following two predictions: (1) If an individual lacks how-to knowledge (operationalized by performing a median-split procedure on the howto knowledge scores and as an 'incorrect' score on a how-to knowledge statement), he or she should also lack principles knowledge (operationalized as a score of ' 0 ' on the accompanying principles knowledge index of the how-to knowledge statement; hypothesis 2). (2) If an individual does have adequate principles knowledge (operationalized by performing a median-split procedure 
on the principles knowledge scores), he or she should also have howto knowledge (operationalized as a 'correct' score on the accompanying how-to knowledge statement; hypothesis 3). In contrast, having how-to knowledge does not guarantee principles knowledge, and not having principles knowledge is unrelated to having or not having how-to knowledge.

To summarize, the purpose of the present study was twofold. First, we attempted to provide an overview of the Dutch general public's knowledge of the genetic risk factors of multifactorial diseases, guided by Rogers's knowledge framework. Second, we aimed to test the empirical validity of the distinction between awareness, how-to and principles knowledge.

\section{Methods}

\section{Participants}

A total of 2500 individuals were approached via an Internet consumer panel affiliated with Maastricht University. This panel has a total of 20,000 members from among whom representative samples can be drawn. Respondents were rewarded for their participation in line with the norms of the consumer panel.

\section{Procedure}

The internet consumer panel sent emails to the 2500 individuals who had been selected to form a sample representative of the general population (see Table 3.1). The email contained an internet link to a login page. The link expired after one week. After logging into their account, participants could fill out the current questionnaire, containing measures of socio-demographic characteristics and awareness, how-to and principles knowledge. Before answering any questions, they were asked to read an introductory text. This text informed them that the purpose of the questionnaire was to examine what they knew about multifactorial diseases, and provided them with a definition of these diseases. When finished with the questionnaire, participants were automatically redirected to the consumer panel's homepage.

\section{Measures}

Demographic characteristics. Participants' age, sex, and level of education were known from the internet consumer panel.

Awareness knowledge. Although we were primarily interested in awareness knowledge of genetic risk factors for multifactorial diseases, we assessed both participants' awareness knowledge of 
multifactorial diseases (Had you ever heard of a multifactorial disease prior to this study? $1=$ yes, $0=$ no) and their awareness knowledge of genetic risk factors for multifactorial diseases (Had you ever heard of genetic predisposition to multifactorial diseases prior to this study? $1=$ yes, $0=$ no). These questions were used separately in all analyses.

Perceived influence of genetics. We also asked participants whether they thought genetic risk factors influenced the development of multifactorial diseases (Do you think that genetic predispositions influence the development of multifactorial diseases? $1=$ yes, $2=$ no, and $3=$ don't know).

How-to knowledge. How-to knowledge was assessed by seven items (see Table 3.3). Six items were adopted from a previous study by Henneman and colleagues (2004). These items were checked in semi-structured interviews with five members of the general population, which resulted in the formulation of one additional item. The interviews suggested that the items represented common misconceptions about genetics and its influence on disease development. Example statements are: Healthy parents can have a child with a genetic disease and Some genetic disorders express themselves later in adult life, $1=$ true, $2=$ not true, and $3=$ don't know. Correct answers were recoded as ' 1 ', don't know answers as ' 0 ' and incorrect answers as ' 1 '. Since the how-to items were measured on a categorical scale, these seven items were summed into the howto knowledge score (rather than using a mean score which requires interval scales). This coding deviates from the original coding of Henneman and colleagues' study (2004), where correct answers were coded as ' 1 ' and incorrect and don't know answers as ' 0 '. Although additional analyses with the original coding revealed similar results to those with the present coding, we felt that the present coding was more detailed and thus provided more information about the general public's how-to knowledge ${ }^{1}$

Principles knowledge. We assessed principles knowledge by asking participants to comment on their own answers to the seven how-to knowledge questions. Principles knowledge was assessed using open-ended questions to ensure the diversity and richness of the answers. Moreover, open-ended questions provide the advantage of non-directive assessment, which is especially important when

\footnotetext{
${ }^{1}$ While it might seem questionable to present this scale as a definitive assessment of the scope and adequacy of the general public's how-to knowledge, it is worth pointing out that individuals rarely acquire scientific knowledge in isolation. We therefore assume that these seven items are a good indication of the presence or absence of other how-to knowledge about genetics and disease development (Allum, Sturgis, Tabourazi, \&Brunton-Smith, 2008; Sturgis \& Allum, 2004).
} 
examining public knowledge of genetics (Condit, 2001). To assess the accuracy of participants' answers, two professional geneticists were asked to provide the correct answers. Two raters independently compared participants' answers to those given by the professional geneticists on two different occasions. The geneticists and coders were blinded to whether or not participants had reported the correct answer to the how-to knowledge statements. Although participants' answers may have reflected awareness knowledge and how-to knowledge as well as principles knowledge, coders were instructed to specifically code participants' knowledge of the underlying working mechanisms explaining the how-to statements. Principles knowledge answers were scored on a five-point scale ranging from 0 to 4 based on this comparison. The following scoring system was used to rate participants' answers: incorrect answers were scored as 0; answers providing an example medical condition were scored as 1 (e.g., 'Healthy parents can have a child with Down Syndrome'); answers detailing experiential knowledge were scored as 2 (e.g., 'My daughter is diabetic and we, her parents, are not'); answers detailing implicit knowledge of the working mechanisms of genetics were scored as 3 (e.g., 'You can be a carrier of a faulty gene and if your partner has the same faulty gene, your child can inherit the disease'); and answers detailing explicit knowledge of working mechanisms of genetics were scored as 4 (e.g., Two carriers of a recessive gene can both pass this gene on to their child, who will then presumably develop the disorder. Because the parents' recessive genes are compensated by a dominant gene, they will not develop the disorder and thus appear healthy'). Agreement analyses revealed that the intra-rater reliability (ICCs > .93) was good. Also, the agreement between raters was adequate (ICC $=.86$ ). Given that this coding scheme may be considered somewhat ambiguous (e.g., we could not be certain that participants reporting experiential knowledge, for instance, did not possess implicit or even explicit knowledge), we repeated all principles knowledge analyses with a dichotomized coding $(0=$ no principles knowledge and $1=$ some to detailed principles knowledge). These analyses revealed similar results to the more elaborate coding. As we believe that the elaborate coding provided a more detailed overview of the general public's knowledge of genetics, the results section presents the analyses with the more elaborate coding.

\section{Results}

\section{Sample Characteristics}

In total, 1624 out of 2500 participants filled out the questionnaire, resulting in a $64.96 \%$ response rate. Table 3.1 presents the 
demographic characteristics of the final sample. This sample seems to provide a good cross-section of the general population in terms of age, sex and education level. To examine whether respondents differed from non-respondents, we performed chi-square tests with respondent (yes versus no) on the one hand, and sex, education level and age group on the other hand as variables. Analyses revealed no significant difference between respondents and non-respondents in terms of sex $\left(\chi^{2}(2)=0.002, p=.99\right)$ and education level $\left(\chi^{2}(2)=\right.$ $1.38, \mathrm{p}=.50$ ), but did reveal a significant difference concerning age, $\chi^{2}(2)=6.26, p=.04$. Respondents were more likely to be middle aged than non-respondents (53.2\% versus $36.8 \%$ respectively), and less likely to be of old age ( $14.7 \%$ versus $25.3 \%$ ).

\section{Awareness Knowledge}

Five hundred forty-nine (33.8\%) participants reported having heard of multifactorial diseases and two hundred ninety (17.9\%) participants reported having heard of genetic risk factors for multifactorial diseases. When asked, six hundred eleven (37.6\%) participants thought genetic risk factors had an influence on the development of multifactorial diseases, whereas nine hundred one (55.5\%) participants reported not knowing whether genetic risk factors had an influence on disease development.

Awareness knowledge of multifactorial diseases was associated with level of education and perceived genetic influence (see Table 3.2). Participants who were higher educated, those who assumed that genetic factors had any influence or no influence on disease development compared to those who did not know whether genetics factors influence disease development had more awareness knowledge of multifactorial diseases.

Awareness knowledge of genetic risk factors for multifactorial diseases was associated with perceived genetic influence. Those who perceived an influence or no influence of genetic risk factors on disease development compared to those who did not know whether genetics risk factors influence disease development, those reporting a positive as compared to an unknown family history of CVD, those reporting a positive as compared to an unknown family history of hypertension had more awareness knowledge of genetic risk factors for multifactorial diseases.

How-to Knowledge

On a - 7 to +7 scale, mean how-to knowledge score was 2.48 (SD = 2.53; range: -5 to +7 ). How-to knowledge was significantly associated with age, gender, level of education, perceived genetic influence (see 
Table 3.1. Demographic characteristics of the sample (subsample filling out principles knowledge questions in parenthesis).

\begin{tabular}{|c|c|c|c|c|}
\hline \multirow{2}{*}{$\begin{array}{l}\text { Demographic } \\
\text { characteristics }\end{array}$} & \multicolumn{2}{|c|}{ Respondents } & \multirow{2}{*}{$\begin{array}{c}\text { Total } \\
\text { sample, \% }\end{array}$} & \multirow{2}{*}{$\begin{array}{l}\text { Dutch } \\
\text { population } \\
\text { data, \% a } \\
\end{array}$} \\
\hline & $\%$ & $\mathbf{n}$ & & \\
\hline \multicolumn{5}{|l|}{ Gender } \\
\hline Male & $48.5(45.3)$ & $788(281)$ & 48 & 49.4 \\
\hline Female & $51.5(54.7)$ & 836 (339) & 52 & 50.6 \\
\hline \multicolumn{5}{|l|}{ Age } \\
\hline $20-39$ years & $32.1(36.9)$ & 522 (229) & 35 & 34.8 \\
\hline 40-64 years & $53.2(49.4)$ & 864 (306) & 45 & 46.2 \\
\hline$\geq 65$ years & $14.7(13.7)$ & $238(85)$ & 20 & 19.1 \\
\hline \multicolumn{5}{|l|}{ Level of education } \\
\hline Low & $31.7(26.8)$ & $515(166)$ & 30 & 33.4 \\
\hline Medium & $39.1(40.3)$ & $635(250)$ & 42 & 41.0 \\
\hline High & $29.2(32.9)$ & 474 (204) & 28 & 25.6 \\
\hline
\end{tabular}

Table 3.2). Older as compared to younger participants and men $(\mathrm{M}=$ $2.34, \mathrm{SD}=2.37)$ as compared to women $(\mathrm{M}=2.61, \mathrm{SD}=2.30, \mathrm{p}=$ $.02)$ had less how-to knowledge. High- ( $\mathrm{M}=3.37, \mathrm{SD}=2.20)$ and medium- $(\mathrm{M}=2.51, \mathrm{SD}=2.34)$ as compared to low-educated participants $(\mathrm{M}=1.62, \mathrm{SD}=2.14$, ps <.001), those who perceived an influence of genetic risk factors on disease development $(\mathrm{M}=3.09$, $\mathrm{SD}=2.30$ ) compared to those who did not know whether genetics risk factors influence disease development $(\mathrm{M}=2.06, \mathrm{SD}=2.30)$ had better how-to knowledge. Similar patterns were observed for individual items. Table 3.3 presents a detailed overview of the proportion of participants who correctly answered the individual statements stratified by level of education and gender.

\section{Principles Knowledge}

The characteristics of the subsample $(n=620)$ that filled out the principles knowledge questions are presented in Table 1 . Analyses revealed that participants who filled out the principles knowledge questions were slightly younger $(\mathrm{M}=46.47, \mathrm{SD}=16.03)$ than those who did not $(\mathrm{M}=48.83, \mathrm{SD}=14.83$, $\mathrm{t}(1622)=3.01, \mathrm{p}=.003)$, were more likely to be women than men ( $55 \%$ versus $50 \%$ of those who did not fill out the principles knowledge questions; $\chi^{2}=4.11, \mathrm{p}=.04$ ), and were more likely to be highly educated ( $43 \%$ versus $27 \%$ of those who 
Chapter 3 | Public knowledge of genetic risk factors

Table 3.2. Association of awareness, how-to and principles knowledge with demographic characteristics.

\begin{tabular}{|c|c|c|c|c|c|c|c|c|}
\hline \multirow[t]{2}{*}{$\begin{array}{l}\text { Demographic } \\
\text { variables }\end{array}$} & \multicolumn{2}{|c|}{$\begin{array}{c}\text { Awareness of } \\
\text { multifactorial diseases* }\end{array}$} & \multicolumn{2}{|c|}{$\begin{array}{c}\text { Awareness of genetic } \\
\text { risk factors* }\end{array}$} & \multicolumn{2}{|c|}{ How-to knowledge ${ }^{\ddagger}$} & \multicolumn{2}{|c|}{$\underset{f}{\text { Principles knowledge }}$} \\
\hline & $\beta$ & $\mathrm{p}$-value & $\beta$ & $\mathrm{p}$-value & $\beta$ & $\mathrm{p}$-value & $\beta$ & $\mathrm{p}$-value \\
\hline Age, years & .004 & .26 & .005 & .33 & -.23 & $<.001$ & -.12 & $<.001$ \\
\hline $\begin{array}{l}\text { Gender, men vs. } \\
\text { women }\end{array}$ & .116 & .18 & .106 & .48 & -.06 & $<.01$ & -.07 & .005 \\
\hline $\begin{array}{l}\text { Level of education } \\
\text { Medium vs. low } \\
\text { High vs. low }\end{array}$ & $\begin{array}{l}.530 \\
.658\end{array}$ & $\begin{array}{l}<.001 \\
<.001\end{array}$ & $\begin{array}{l}-.084 \\
.131\end{array}$ & $\begin{array}{l}.64 \\
.49\end{array}$ & $\begin{array}{l}.13 \\
.29\end{array}$ & $\begin{array}{l}<.001 \\
<.001\end{array}$ & $\begin{array}{l}.08 \\
.19\end{array}$ & $\begin{array}{c}.01 \\
<.001\end{array}$ \\
\hline $\begin{array}{l}\text { Perceived genetic } \\
\text { influence } \\
\text { Yes vs. don't know } \\
\text { No vs. don't know }\end{array}$ & $\begin{array}{l}1.258 \\
1.044\end{array}$ & $\begin{array}{l}<.001 \\
<.001\end{array}$ & $\begin{array}{l}2.181 \\
1.607\end{array}$ & $\begin{array}{l}<.001 \\
<.001\end{array}$ & $\begin{array}{l}.14 \\
.03\end{array}$ & $\begin{array}{c}<.001 \\
.22\end{array}$ & $\begin{array}{l}.10 \\
.04\end{array}$ & $\begin{array}{c}.002 \\
.15\end{array}$ \\
\hline
\end{tabular}

* Values based on logistic regression

‡ Values based on linear regression. 
did not fill out the principles knowledge questions; $\chi^{2}=12.84, p=$ .002). Additionally, participants who filled out the principles knowledge questions were more likely to be aware of multifactorial diseases (39.1\% versus $30.5 \%$ of those who did not fill out the principles knowledge questions, $x^{2}=13.01, p<.001$ ) and had more how-to knowledge $(\mathrm{M}=2.94, \mathrm{SD}=2.33)$ than those who did not fill out the principles knowledge questions $(\mathrm{M}=2.20, \mathrm{SD}=2.30, \mathrm{t}(1622)$ $=6.32, \mathrm{p}<.001$ ).

On a $0-4$ scale, in which 0 represents no principles knowledge and 4 represents the most developed principles knowledge, the mean principles knowledge score was 0.88 (SD $=0.77$; range: 0 to 4 ). Principles knowledge was significantly related to age, sex, and education level, but not to perceived influence of genetics, reporting a family history of CVD, or reporting a family history of hypertension. Younger as compared to older, female $(\mathrm{M}=0.93, \mathrm{SD}=0.79)$ as compared to male $(\mathrm{M}=0.82, \mathrm{SD}=0.75)$, higher educated $(\mathrm{M}=1.13$, $\mathrm{SD}=0.87)$ as compared to medium $(\mathrm{M}=0.85, \mathrm{SD}=0.73)$ and lower educated participants $(\mathrm{M}=0.63, \mathrm{SD}=0.60)$, and those with a medium education level versus those with a low level had better principles knowledge (see Table 3.2). Except for statements 2 and 4, similar patterns were observed for individual items. Table 3.4 presents a detailed overview of the mean principles knowledge score for individual statements stratified by education level and sex.

\section{Relationship Between Awareness, How-to And Principles Knowledge}

The second goal of the present study was to examine whether the distinction between awareness, how-to and principles knowledge can be supported by empirical evidence. Concerning the relationship between awareness knowledge and how-to knowledge, our first hypothesis was that participants who reported having awareness knowledge of genetic risk factors should have better how-to knowledge of genetic risk factors than participants who reported no awareness knowledge. The biserial correlation between awareness knowledge and how-to knowledge was medium-to-large and significant at the .01 level $\left(\mathrm{r}_{\mathrm{b}}=.49\right.$, CI $\left.=[.45 ; .53], \mathrm{p}<.01\right)$. Preliminary analyses revealed that the distribution of how-to knowledge scores was not normal in the aware and the unaware groups (Kolmogorov-Smirnov's Z $=.13$ and .10 respectively, ps < .001). Furthermore, Levene's test of variance revealed that the aware and unaware groups did not have equal variances in terms of how-to knowledge, $\mathrm{F}=4.32, \mathrm{p}=.04$. Therefore, we conducted a nonparametric statistical test (i.e., the Mann-Whitney test). This analysis revealed that participants who reported being aware of the existence 
Chapter 3 | Public knowledge of genetic risk factors

Table 3.3. Number of correct answers (percentages in parenthesis) to the how-to knowledge statements stratified by level of education and gender.

\begin{tabular}{|c|c|c|c|c|c|c|}
\hline \multirow[t]{2}{*}{ How-to knowledge statement } & \multicolumn{3}{|c|}{ Level of education } & \multicolumn{2}{|c|}{ Gender } & \multirow[t]{2}{*}{ Total } \\
\hline & Low & Middle & High & Male & Female & \\
\hline \multicolumn{7}{|c|}{$\begin{array}{l}\text { Healthy parents can have a child with a } \\
\text { genetic disease }(\mathrm{T})\end{array}$} \\
\hline Correct & $324(62.9)$ & $476(75.0)$ & 412 (86.9) & $583(74.0)$ & $629(75.2)$ & $1212(74.6)$ \\
\hline Incorrect & $37(7.2)$ & $38(6.0)$ & $13(2.7)$ & $42(5.3)$ & $46(5.5)$ & $88(5.4)$ \\
\hline Don't know & $154(29.9)$ & $121(19.1)$ & $49(10.3)$ & $163(20.7)$ & $161(19.3)$ & $324(20.0)$ \\
\hline \multicolumn{7}{|c|}{$\begin{array}{l}\text { If a person has a genetic predisposition for a } \\
\text { disease, this person will certainly get this } \\
\text { disease (F) }\end{array}$} \\
\hline Correct & 358 (69.5) & $502(79.1)$ & 426 (89.9) & $589(74.7)$ & $697(83.4)$ & $1286(79.2)$ \\
\hline Incorrect & $29(5.6)$ & $18(2.8)$ & $4(0.8)$ & $31(3.9)$ & $20(2.4)$ & $51(3.1)$ \\
\hline Don't know & $128(24.9)$ & $115(18.1)$ & $44(9.3)$ & $168(21.3)$ & 119 (14.2) & $287(17.7)$ \\
\hline \multicolumn{7}{|c|}{$\begin{array}{l}\text { A disease is only genetically determined if } \\
\text { more than one family member is affected }(\mathrm{F})\end{array}$} \\
\hline Correct & $111(21.6)$ & $220(34.6)$ & $206(43.5)$ & $276(35.0)$ & $261(31.2)$ & $537(33.1)$ \\
\hline Incorrect & $198(38.4)$ & $215(33.9)$ & $150(31.6)$ & $265(33.6)$ & $298(35.6)$ & $563(34.7)$ \\
\hline Don't know & $206(40.0)$ & $200(31.5)$ & $118(24.9)$ & $247(31.3)$ & $277(33.1)$ & $524(32.3)$ \\
\hline \multicolumn{7}{|c|}{ Genetic diseases always skip a generation (F) } \\
\hline Correct & $199(38.6)$ & $276(43.5)$ & $239(50.4)$ & $290(36.8)$ & $424(50.7)$ & $714(44.0)$ \\
\hline Incorrect & 89 (17.3) & $95(15.0)$ & $55(11.6)$ & $142(18.0)$ & $97(11.6)$ & 239 (14.7) \\
\hline Don't know & $227(44.1)$ & 264 (41.6) & $180(38.0)$ & 356 (45.2) & 315 (37.7) & $671(41.3)$ \\
\hline \multicolumn{7}{|l|}{$\begin{array}{l}\text { Some of the genetic disorders express } \\
\text { themselves later in adult life }(\mathrm{T})\end{array}$} \\
\hline Correct & $274(53.2)$ & 418 (65.8) & $371(78.3)$ & $491(62.3)$ & $572(68.4)$ & $1063(65.5)$ \\
\hline Incorrect & $82(15.9)$ & $65(10.2)$ & $31(6.5)$ & $83(10.5)$ & $95(11.4)$ & 178 (11.0) \\
\hline Don't know & 159 (30.9) & 152 (23.9) & 72 (15.2) & $214(27.2)$ & 169 (20.2) & 383 (23.6) \\
\hline
\end{tabular}


Chapter 3 | Public knowledge of genetic risk factors

\begin{tabular}{|c|c|c|c|c|c|c|}
\hline \multirow[t]{2}{*}{ How-to knowledge statement } & \multicolumn{3}{|c|}{ Level of education } & \multicolumn{2}{|c|}{ Gender } & \multirow[t]{2}{*}{ Total } \\
\hline & Low & Middle & High & Male & Female & \\
\hline \multicolumn{7}{|c|}{$\begin{array}{l}\text { People are genetically more related to a parent } \\
\text { than to their brother or sister }(\mathrm{F})\end{array}$} \\
\hline Correct & $102(19.8)$ & $146(23.0)$ & $129(27.2)$ & 178 (22.6) & 199 (23.8) & 377 (23.2) \\
\hline Incorrect & 178 (34.6) & $203(32.0)$ & 165 (34.8) & 288 (36.5) & 258 (30.9) & 546 (33.6) \\
\hline Don't know & $235(45.6)$ & $286(45.0)$ & $180(38.0)$ & $322(40.9)$ & 379 (45.3) & $701(43.2)$ \\
\hline \multicolumn{7}{|c|}{$\begin{array}{l}\text { The negative consequences of having a genetic } \\
\text { predisposition to a disease can be lessened or } \\
\text { prevented by a healthy lifestyle (T) }\end{array}$} \\
\hline Correct & 224 (43.5) & 336 (52.9) & 311 (65.6) & 446 (56.6) & $425(50.8)$ & $871(53.6)$ \\
\hline Incorrect & $143(27.8)$ & $143(22.5)$ & 77 (16.2) & 156 (19.8) & 207 (24.8) & $363(22.4)$ \\
\hline Don't know & 148 (28.7) & 156 (24.6) & 86 (18.1) & $186(23.6)$ & 204 (24.4) & $390(24.0)$ \\
\hline
\end{tabular}


of genetic risk factors for multifactorial disease had higher scores on the how-to knowledge scale $(\mathrm{M}=3.28, \mathrm{SD}=2.18, \mathrm{Mdn}=3.00)$ than those who did not report being aware of these factors $(\mathrm{M}=2.31, \mathrm{SD}=$ 2.33, $\mathrm{Mdn}=2.00$ : Mann-Whitney's U = 146389.0, $\mathrm{z}=6.55, \mathrm{p}<.001$. Similar results were observed for principles knowledge. Participants who reported being aware of the existence of genetic risk factors for multifactorial disease had higher scores on the principles scale $(\mathrm{M}=$ 1.82 , $\mathrm{SD}=0.38, \mathrm{Mdn}=1.00)$ than those who did not report being aware of these factors $(\mathrm{M}=0.88, \mathrm{SD}=0.77, \mathrm{Mdn}=0.75$ : MannWhitney's U = 149796.0, $\mathrm{z}=4.06, \mathrm{p}<.001$ )

Our second hypothesis was that participants who had inadequate how-to knowledge should also have no principles knowledge. After standardizing how-to knowledge and principles knowledge scores, we calculated the correlation between how-to and principles knowledge. The resulting correlation was medium-sized and significant at the .01 level, Pearson's $r=.38, \mathrm{p}<.001$. Since no definition of adequate howto knowledge (i.e. how much how-to knowledge is needed to meet a given decisional task) is available at this time, we used a median split procedure to create a low or inadequate how-to knowledge group and a high or adequate how-to knowledge group. Since principles knowledge was not normally distributed among the low and the high how-to knowledge groups (Kolmogorov-Smirnov's $\mathrm{Z}=.16$ and .17 respectively, ps <.001), we used the Mann-Whitney test to examine whether the two groups differed in terms of principles knowledge scores. Analysis revealed a significant difference between the two how-to knowledge groups; Mann-Whitney's U = 21079.0, $z=7.76$, $p$ $<$.001. A Wilcoxon signed-rank sum test among the low how-to knowledge group tested the hypothesis that in this group principles knowledge was ' 0 '. Using the procedure outlined by Siegel and Castellan (1988), the analysis confirmed our hypothesis; $\mathrm{W}=4, \mathrm{z}=$ 1.53, $\mathrm{p}=.13$. We then used the Wilcoxon signed-rank sum test to examine this hypothesis for separate how-to statements, confirming for all separate how-to statements that principles knowledge is likely to be ' 0 ' (i.e., inadequate) if how-to knowledge is low (i.e., a score of 'incorrect' on that statement), $0<$ Ws $<10$, zs $<1.30$, ps $>$.19. In other words, if how-to knowledge is low (operationalized by using a median-split procedure on the total how-to scores and by scoring 'incorrect' on the individual how-to statements), principles knowledge is also low (operationalized as scoring ' 0 ' on the total principles knowledge score and as scoring ' 0 ' on the individual knowledge statements, respectively), thereby confirming our second hypothesis.

Concerning our third hypothesis (i.e., that participants with principles knowledge should also have how-to knowledge), we also 
Chapter 3 | Public knowledge of genetic risk factors

Table 3.4. Mean principles knowledge scores (standard deviation in parenthesis) for the how-to knowledge statements stratified by level of education and gender.

\begin{tabular}{|c|c|c|c|c|c|c|}
\hline \multirow[t]{2}{*}{ How-to knowledge statement } & \multicolumn{3}{|c|}{ Level of education } & \multicolumn{2}{|c|}{ Gender } & \multirow[t]{2}{*}{ Total } \\
\hline & Low & Middle & High & Male & Female & \\
\hline $\begin{array}{l}\text { Healthy parents can have a child with a } \\
\text { genetic disease }(\mathrm{T})\end{array}$ & $0.22(0.56)$ & $0.40(0.82)$ & $0.57(1.04)$ & $0.33(0.76)$ & $0.45(0.89)$ & $0.39(0.83)$ \\
\hline $\begin{array}{l}\text { If a person has a genetic predisposition for a } \\
\text { disease, this person will certainly get this } \\
\text { disease }(\mathrm{F})\end{array}$ & $0.11(0.46)$ & $0.21(0.64)$ & $0.29(0.77)$ & $0.18(0.61)$ & $0.22(0.65)$ & $0.20(0.63)$ \\
\hline $\begin{array}{l}\text { A disease is only genetically determined if } \\
\text { more than one family member is affected } \\
\text { (F) }\end{array}$ & $0.02(0.21)$ & $0.09(0.47)$ & $0.17(0.65)$ & $0.10(0.49)$ & $0.08(0.45)$ & $0.09(0.47)$ \\
\hline Genetic diseases always skip a generation (F) & $0.05(0.22)$ & $0.07(0.37)$ & $0.10(0.40)$ & $0.06(0.31)$ & $0.08(0.37)$ & $0.07(0.34)$ \\
\hline $\begin{array}{l}\text { Some of the genetic disorders express } \\
\text { themselves later in adult life }(\mathrm{T})\end{array}$ & $0.02(0.15)$ & $0.05(0.26)$ & $0.15(0.50)$ & $0.08(0.37)$ & $0.06(0.29)$ & $0.07(0.33)$ \\
\hline $\begin{array}{l}\text { People are genetically more related to a parent } \\
\text { than to their brother or sister }(F)\end{array}$ & $0.01(0.14)$ & $0.02(0.22)$ & $0.03(0.26)$ & $0.02(0.21)$ & $0.02(0.21)$ & $0.02(0.21)$ \\
\hline $\begin{array}{l}\text { The negative consequences of having a genetic } \\
\text { predisposition to a disease can be } \\
\text { lessened or prevented by a healthy } \\
\text { lifestyle (T) }\end{array}$ & $0.02(0.13)$ & $0.06(0.27)$ & $0.07(0.29)$ & $0.04(0.23)$ & $0.05(0.26)$ & $0.05(0.24)$ \\
\hline
\end{tabular}


used a median-split procedure to create a low or inadequate principles knowledge group and a high or adequate principles knowledge group. Although the how-to knowledge distributions for the low and high principles knowledge groups seemed to be normal (Kolmogorov-Smirnov Zs <.005, ps > .05), the variances were not equal between the two groups $(\mathrm{F}(1,618)=8.87$, $\mathrm{p}<.01)$. We therefore compared the low and high principles knowledge groups in terms of how-to knowledge using the Mann-Whitney test. Analysis revealed a significant difference between the two principles knowledge groups, Mann-Whitney's U = 31658.5, $\mathrm{z}=7.41, \mathrm{p}<.001$. Subsequently, we examined whether the high principles knowledge group also possessed high how-to knowledge (defined as scoring above the mean how-to knowledge of the total sample including the inadequate principles knowledge group). As we established that the distribution of how-to knowledge was normal for the adequate principles group, we performed a one-sample t-test with test value of 2.48 (i.e., mean how-to knowledge score of the total sample). This test revealed that the high principles group scored significantly higher on the how-to knowledge index $(\mathrm{M}=3.64, \mathrm{SD}=2.03)$ than the mean of the total sample, $\mathrm{t}(316)=10.23, \mathrm{p}<.001$. This procedure was also applied to separate items with one exception: since scores on the individual items were not continuous (i.e., 'incorrect', 'don't know' and 'correct'), we used chi-square tests instead of one-sample t-tests to examine whether participants with high principles knowledge concerning an individual item were also likely to have 'correct' how-to knowledge of that item (minimum observed count $=1$; minimum expected count $=5.52$ ). All chi-square tests for the individual items observed significant differences in distribution of how-to knowledge scores between the low and high principles knowledge groups ( $\chi^{2} \mathrm{~s}>$ 6.28 , ps <.04). More than $95 \%$ of the high principles knowledge group scored 'correct' on the accompanying how-to knowledge items (99, 99, 95, 96, and 99\% for individual items 1, 2, 3, 5, and 6 respectively), except for items 4 and 7 (70 and $73 \%$, respectively).

\section{Discussion and conclusion}

\section{Discussion}

The purpose of the present study was twofold. First, we wanted to present an overview of the Dutch general population's knowledge of genetics using Rogers's knowledge framework. Second, we aimed to test the empirical validity of the distinction between awareness knowledge, how-to knowledge and principles knowledge. Concerning our first goal, approximately $20 \%$ were aware of the existence of genetic risk factors for multifactorial diseases. Although similar 
percentages have been found in previous research (Waller et al., 2004; Wardle et al., 2001), it remains relatively low compared to the current trend in more recent research (Morris et al., 2003; Smerecnik et al., 2008; Van den Nieuwenhoff et al., 2006). The low levels of awareness observed may be due to the unspecified nature of the target (i.e., asking about multifactorial diseases). Indeed, we asked participants whether they had heard of the genetic risk factors for multifactorial diseases, while $70 \%$ had not in fact heard of multifactorial diseases themselves. Moreover, participants may have been familiar with the concept of diseases with multiple causes, including genes, but may not have heard of the term 'multifactorial diseases'. Unfortunately, there is no commonly agreed vocabulary among experts (terms such as multifactorial diseases, common complex diseases and diseases with multiple causes are used interchangeably), which complicates assessment of whether the general public is familiar with such diseases.

The results suggest that the general public had limited how-to knowledge, which corresponds to previous findings on public knowledge (De Vries et al., 2005; Etchegary et al., 2009; Henneman et al., 2004; Molster, Charles, Samanek, \& O'Leary, 2008). Also consistent with previous research (Etchegary et al., 2009; Hahn et al., 2008) is that several misconceptions still exist. For instance, while the majority knew that healthy parents can have a child with a genetic disonder or that having a genetic predisposition does not guarantee the development of a particular disease, few participants knew that not having a family member with a genetic disease does not exclude one from having a genetic predisposition to multifactorial diseases, or that people are not genetically more related to their parents than to their brother or sister.

In accordance with the few previous findings available (Mesters, Ausems, \& De Vries, 2005; Molster et al., 2008), principles knowledge was observed to be flawed and superficial. For instance, while a majority was able to correctly indicate that some genetic disorders manifest themselves only later in life, they were unable to explain why this is true. Considering that the subsample who filled out the principles questions was more highly educated than the subsample who neglected to fill out these questions, this may even be an optimistic approximation rather than an accurate reflection.

Our second goal was to test the empirical validity of the distinction between awareness knowledge, how-to knowledge and principles knowledge. In general, the results seem to provide evidence for this hypothesized distinction. Participants with awareness knowledge were more likely than their unaware counterparts to have how-to knowledge, and how-to knowledge seemed to be related to 
principles knowledge. The results show that our expectations (based on item response theory) were confirmed. That is, we found that those participants who had inadequate how-to knowledge (i.e., scored 'incorrect' on a how-to knowledge statement) were likely to also have inadequate principles knowledge (i.e., score ' 0 ' on the principle knowledge index), and those with adequate principles knowledge (operationalized by the median-split procedure) were also more likely to have adequate how-to knowledge (i.e., score 'correct' on the how-to statement) and more likely to be aware of the genetic risk factors for multifactorial diseases.

\section{Directions for future research}

According to Rogers's (2003) innovation-decision process, the knowledge phase is followed by the persuasion phase. In this phase an individual will form a favorable or unfavorable attitude towards the existence and use of genetic risk factors in decision making regarding health behavior. Understanding from the knowledge phase may be used to this end, but Rogers (2003) also suggests that an individual seeks to reduce his or her uncertainty about the expected consequences of genetic risk factors for health behavior. This kind of information is often readily available from scientific research (Rogers, 2003). But how do we communicate this information to the general population in such as way that it actually reduces uncertainty and promotes adoption? Although the mass media has the advantage of wide reach and high exposure rates and may thus be considered the communication channel of choice, it may not be particularly well suited to this task. Indeed, the results show that a majority of our sample still harbors several misconceptions about genetics and its influence on disease development, which may disrupt future public health communications on genetic risk factors. Employing such misconceptions in understanding future communications about genetics, individuals may process the information incorrectly or, alternatively, may falsely conclude that they are not at risk (Chapple et al., 1995), which is especially likely if they are unaware of their misconceptions (Lanie et al., 2004; Renner \& Renner, 2001; Richards \& Ponder, 1996). Consequently, individuals may not pay attention to future communications about genetics due to their incorrect estimates of risk perception and subsequent low interest (Wiebe \& Black, 1997). These issues might seem to suggest that we need to remedy these misconceptions in the general public, specifically among older, less well-educated individuals from underserved minority groups (Catz et al., 2005). However, since our results suggest the existence of several widespread misconceptions, we have to ensure that future educational efforts do not result in adverse 
effects on health behavior and public health. As such, we recommend that future research investigate in detail the effects of genetic information on comprehension, risk perception and preventive behavior, to name but a few important key concepts.

Rogers (2003) suggested that while the mass media is effective at the knowledge phase, interpersonal communication may be more effective at the persuasion stage. Health professionals presumably are the prime candidates for this endeavor. As health professionals' knowledge of genetics seems inadequate (Baars, Henneman et al., 2005) and research suggests that medical students do not acquire adequate knowledge of genetics during their studies (Vural, Tomatir, Kurban, \& Taspinar, 2009), health professionals may need to be educated about genetics first. These issues may tempt us to educate individuals about the underlying principles of genetics only when relevant (e.g., when diagnosed with a positive family history). However, without adequate principles knowledge individuals may draw incorrect conclusions from fairly straightforward health messages communicating genetic information. This highlights the urgent need for future research into the effects of media messages on psychological functioning and preventive behavior, as well as into the influence of principles knowledge on adequate decision making. Subsequently, several strategies should be developed and extensively tested before being used to educate the general population about the underlying mechanisms of genetics.

\section{Limitations}

Our results, as well as their implications, need to be interpreted with some caution due to several limitations of this study. First, and perhaps foremost, some items we used to assess how-to knowledge may have been interpreted in different ways by different participants. For instance, the statement People are genetically more related to their parents than to their brother or sister' can be read as asking about the cumulative genetic relationship to both parents (which is $100 \%$ ) or to only one of the parents. These issues reflect the need for a collective process to decide what knowledge or understanding the general public needs to have.

A second, related limitation concerns the fact that principles knowledge was measured using open-ended questions. While providing the advantage of non-directive assessment, which is important in research into public knowledge of genetics (Condit, 2001), it also has several disadvantages, such as differential elicitation among participants and issues of coding participants' responses. That is, although we compared participants' answers to those given by professional geneticists and both the intra-rater and 
inter-rater reliability were high, a certain amount of subjectivity could not be avoided in these cases. Additionally, only an approximate 25$30 \%$ of the participants filled out the principles knowledge questions, which may have distorted the results. Although we were unable to assess the reasons for not filling out these questions, analyses revealed that participants who did fill them out were younger, more likely to be women, more highly educated, more likely to be aware of genetic risk factors for multifactorial diseases, and had higher how-to knowledge than those who did not fill out these questions. Our observation of the general public's principles knowledge as being poor may therefore be an optimistic approximation rather than a realistic reflection of the general population's principles knowledge. To avoid these issues, future research may try to devise strategies to prompt the less well-educated, older and male participants to fill out open-ended questions or, alternatively, formulate non-directive closed questions to assess principles knowledge.

Third, although our second and third hypotheses are concerned with the adequacy of how-to knowledge and principles knowledge, we did not actually test this. Lacking a precise definition of 'adequate' knowledge, we used a median-split procedure to create low and high knowledge groups. If one were to use a relatively common definition of 'adequate' say having the requisite qualities or resources to meet a task' simply scoring higher than the median can still reflect inadequate knowledge. This issue reflects the need for a good definition of 'adequate' or exactly how much knowledge individual members of the general public need to engage in proper decisionmaking.

\section{Conclusion}

The present results suggest that a minority of the general population was aware of genetic risk factors of multifactorial diseases, overall how-to knowledge seemed limited, and principles knowledge was generally poor. We observed several existing misconceptions about genetics and its influence on disease development, which may need remedying. Additionally, our results suggest that how-to and principles knowledge indeed appear to be conceptually distinct forms of knowledge. These findings support previous suggestions that Rogers's knowledge framework (2003) provides a sophisticated tool to assess public knowledge of genetics (Smerecnik et al., 2008). Future research may build upon and extend our findings by examining the persuasion, decision, implementation, and possibly the confirmation stages of the innovation-decision process concerning genetics education. 


\section{Chapter 4}

Alerting the general population to genetic risks: The value of health messages communicating the existence of genetic risk factors for public health

promotion

Published as: Smerecnik, C. M. R., Mesters, I., De Vries, N. K. \&De Vries, H. (2009). Alerting the general population to genetic risks: The value of health messages communicating the existence of genetic risk factors for public health promotion. Health Psychology, 28, 734-745. 


\begin{abstract}
Objective. Health messages alerting the public to previously unknown genetic risk factors for multifactorial diseases are increasingly prevalent in our society. However, research into its impact on the public's willingness to engage in preventive behaviour is scarce.

Design. Three experimental studies examined the effects of health messages communicating information about genetic risk factors for salt sensitivity (Studies 1A and 1B) and heightened cholesterol (Study 2) versus general information without reference to genetic risk factors among participants who were or were not aware of genetic risk factors for salt sensitivity or heightened cholesterol at the moment of information exposure.
\end{abstract}

Main outcome measures. Risk perception; intention to engage in preventive behaviour.

Results. Unaware participants who received a genetic health message reported lower susceptibility compared to the general health message, which was associated with lowered intentions to engage in preventive behaviour. No such effects were observed for aware participants.

Conclusion. Alerting the public to the existence of genetic risk factors may not necessarily be beneficial to public health. Public health promoters should be aware of the possible adverse effects and may simultaneously educate the public about the meaning and consequences of such factors. 


\section{Introduction}

Nowadays, the implications of genetic polymorphisms (i.e. genetic variants) for disease development are increasingly better understood. At the same time, advances in genetic knowledge raise the question whether and how to keep the largely uninformed public abreast of such knowledge. Indeed, while technological (e.g., genetic testing) and biochemical (e.g., pharmacogenetics) applications of genetics are considered the spearheads of genetic advancements, the ultimate and immediate value of professional knowledge of genetics for the general public is probably enhanced by educating people about genetics (Burke et al., 2002; Wang et al., 2005). Alerting people to the existence of genetic risks may be a way of educating them with the ultimate goal of promoting the appropriate preventive behaviour (cf. Collins et al., 2003; Khoury et al., 2000).

The mass media is likely the most common source of information about genetics for a large majority of the general population (Conrad, 1997; Ikeda, 2008). Media coverage of genetics has increased greatly since the announcement of the Human Genome Project in 2000 (Bubela \& Caulfield, 2004; Cappella, Lerman, Romantan, \& Baruh, 2005; Tambor et al., 2002). The effects of mass-media messages about genetics on the general public's willingness to engage in preventive behaviour, however, need investigation. In this paper, we use the term health messages to refer to any message that links genetics to chronic disease and is presented to the general public via the mass media (e.g., newspaper articles, public health campaigns, and press releases).

Creating public awareness can be considered a necessary first step in motivating the public to engage in adequate preventive behaviour (Smerecnik et al., 2008). Health messages linking genetics to chronic disease are steadily increasing (cf. Bubela \& Caulfield, 2004; Cappella et al., 2005). However, there is a relative lack of evidence on the impact of alerting the general public to the existence of genetic risk factors for multifactorial disease on their willingness to engage in preventive behaviour. Several authors have indeed warned against the potentially adverse effects of educating the general population about genetics (Condit et al., 2004; De Vries et al., 2005; Mesters et al., 2005), but on theoretical grounds only. Without insight into the effects of genetic information, genetic-based public health campaigns may 'do more harm than good' (Condit, 2001; Khoury et al., 2000).

The ultimate value of genetic information probably lies in its ability to personalize risks for individual members of the general population (Guttmacher \& Collins, 2005; Janssens \& Van Duijn, 2008). Recent research has postulated that personalized DNA risk 
information on obesity (Frosch et al., 2005), smoking (Sanderson et al., 2008), and hypercholesterolemia (Marteau et al., 2004) may result in enhanced preventive behaviour. Health messages directed at the general population, however, inevitably lack such personalization. Nonetheless, such messages often attempt to arouse feelings of susceptibility (i.e., risk perception) in its recipients, which is assumed to lead to increased willingness to engage in preventive behaviour. The present paper describes three experimental studies which explored the effect of health messages alerting the public to the existence of previously unknown genetic risks on the intention to engage in relevant preventive behaviour. At the same time, it also examines the possible cognitive processes underlying this relationship.

\section{Theoretical perspective}

Several sociocognitive models of behaviour, such as the Health Belief Model (Janz \& Becker, 1984; Rosenstock, 1974) and Protection Motivation Theory (Rogers, 1975; 1983) posit risk perception as a central concept determining the intention to engage in preventive behaviour. The 'motivational hypothesis' of behaviour change views risk perception as its primary motivator (Renner, Panzer, Oeberst, \& Hartung, 2007). In general, high perceived risk is assumed to enhance the intention to engage in preventive behaviour. Additionally, risk perception influences the attention paid to (Wiebe \& Black, 1997) and processing of (Das, de Wit, \& Stroebe, 2003; De Hoog, Stroebe, \& de Wit, 2005) subsequent information on a particular health risk.

Although the relationship between health messages communicating genetic information and risk perception has received little to no attention, several researchers have discussed the importance of risk perception in genetic susceptibility testing (for an overview see Gooding, Organista, Burack, \& Biesecker, 2006). In general, researchers agree that perceived susceptibility is positively related to interest in using genetic testing for breast cancer (e.g., Lipkus, Iden, Terrenoire, \& Feaganes, 1999), colorectal cancer (e.g., Bunn, Bosompra, Ashikaga, Flynn, \& Worden, 2002), and Alzheimer disease (Gooding, Linnenbringer, Burack, Roberts, Green, \& Biesecker, 2006).

However, empirical evidence exists that suggests individuals generally have the tendency to underestimate their personal risk (Weinstein, 1980), resulting in reduced intention for preventive behaviour (Barnoy, Bar-Tal, \& Treister, 2003). Optimism may result from using past experience to predict future personal susceptibility to a health threat (Weinstein, 1982), which seems especially relevant 
when considering potential genetic risks (Weinstein, 1987). For instance, upon learning of the existence of genetic risk factors, a perceived lack of family history of a given disease may lead to an underestimation of personal susceptibility (Hailey, Carter, \& Burnett, 2000).

Alternatively, underestimating personal risk may be a strategy to maintain psychological wellbeing. Acknowledging personal susceptibility to a health threat is assumed to provoke negative affect (J anoff-Bulman \& Lang-Gunn, 1988), and to reduce these feelings individuals use defensive coping strategies (Kirscht, Haefner, Kegeles, \& Rosenstock, 1966). Several studies have observed that 'genetics' may be perceived as scary and as such provoke negative affect. For instance, Condit and colleagues (2002; 2004) observed that laypeople experienced strong negative associations with the term mutation although they had adequate knowledge of its meaning. They suggested that health messages using genetic words with negative connotations may lead to adverse effects, and perhaps even do more harm than good.

These issues raise concerns about the strategy of alerting the general public to the existence of genetic risk factors to promote public health. Research is needed to investigate the effects of firsttime genetic risk information exposure on risk perception and the intention to engage in preventive behaviour. In three studies, we therefore examined the effect of alerting individuals to the existence of the genetic risk factors for salt sensitivity (Studies 4.1A and 4.1B) and heightened cholesterol (Study 4.2). We chose these two medical conditions as they both constitute risk factors for cardiovascular disease, and polymorphisms (i.e. genetic variants) that appear to increase susceptibility have recently been discovered. Salt sensitivity refers to the fact that some individuals show a greater increase in blood pressure following similar amounts of salt intake compared to others (Weinberger, 1991). A number of different polymorphisms seem to be causally involved in this phenomenon (Beeks et al., 2004; Sanada et al., 2006). The alpha-adducin polymorphism Gly 460 Trp has been suggested to be the most important of these (Beeks et al., 2004; Cusi et al., 1997). Recent research has also identified a number of genetic polymorphisms that predispose individuals to heightened cholesterol levels, such as the apolipoprotein B (Ludwig et al., 1997) and the PCSK9 (Abifadel et al., 2003) genes.

Based on the literature mentioned above, we expected that alerting individuals to the existence of genetic risk factors would result in decreased risk perception (hypothesis 1). Furthermore, we expected that this decrease would be associated with decreased intention to engage in preventive behaviour (hypothesis 2). In Studies 
4.1A and 4.1B, we investigated whether these effects could be due to incorrect extrapolation from past experience (i.e., perceived family history); in Study 4.2 we examined the effect of genetic health messages on negative affect as well as whether negative affect mediated the effect of genetic health messages on perceived susceptibility and intention. Because argumentation theory posits that an argument will only lead to persuasion if it is correct, new, and relevant to the topic under consideration (Vinokur \& Burnstein, 1978), we expected that information about the existence of genetic risk factors would only affect individuals who were unaware of the existence of genetic risk factors for salt sensitivity or heightened cholesterol levels at the moment of information exposure (i.e., for whom the information is new). Although it could be argued that information about the existence of genetic risk factors oould also influence previously aware individuals by being newly considered (i.e., an aocessibility effect), the discrepancy between prior knowledge and information is likely to be larger among the previously unaware individuals. Moreover, a health message's impact on risk perception and intention is probably related to individuals' confidence in reaching a decision in accordance with their current motivational concerns (Eagly \& Chaiken, 1993). Upon learning about the existence of genetic risk factors, previously unaware individuals may perceive their existing knowledge as insufficient and are therefore probably more likely to be influenced by the health message. Thus, we hypothesized that alerting people to the existence of genetic risk factors for salt sensitivity or cholesterol would only affect individuals who were unaware of it at the moment of information exposure (hypothesis 3).

\section{Studies 4.1A and 4.1B}

\section{Methods}

\section{Participants}

We approached 200 students from Maastricht University to participate in Study $4.1 \mathrm{~A}$ (response rate $=72.5 \%, \mathrm{~N}=145$ ). Since students are unlikely to have experienced hypertension and may be unlikely to consider it a relevant threat, we approached 200 individuals in the departure hall of the Maastricht-Aachen Airport for study $4.1 \mathrm{~B}$ (response rate $=74 \%, \mathrm{~N}=148$ ). Table 4.1 presents the demographic characteristics of both samples. Participants were not compensated for their participation. 


\section{Procedure}

After giving informed consent, the participants were presented with a self-administered questionnaire. The questionnaires had been randomly ordered and distributed by a research assistant, who was blind to the study's design and purpose. After answering questions on demographic characteristics in the pretest questionnaire, the participants were instructed to carefully read the scenario text. They were randomly assigned to receive either a genetic health message, communicating the existence of genetic risk factors for salt sensitivity, or a general health message (used as the reference category in all analyses), communicating health information on salt sensitivity without reference to genetic risk factors. The participants were led to believe that the scenario represented an article from a large daily newspaper. Afterwards, they filled out questions regarding risk perception and intention to engage in preventive behaviour. They were then given the opportunity to ask questions, and, finally, were debriefed about the study's purpose.

\section{Materials}

The scenarios and questionnaires were based on a pilot test conducted among 80 Maastricht University students. One health message presented information on the existence of genetic risk factors for salt sensitivity, while the other provided general information on salt sensitivity without reference to its genetic risk factors (see Appendix 1). Note that this does not entail providing personalized DNA risk information, but simply communicating the fact that salt sensitivity is partly caused by genetic factors. Since genetic testing for salt sensitivity is not yet commercially available, we decided not to include any reference to this to prevent misinforming participants.

\section{Measures}

Before reading the scenario information, patricipants reported on the following demographic characteristics: age, sex, education level, and hypertension status ("Are you currently diagnosed with hypertension? $1=$ no, 2 = yes). They were also asked to indicate whether they were currently on a salt-restricted $\operatorname{diet}(1=$ no, $2=$ yes).

Family history of CVD and family history of hypertension ("Are one or more of your family members diagnosed with CVD/hypertension?" 1 =no, 2 =yes, $3=$ don't know) were assessed to examine the possible moderating effects of extrapolation from past 
Chapter 4 | Alerting the public to genetic risks

Table 4.1. Demographic characteristics of the general versus genetic health message type groups.

\begin{tabular}{|c|c|c|c|c|c|c|c|c|c|c|c|c|}
\hline \multirow{3}{*}{$\begin{array}{c}\text { Demographic } \\
\text { characteristics }\end{array}$} & \multicolumn{4}{|c|}{ Study 4.1A } & \multicolumn{4}{|c|}{ Study 4.1B } & \multicolumn{4}{|c|}{ Study 4.2} \\
\hline & \multicolumn{2}{|c|}{ HM type } & \multirow{2}{*}{$\begin{array}{l}\text { Test- } \\
\text { value }\end{array}$} & \multirow{2}{*}{$\begin{array}{c}\text { P- } \\
\text { value }\end{array}$} & \multicolumn{2}{|c|}{ HM type } & \multirow{2}{*}{$\begin{array}{l}\text { Test- } \\
\text { value }\end{array}$} & \multirow{2}{*}{$\begin{array}{c}\text { P- } \\
\text { value }\end{array}$} & \multicolumn{2}{|c|}{ HM type } & \multirow{2}{*}{$\begin{array}{l}\text { Test- } \\
\text { value }\end{array}$} & \multirow{2}{*}{$\begin{array}{c}\text { P- } \\
\text { value }\end{array}$} \\
\hline & Genetic & General & & & Genetic & General & & & Genetic & General & & \\
\hline Age (years) & 23.01 & 24.57 & 1.54 & .13 & 42.45 & 41.59 & 0.30 & .76 & 43.19 & 48.47 & 2.06 & .04 \\
\hline Sex & & & 0.627 & .43 & & & 2.74 & .10 & & & 0.01 & .96 \\
\hline Men & 28 & 34 & & & 30 & 42 & & & 13 & 12 & & \\
\hline Women & 43 & 40 & & & 42 & 34 & & & 60 & 55 & & \\
\hline Education level & & & 6.38 & .10 & & & 1.84 & .77 & & & 3.28 & .51 \\
\hline Primary school & 0 & 0 & & & 7 & 5 & & & 3 & 0 & & \\
\hline Secondary school & 49 & 36 & & & 17 & 22 & & & 30 & 33 & & \\
\hline $\begin{array}{l}\text { Middle vocational } \\
\text { education }\end{array}$ & 1 & 1 & & & 23 & 25 & & & 24 & 22 & & \\
\hline $\begin{array}{l}\text { Higher vocational } \\
\text { education }\end{array}$ & 8 & 13 & & & 18 & 19 & & & 12 & 10 & & \\
\hline University & 13 & 24 & & & 7 & 4 & & & 4 & 2 & & \\
\hline Disease status $^{\ddagger}$ & & & 2.07 & .36 & & & 0.57 & .75 & & & 1.73 & .42 \\
\hline Yes & 3 & 2 & & & 13 & 15 & & & 7 & 8 & & \\
\hline No & 64 & 64 & & & 51 & 51 & & & 53 & 41 & & \\
\hline Don't know & 11 & 6 & & & 6 & 9 & & & 15 & 19 & & \\
\hline Family history of CVD & & & 0.621 & .73 & & & 6.51 & .04 & & & 3.08 & .22 \\
\hline Yes & 28 & 33 & & & 23 & 40 & & & 38 & 25 & & \\
\hline No & 37 & 34 & & & 38 & 30 & & & 33 & 28 & & \\
\hline Don't know & 6 & 5 & & & 9 & 5 & & & 12 & 14 & & \\
\hline $\begin{array}{c}\text { Family history of } \\
\text { disease }^{\ddagger}\end{array}$ & & & 2.90 & .24 & & & 3.91 & .14 & & & 0.64 & .73 \\
\hline Yes & 41 & 51 & & & 42 & 53 & & & 41 & 40 & & \\
\hline No & 21 & 16 & & & 21 & 20 & & & 24 & 22 & & \\
\hline Don't know & 9 & 5 & & & 7 & 2 & & & 8 & 5 & & \\
\hline Special diet ${ }^{\ddagger}$ & & & 1.06 & .30 & & & 0.23 & .63 & & & 7.12 & .31 \\
\hline Yes & 1 & 3 & & & 5 & 7 & & & 31 & 33 & & \\
\hline No & 71 & 68 & & & 68 & 65 & & & 32 & 40 & & \\
\hline
\end{tabular}


experience on risk perception and intention to engage in preventive behaviour.

After reading the health message, participants answered several questions concerning risk perception and intention to engage in preventive behaviour. All measures were assessed on 7 point Likert scales ranging from $1=$ totally disagree to $7=$ totally agree. Risk perception was assessed by measuring perceived susceptibility and perceived severity. Perceived susceptibility of having salt-sensitive blood pressure was measured using three items (e.g., "I am vulnerable to a salt-sensitive blood pressure"; cf. Kaptein, van Korlaar, Cameron, Vossen, van der Meer, \& Rosendaal, 2007; Study 4.1A: Cronbach's $a=.90, \mathrm{M}=2.84, \mathrm{SD}=1.28$; Study 4.1B: Cronbach's $\alpha=.84, \mathrm{M}=3.34, \mathrm{SD}=1.37$ ). Perceived severity was also measured by three items (e.g., "Having a salt-sensitive blood pressure is a substantial threat to my health"; cf. Wright, French, Weinman, \& Marteau, 2006; Study 4.1A: Cronbach's $\alpha=.73, \mathrm{M}=5.15, \mathrm{SD}=1.03$; Study 4.1B: Cronbach's $\alpha=.71, \mathrm{M}=5.33, \mathrm{SD}=1.09$ ). Additionally, the intention to engage in preventive behaviour was assessed using three items (e.g., "I intend to restrict my salt intake"; cf. Wright et al., 2006; Study 4.1A: Cronbach's $\alpha=.78, \mathrm{M}=2.45, \mathrm{SD}=1.25$; Study 4.1B: Cronbach's $\alpha=.82, \mathrm{M}=4.14, \mathrm{SD}=1.67$ ).

Finally, after answering the questions on risk perception and intention, we assessed participants' awareness status by using one forced-choice question: "Had you ever heard of genetic risk factors for salt sensitivity before you participated in this study?" $1=$ yes, $0=$ no (used as the reference category for all analyses).

\section{Statistical analyses}

Initial analyses checked whether randomization was successful and whether the 'aware' versus 'unaware' groups were comparable in terms of demographic characteristics. To this end, we conducted analyses of variance for the age variable and chi square tests for the sex, education level, hypertension status, family history of CVD, and family history of hypertension variables. Demographic characteristics on which the health message type groups and the aware and unaware groups differed were used as covariates in subsequent analyses.

Subsequently, we performed regression analyses with health message type, awareness status, and their interaction as independent variables, and susceptibility, severity, and intention as dependent variables. Family history of CVD, family history of hypertension, and their interactions with health message type were added to the model, to examine whether the effects of health message type on susceptibility and intention were the result of extrapolation from past experience. In cases where the health message type by awareness 
interaction effect proved to be significant, we proceeded to analyze the effect of health message type on susceptibility, severity, and intention for previously aware and previously unaware participants separately.

Finally, to test the hypothesis that the effect of health message type on intention would be the result of perceived susceptibility, we conducted mediation analyses. Following Baron and Kenny (1986), we examined whether: (1) health message type accounts for variations in susceptibility, (2) susceptibility accounts for variations in intention, and (3) the previously significant effect of health message type on intention was reduced to non-significance after susceptibility was added to the model.

\section{Results and discussion}

\section{Sample characteristics}

About $75 \%$ of both samples reported being unaware of the existence of genetic risk factors of salt sensitivity prior to this study (Study 4.1A: $\mathrm{n}=111$; Study 4.1B: $\mathrm{n}=115$ ). The experimental groups significantly differed on perceived family history of CVD (Study 4.1A: $\chi^{2}=0.62, \mathrm{p}=.73$; Study 4.1B: $\chi^{2}=6.51, \mathrm{p}=.04$ ), but did not differ in terms of age, sex, education level, or family history of hypertension (see Table 4.1). Awareness of the genetic risk factors for salt sensitivity was significantly related to hypertension status (Study 4.1A: $\chi^{2}=6.78, \mathrm{p}=.03$; Study 4.1B: $\chi^{2}=0.36, \mathrm{p}=.84$ ), but was not related to age, sex, education level, family history of CVD, or family history of hypertension.

\section{Genetic information and risk perception}

Although regression analyses did not reveal a significant main effect of health message type on susceptibility (Study 4.1A: $\beta=-.10, \mathrm{p}=.27$; Study 4.1B: $\beta=-.05, \mathrm{p}=.60$ ), we did observe the expected health message type by awareness interaction effect (Study $4.1 \mathrm{~A}: \beta=.56, \mathrm{p}=$ .04; Study 4.1B: $\beta=.89, \mathrm{p}<.005$; see Figure 4.1). No significant effects of family history of CVD or hypertension or any interaction of family history with health message type were observed (see Table 4.2), suggesting that the health message type effects on susceptibility were not due to extrapolation from past experience.

After stratifying previously aware and previously unaware individuals, we observed a significant effect of health message type on susceptibility for previously unaware individuals (Study 4.1A: $\beta=-$ $.18, \mathrm{p}=.05$; Study 4.1B: $\beta=-.19, \mathrm{p}=.05$ ). Among previously unaware participants, the genetic health message resulted in lower perceived 
Table 4.2. Regression models on susceptibility from Studies 4.1A, 4.1B, and 4.2

\begin{tabular}{|c|c|c|c|c|c|c|}
\hline & \multicolumn{2}{|c|}{ Study 1A } & \multicolumn{2}{|c|}{ Study 1B } & \multicolumn{2}{|c|}{ Study 2} \\
\hline & $\beta$ & $\mathrm{R}^{2}$ & $\beta$ & $\mathrm{R}^{2}$ & $\beta$ & $\mathrm{R}^{2}$ \\
\hline Model 1 & & .07 & & .04 & & .13 \\
\hline Disease status ${ }^{\ddagger}$ & - & & -.07 & & - & \\
\hline Family history of CVD & -.17 & & -.13 & & -.14 & \\
\hline Family history of disease & -.02 & & .03 & & -.09 & \\
\hline HM type & -.10 & & -.05 & & $-.73^{* *}$ & \\
\hline Awareness & .02 & & .05 & & -.12 & \\
\hline Model 2 & & .10 & & .12 & & .18 \\
\hline Disease status ${ }^{\ddagger}$ & - & & -.07 & & . & \\
\hline Family history of CVD & -.20 & & -.14 & & -.15 & \\
\hline Family history of disease ${ }^{\ddagger}$ & .07 & & -.02 & & -.14 & \\
\hline HM type & $-.65^{*}$ & & $-1.10 * *$ & & -.29 & \\
\hline Awareness & -.10 & & -.20 & & .04 & \\
\hline $\begin{array}{l}\text { HM type by family history of } \\
\text { CVD }\end{array}$ & .11 & & .06 & & .08 & \\
\hline $\begin{array}{l}\text { HM type by family history of } \\
\text { disease }^{\ddagger}\end{array}$ & -.16 & & .20 & & .12 & \\
\hline HM type by awareness & $.56^{*}$ & & $.89 * *$ & & .47 & \\
\hline
\end{tabular}

susceptibility (Study 4.1A: $\mathrm{M}=2.54, \mathrm{SD}=1.14$; Study 4.1B: $\mathrm{M}=2.99$, $\mathrm{SD}=1.27$ ) than the general health message (Study 4.1A: $\mathrm{M}=3.00, \mathrm{SD}$ = 1.36; Study 4.1B: $\mathrm{M}=3.60, \mathrm{SD}=1.41$ ). For previously aware individuals, we observed no significant effect of health message type on susceptibility in Study 4.1A ( $\beta=.27, \mathrm{p}=.15)$. In contrast, in Study $4.1 \mathrm{~B}$, we did observe such an effect $(\beta=.50, \mathrm{p}=.02)$. No effects of health message type on severity were observed (ps >.37).

\section{Genetic information and intention}

Regression analyses did not reveal a significant main effect of health message type (Study 4.1A: $\beta=.49, \mathrm{p}=.26$; Study 4.1B: $\beta=-.56, \mathrm{p}=$ .15; see Figure 4.2), but did reveal the expected health message type by awareness interaction effect (Study 4.1A: $\beta=.21$, $\mathrm{p}=.05$; Study 4.1B: $\beta=.57, \mathrm{p}=.05$; see Figure 4.2). Again, no effects, including moderating effects, of family history of CVD and hypertension were observed (see Table 4.3), suggesting that extrapolation from past experience cannot account for the effects of health message type on intention. 
Chapter 4 | Alerting the public to genetic risks
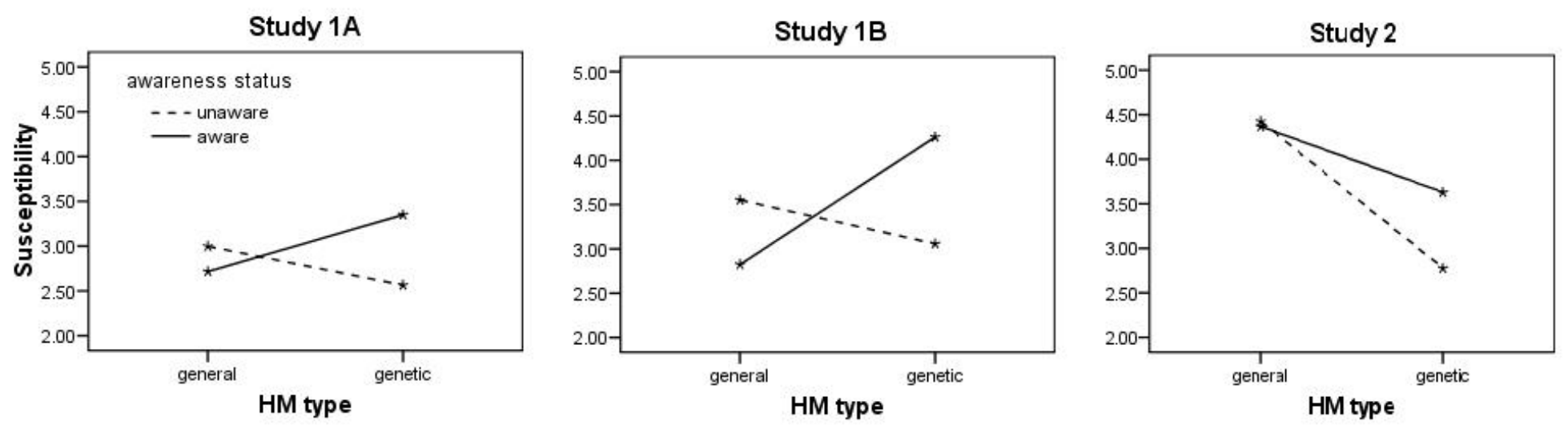

Figure 4.1. Susceptibility scores for studies 4.1A, 4.1B, and 4.2

Left panel: Susceptibility scores for the stratified samples categorized by health message (HM) type for Study 4.1A.

Middle panel: Susceptibility scores for the stratified samples categorized by health message type for Study 4.1B.

Right panel: Susceptibility scores for the stratified samples categorized by health message type for Study 4.2. 
Table 4.3. Regression models on intention from Studies 4.1A, 4.1B, and 4.2

\begin{tabular}{|c|c|c|c|c|c|c|}
\hline & \multicolumn{2}{|c|}{ Study $4.1 \mathrm{~A}$} & \multicolumn{2}{|c|}{ Study 4.1B } & \multicolumn{2}{|c|}{ Study 4.2} \\
\hline & $\beta$ & $\mathrm{R}^{2}$ & $\beta$ & $\mathrm{R}^{2}$ & $\beta$ & $\mathrm{R}^{2}$ \\
\hline Model 1 & & .10 & & .18 & & .17 \\
\hline Disease status ${ }^{\ddagger}$ & - & & $-.26^{* *}$ & & - & \\
\hline Family history of CVD & .02 & & $-.21 *$ & & -.16 & \\
\hline Family history of disease ${ }^{+}$ & -.09 & & -.00 & & $-.34^{* *}$ & \\
\hline HM type & .02 & & -.13 & & $-.23^{* *}$ & \\
\hline Awareness & .02 & & 10 & & .00 & \\
\hline Model 2 & & .20 & & .21 & & .18 \\
\hline Disease status ${ }^{\ddagger}$ & - & & $-.25^{* *}$ & & - & \\
\hline Family history of CVD & .06 & & -.19 & & -.07 & \\
\hline Family history of disease ${ }^{+}$ & -.07 & & .01 & & $-.23 *$ & \\
\hline HM type & .49 & & -.56 & & -.17 & \\
\hline Awareness & .08 & & -.05 & & .25 & \\
\hline HM type by family history of CVD & -.14 & & -.08 & & .14 & \\
\hline HM type by family history of disease & -.08 & & .01 & & -.30 & \\
\hline HM type by awareness & $.21 *$ & & $.57 *$ & & -.02 & \\
\hline Model 3 & & NA & & NA & & .28 \\
\hline Disease status ${ }^{\ddagger}$ & NA & & NA & & - & \\
\hline Family history of CVD & NA & & NA & & -12 & \\
\hline Family history of disease & NA & & NA & & $-.31 *$ & \\
\hline HM type & NA & & NA & & $-.19 *$ & \\
\hline Awareness & NA & & NA & & -.01 & \\
\hline Susceptibility & NA & & NA & & $.17 *$ & \\
\hline Severity & NA & & NA & & $.30 *$ & \\
\hline Negative affect & NA & & NA & & -.02 & \\
\hline Positive affect & NA & & NA & & -.13 & \\
\hline
\end{tabular}

‡ Hypertension in studies 4.1A and 4.1B, heightened cholesterol levels in Study 4.2.

${ }^{*} \mathrm{p}<.05,{ }^{* *} \mathrm{p}<.01, \mathrm{NA}=$ full-sample analyses not conducted (i.e. health message type by awareness interaction significant).

Note. For health message (HM) type, the general HM is used as the reference category, for awareness the unaware group is the reference category.

For previously unaware individuals, we observed a significant effect of health message type on intention (Study 4.1A: $\beta=-.54, \mathrm{p}=$ .01 ; Study 4.1B: $\beta=-.24, \mathrm{p}=.02$ ), which was reduced to nonsignificance after susceptibility (Study $4.1 \mathrm{~A}: \beta=.21, \mathrm{p}=.03$; Study 4.1B: $\beta=.43, \mathrm{p}<.001$ ) was added to the analysis. For the previously aware individuals, in contrast, we did not observe a significant effect of health message type on intention (Study 4.1A: $\beta=-.21, \mathrm{p}=.26$; Study 4.1B: $\beta=.21, \mathrm{p}=.33$ ), nor an effect of susceptibility on intention (Study 4.1A: $\beta=.33, \mathrm{p}=.17$; Study 4.1B: $\beta=.37, \mathrm{p}=.13$ ). These results suggest that informing individuals about the existence of genetic risk factors for salt-sensitive blood pressure leads to decreased perceived susceptibility, which in turn results in lower intention to restrict salt intake, but only among previously unaware individuals (confirming hypothesis 3). 


\section{Study 4.2}

In Study 4.2 we examined the role of negative affect in explaining the effect of genetic health messages on perceived susceptibility and intention. Additionally, the health message focused on cholesterol instead of salt sensitivity as in Studies 4.1A and 4.1B. By changing the health topic we aimed to improve the generalizability of our conclusions.

\section{Methods}

\section{Participants}

We approached 200 individuals to participate in the present study during the annual Spring Fair in Maastricht (response rate $=69.5 \%$; $\mathrm{N}=139$ ). Individuals were offered a cup of tea or coffee while filling out their questionnaire (i.e. after they committed themselves to participating in our study).

\section{Procedure}

The procedure and measures were similar to those used in Studies $4.1 \mathrm{~A}$ and $4.1 \mathrm{~B}$, with the following exceptions. First, the health message focused on heightened cholesterol instead of salt sensitivity (see Appendix 2). Consequently, all measures were rephrased to fit the different health topic used. For instance, instead of asking participants whether they intended to restrict their salt intake, they were asked whether they intended to lower their cholesterol level (e.g., "I intend to consume fewer high-cholesterol foods in the near future", $1=$ totally disagree to $7=$ totally agree). Second, to assess the influence of affect on the effects of genetic information on risk perception and intention to engage in preventive behaviour, we added a total of 16 unidimensional items to measure affect (e.g., "The information made me feel ..." 1 = not at all happy to 10 = very happy, $1=$ not at all worried to $10=$ very worried). Exploratory factorial analysis with oblique rotation revealed the existence of two underlying factors. Eight items loaded on factor one and represented negative affect (eigenvalue $=8.77, \mathrm{R}^{2}=0.55$; Cronbach's $\alpha=.95, \mathrm{M}=$ $4.80, \mathrm{SD}=1.41$ ). The remaining eight items loaded on factor two and represented positive affect (eigenvalue $=4.22, \mathrm{R}^{2}=0.27$; Cronbach's $\alpha=.98, \mathrm{M}=7.82, \mathrm{SD}=2.05$ ). 
Chapter 4 | Alerting the public to genetic risks
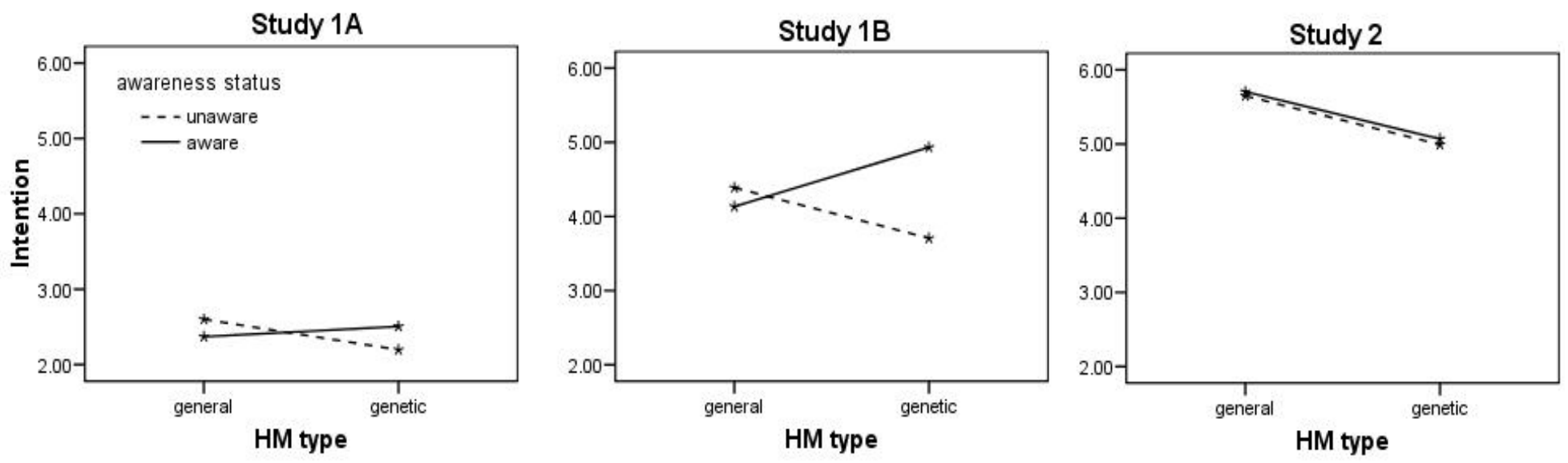

Figure 4.2. Intention scores for studies 4.1A, 4.1B, and 4.2.

Left panel: Intention scores for the stratified samples categorized by health message (HM) type for Study 4.1A.

Middle panel: Intention scores for the stratified samples categorized by health message type for Study 4.1B.

Right panel: Intention scores for the stratified samples categorized by health message type for Study 4.2. 


\section{Statistical analyses}

In general, the analyses were similar to those performed in Studies $4.1 \mathrm{~A}$ and $4.1 \mathrm{~B}$. However, additional analyses were conducted to examine the effect of health message type on negative and positive affect. Subsequently, we used mediation analyses to examine whether the health message type effect on intention could be the result of differential health message effects on negative affect. Following Baron and Kenny (1986), we examined whether: (1) health message type accounts for variations in negative affect, (2) negative affect accounts for variations in intention, and (3) the previously significant effect of health message type on intention was reduced to non-significance after negative affect was added to the model.

\section{Results and discussion}

Sample characteristics

About $40 \%$ of the sample reported being unaware of the existence of genetic risk factors for cholesterol prior to this study $(\mathrm{n}=53)$. The health message type groups differed significantly in age, $\mathrm{t}(138)=$ 2.05, $\mathrm{p}=.04$, but not in terms of sex, education level, cholesterol status, family history of CVD, or family history of cholesterol (ps > .22; see Table 4.1). Awareness of the genetic risk factors of heightened cholesterol was not significantly related to age, sex, education level, cholesterol status, family history of CVD, or family history of cholesterol (ps >.08).

\section{Genetic information and affect}

Regression analysis revealed a significant health message type by awareness interaction effect on negative affect ( $\beta=-.67, \mathrm{p}=.03$ ). When we distinguished between previously aware and previously unaware participants, we observed a significant effect of health message type on negative affect for previously unaware individuals $(\beta$ $=-.36, \mathrm{p}=.01)$, but not for previously aware individuals $(\beta=.03, \mathrm{p}=$ .77; see Figure 4.3). Previously unaware participants who read the genetic health message reported experiencing less negative affect ( $M$ $=2.32, \mathrm{SD}=1.59$ ) than unaware individuals who read the general health message $(\mathrm{M}=3.62, \mathrm{SD}=2.03)$. No effects were observed for positive affect ( $\mathrm{ps}>.51$ ).

Genetic information and risk perception

Regression analysis (see Table 4.2) revealed a significant main effect of health message type on susceptibility $(\beta=-.73, \mathrm{p}=.01$ ), which 
seemed to be qualified by a marginally significant health message type by awareness interaction effect ( $\beta=.47, \mathrm{p}=.10$; see Figure 4.1 ). When we distinguished between previously aware and previously unaware participants, we observed a significant effect of health message type on susceptibility for previously unaware individuals ( $\beta$ $=-.46, \mathrm{p}=.001$ ) and a marginal effect for previously aware individuals $(\beta=-.18, \mathrm{p}=.09$ ). Previously unaware individuals who read the genetic health message had significantly lower perceived susceptibility $(\mathrm{M}=2.77, \mathrm{SD}=1.53)$ than those who read the general health message $(\mathrm{M}=4.42, \mathrm{SD}=1.66)$. No effects were observed for perceived severity (ps >.53).

\section{Genetic information and intention}

Although we did not observe the expected health message type by awareness interaction effect on intention $(\beta=-.02, \mathrm{p}=.79)$, we did observe a significant main effect of health message type ( $\beta=-.23, \mathrm{p}=$ .008; see Table 4.3 and Figure 4.2). Participants who read the genetic health message had significantly less intention to lower cholesterol levels $(M=5.02, S D=1.57)$ than those who read the general health message $(M=5.68, S D=1.24)$. The significant effect of health message type on intention was slightly reduced in significance $(\beta=$ $.19, \mathrm{p}=.02)$ after susceptibility was added to the model $(\beta=.17, \mathrm{p}=$ $.04)$, suggesting that the health message type effect on intention was partially mediated by susceptibility. Additionally, we observed a significant effect of severity on intention $(\beta=.30, \mathrm{p}<.001)$, but no effects of positive or negative affect (ps $>.18$ ). These results suggest that informing individuals about the existence of genetic risk factors for heightened cholesterol levels leads to decreased perceived susceptibility, which in turn results in lower intention to reduce cholesterol levels. In contrast to Studies $4.1 \mathrm{~A}$ and $4.1 \mathrm{~B}$, however, these results were observed for both previously aware and previously unaware individuals.

\section{Meta-analy tical combinations}

Although our three studies seem to reveal a general pattern in which genetic health messages about salt sensitivity and heightened cholesterol are not necessarily valuable when educating a previously unaware population, we did observe a discrepancy between the studies on salt sensitivity (Studies $4.1 \mathrm{~A}$ and $4.1 \mathrm{~B}$ ) and the study on cholesterol (Study 4.2). That is, in Study 4.2 we did not observe the health message type by awareness status interaction effect on intention as observed in Studies 4.1A and 4.1B. Another inconsistency between the studies concerns the fact that, in Studies 4.1A and 4.2, we did not observe the genetic health message to affect perceived 
susceptibility for previously aware participants, while in Study 4.1B we observed a positive effect.
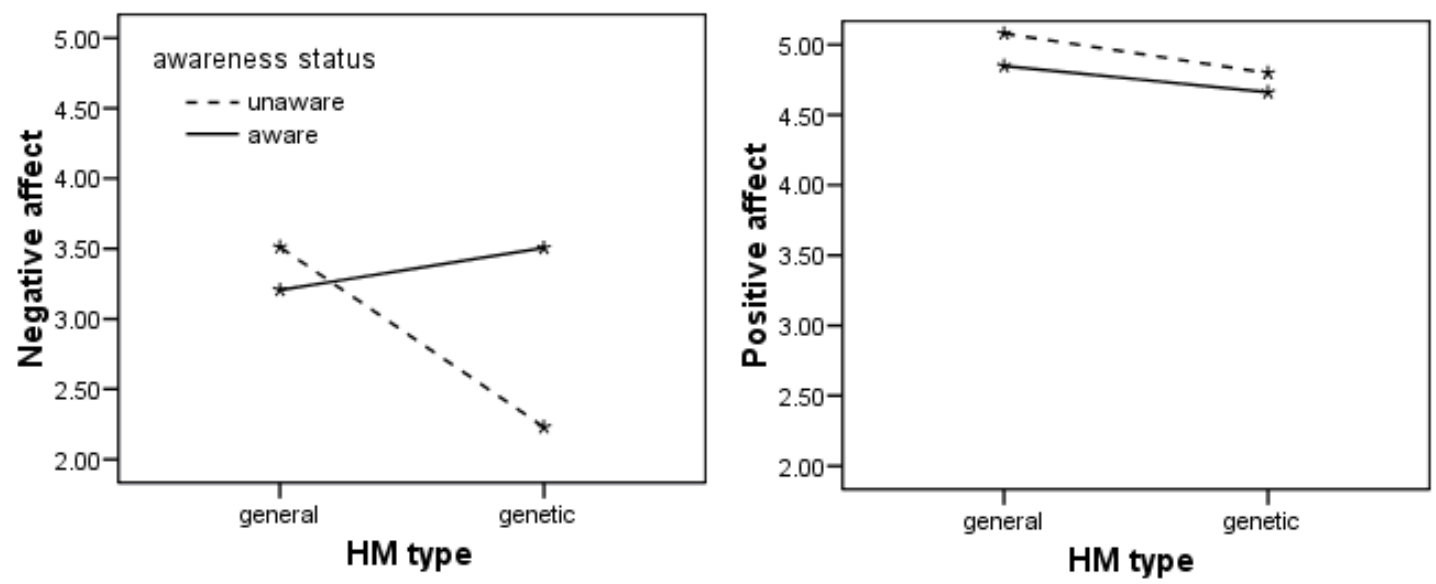

Figure 4.3. Negative and positive affect scores for study 4.2.

Left panel: Negative affect scores for the stratified samples categorized by health message type for Study 4.2.

Right panel: Positive affect scores for the stratified samples categorized by health message type for Study 4.2.

We performed a meta-analysis across all three studies to examine whether these inconsistencies were the result of the different health issues (salt sensitivity and heightened cholesterol respectively) and health behaviours (restricting salt intake and consuming less high cholesterol foods respectively) under consideration (see Clark, Wegener, \& Fabrigar, 2008 for a similar analytical strategy). To this end, we used the p-values to calculate $z$-scores for all the effects across Studies 4.1A, 4.1B and 4.2. The z-scores were then added across the three studies and divided by the square root of three (the number of studies that had been combined). Subsequently, the resulting z-scores for each effect were used to calculate new $\mathrm{p}$-values (for a more detailed description of this procedure see Rosenthal, (1991)).

The studies were observed to be homogeneous concerning susceptibility $\left(\mathrm{x}^{2}(2)=0.86, \mathrm{p}=.65\right)$ and intention $\left(\mathrm{x}^{2}(2)=4.00, \mathrm{p}=\right.$ $.14)$. The results of these meta-analytic combinations revealed the expected health message type by awareness interaction effect on susceptibility $(\mathrm{z}=3.24, \mathrm{p}<.001)$. When we distinguished between previously aware and previously unaware participants, we observed health message type to have a significant effect on susceptibility for 
previously unaware participants $(\mathrm{z}=3.63, \mathrm{p}<.001)$, but not for previously aware participants $(\mathrm{z}=101, \mathrm{p}=.16)$. In other words, across the three studies, participants who reported being unaware of the existence of genetic risk factors for salt sensitivity and heightened cholesterol responded to the genetic health message with lowered perceived susceptibility.

The meta-analytical combinations concerning the intention measure revealed a marginally significant health message type by awareness interaction effect $(\mathrm{z}=1.43, \mathrm{p}=.08)$. For previously unaware participants, we observed a significant effect of health message type on intention $(\mathrm{z}=2.91, \mathrm{p}<.005)$, but not for previously aware individuals $(\mathrm{z}=0.93, \mathrm{p}=.18)$. These results thus suggest that, for previously unaware participants, reading the genetic health message resulted in lower intention to engage in preventive behaviour.

\section{General discussion}

Our three studies, taking into account their meta-analytical combinations, seem to suggest that health messages communicating the existence of genetic risk factors for salt sensitivity and heightened cholesterol lead to decreased perceived susceptibility, but only among individuals who were unaware of the existence of such factors at the moment of information exposure. Our hypothesis 3, in other words, was confirmed. We also found a negative effect on the intention to engage in preventive behaviour which seemed to be mediated by perceived susceptibility. In Studies 4.1A and 4.1B, these results were only observed among previously unaware participants, also confirming hypothesis 3. In Study 4.2, however, we observed health message type to have a main effect on intention, suggesting that both previously aware and previously unaware participants reacted adversely to genetic health messages. Overall, the results thus seem to suggest that alerting individuals to the existence of genetic risk factors for a particular disease does not necessarily positively affect their intention to engage in preventive behaviour.

Unexpectedly, the observed effects of genetic health messages on risk perception and the intention to engage in preventive behaviour did not seem to originate from extrapolation of past experiences or evoked negative affect. Studies 4.1A and 4.1B suggest that perceived family histories of CVD or hypertension did not influence the results. As such, the rationale that upon learning of the existence of genetic risk factors, a perceived lack of family history of the disease may lead to an underestimation of personal susceptibility (Hailey et al., 2000) is not supported by our data. Similarly, the results cannot be explained by the fact that genetic health messages produced negative 
affect. Study 4.2 suggests that genetic health messages evoked lower levels of negative affect than general health messages. Although the exact mechanisms responsible are not known, the observed effects of health messages communicating the existence of genetic risk factors on risk perception and the intention to engage in preventive behaviour may thus represent 'adverse' effects. In short, as Condit and colleagues (2004) suggested, genetic health messages may sometimes do more harm than good, at least for previously unaware individuals.

One possible explanation may concern the nature of genetic information. For instance, emphasizing genetic risk factors may result in lower intention due to beliefs of their (relative) uncontrollability (Marteau, 1999). Such beliefs may be lower among previously unaware individuals as they have spent less time dwelling on the matter. In essence, previously aware and previously unaware individuals may differ in their perceptions of response efficacy concerning the recommended behaviours (i.e., lifestyle changes), especially when these behaviours purport to prevent geneticallydetermined disease (Wright et al., 2006). Or, as Marteau and Weinman (2006, p. 1365) argue, individuals may believe that "IF heart disease is caused by genes, THEN there is nothing that can be done" (p. 1365). Indeed, threat perceptions that include genes as a causal factor have been shown to be seen as uncontrollable (Shiloh, Rashuk-Rosenthal, \& Benyamini, 2002). A promising new avenue for research into the impact of genetic information might therefore be to investigate its effects on perceptions of control, coping and response efficacy with respect to the potential differential effects of previously aware and previously unaware individuals.

Notwithstanding the cognitive processes responsible for the observed adverse effect of health messages about the existence of genetic risk factors on risk perception and intention, the results have several important implications for public health promotion. First, simply alerting the general public to the existence of genetic risk factors in order to increase their awareness of genetic risk factors may not result in immediate intention to engage in preventive behaviour. Thus, in doing so health educators should provide more detailed knowledge on the meaning and personal relevance of genetic risk factors (Smerecnik et al., 2008). In line with Rogers's (2003) knowledge framework, the public first needs to be aware of the existence of genetic risk factors (awareness knowledge). They also need to have practical knowledge on how these factors affect disease development and how to cope with them (how-to knowledge), as well as theoretical knowledge of the genetic mechanisms underlying the gene-disease relationship (principles knowledge). As such, creating 
public awareness is a necessary yet insufficient step in motivating the public to engage in adequate preventive behaviour (Smerecnik et al., 2008).

Second, individuals who underestimate their personal susceptibility may be more likely to avoid being exposed to subsequent communications on their susceptibility (Bernhardt, McClain, \& Parrott, 2004; Wiebe \& Black, 1997). In turn, this inattention to subsequent communications may form a barrier to remedying the public's incorrect interpretation of the genetic message. We are thus in dire need of more empirical research on this matter before informing the general public about the existence of genetic risk factors, and especially before deciding on a specific strategy to do so.

The present results must be interpreted with some caution given the following limitations of the studies. First, because we did not assess the baseline levels of perceived susceptibility and intention, we were unable to examine changes in susceptibility and intention due to the genetic health message. However, in view of the experimental design of these studies, we believe the observed 'adverse' effects of genetic health messages to be reliable. Second, we only assessed intention to perform the preventive behaviours, and not actual preventive behaviour. Although intention is the most important determinant of behaviour, explaining approximately $40 \%$ of its variance (Godin \& Kok, 1996), future studies should examine the effects of genetic health messages on actual preventive behaviour. Finally, we did not check whether participants understood the scenario information. It may thus be possible that previously unaware individuals had more difficulty understanding the information on the existence of genetic risk factors for salt sensitivity and cholesterol than the general health information. As a consequence, they may have reported lower perceived susceptibility and lower intention to restrict salt intake or reduce their cholesterol levels. On the other hand, the information used simply mentioned the fact that genetic risk factors for salt sensitivity and heightened cholesterol exist; this should be relatively easy to understand and process. Future studies may nonetheless assess comprehension of genetic information or, alternatively, participants' prior knowledge of genetics.

In conclusion, the present studies suggest that simply alerting the general public to the existence of genetic risk factors for a particular medical condition may not result in immediate intention to engage in preventive behaviour; it may even have adverse effects. If information about the existence of genetic risk factors is accompanied by information explaining its meaning and consequences, this may be a valuable first step in promoting appropriate preventive behaviour in 
response to genetic risks. However, we first need more empirical research on this matter before drawing any conclusions about the value of health messages communicating the existence of genetic risk factors for public health promotion. 


\section{Chapter 5}

Genetic health messages in the mass media: Do the general public perceive non-personalised genetic health messages as personally relevant?

Manuscript submitted as: Smerecnik, C. M. R., Mesters, I., Candel, M. J . J . M., De Vries, H., \& DeVries, N. K. (2009). Genetic health messages in the mass media: Do the general public perceive nonpersonalised genetic health messages as personally relevant? 


\begin{abstract}
Objectives. Although health messages communicating the role of genetics in health and disease development are increasingly prevalent in our society, no research has examined whether the general public perceives such messages as believable or personally relevant. In this paper we examined whether the general public accepts genetic health messages and views them personally relevant and how information acceptance and personal relevance affect relevant health cognitions.

Design. Experimental pretest - postest measurement design was employed to contrast the perceived personal relevance of the genetic health message with a general health message.

Methods. In the present study, we presented participants ( $\mathrm{n}=1319)$ with either a health message about the genetic risk factors for salt sensitivity or with a general health message about salt sensitivity without reference to genetic risk factors. Risk perception and intention to restrict salt intake was assessed before and after participants read the messages while information acceptance and perceived personal relevance were only assessed post-test.
\end{abstract}

Results. Although we observed no effects of health message type on information acceptance, aware participants perceived the genetic health message as less personally relevant compared to the general health message. Susceptibility was observed to mediate the health message type by awareness status interaction effect on intention. Personal relevance, in turn, mediated the health message type by awareness status interaction effect on susceptibility.

Conclusions. Genetic health messages in the mass media may not be effective in promoting (intentions to engage in) preventive behaviour due to low perceived personal relevance of such messages. Future research may test the value of existing strategies to increase personal relevance for genetic health messages. 


\section{Introduction}

Recent advances in genomics have been suggested to radically transform the public health landscape (Collins et al., 2003). Indeed, technological and biochemical applications of genomics have proved to be successful in identifying individual members of the general population who are at increased risk for a given disease due to their genetic makeup. Since the completion of the Human Genome project in 2003, more than 350 genetic tests have become available (National Institutes for Health, 2009) and approximately 450 tests are currently in development (NCBI, 2009). Such genetic services have been proven successful in improving risk perception accuracy (Meiser \& Halliday, 2002; Smerecnik, Mesters, Verweij, de Vries, \& de Vries, 2009) and reducing anxiety (Butow, Lobb, Meiser, Barratt, \& Tucker, 2003).

Several authors have suggested that the value of such applications of genomics can be greatly enhanced by educating the general public about genetics (Burke et al., 2002; Wang et al., 2005). Media coverage of genetics has been quite extensive in the US (cf. Bubela \& Caulfield, 2004). Our preliminary analyses suggest that this is also true in the Netherlands. Approximately one thousand news stories were distributed in daily newspapers and news broadcasts in 2008 alone. A recent controversy surrounding embryo-selection, which even reached the Dutch House of Parliament, reœeived substantial media attention.

The effect of mass media communications about genetics has been heavily debated with opponents arguing that media coverage of genetics may lead to beliefs of genetic determinism (e.g., Katz Rothman, 1998) while proponents argue that beliefs about genetic causation have remained rather consistent despite the recent massive media attention (e.g., Condit et al., 2009). Unfortunately, there is scarce empirical research into the effects of mass media health messages about genetics on health cognitions and precautionary action (Saab et al., 2004). The little evidence that is available, however, suggests that communicating the existence of genetic risk factors to the general public (cf. Rogers, 2003) does not necessarily lead to interest in obtaining a genetic test (Cappella et al., 2005) or to motivation to engage in preventive behaviour (Smerecnik, Mesters, De Vries, \&De Vries, in press).

One study illustrates the importance of the believability or acceptance of genetic health messages in motivating individuals to engage in preventive action. In their study, Cappella et al. (2005) presented smokers with a message communicating the existence of genetic risk factors for smoking addiction or with a message 
communicating the effect smoking has on the gender of smokers' offspring. The genetic message had an adverse effect on perceived susceptibility and the intention to get a genetic test. However, Cappella et al. (2005) observed that these effects were moderated by the believability of the genetic message. That is, when the genetic health message was perceived as more believable, participants felt more susceptible and reported more intentions to obtain a genetic test. Whether message recipients accept a genetic health message as believable or credible is thus of crucial importance for their effect on relevant health cognitions.

However, concerns can and have been raised concerning the public's willingness to accept genetic health messages. According to the Theory of Consonance and Dissoannce (Van Cuilenberg \& Noomen, 1984), people screen all incoming messages with the aim of reducing potential dissonance. As such, people tend to avoid exposure to messages that conflict with their current knowledge, opinions, goals and motivations. However, due to inefficiency of this process or a changing context, conflicting messages with new or contrary information are received which may result in dissonance. The Theory of Consonance and Dissonance posits the two main possibilities for restoring balance (or consonance): (1) change the perceptions of the message or the source (e.g., perceiving the source as less credible or believable) or (2) change the existing opinion, goal or motivation. Under conditions of relatively medium-to-low dissonance, changing the perception of the message or the source is the most likely outcome (Van Cuilenberg \& Noomen, 1984; for a similar discussion see also the Cognitive Dissonance Theory (Festinger, 1962)).

Indeed, Condit (2005) argues that genetic health messages that imply genetic determinism are not likely to be accepted by the majority of the general population (see also Condit, Ferguson, Kassel, Thadhani, Gooding, \& Parrott, 2001). People seem to belief that although genes have some influence in disease development, this influence can be countered by their personal efforts, behaviour, or religious forces. Messages that run counter to these beliefs are either rejected outright or reinterpreted in such a way that the influence of genes is one of many in the multifactorial causation dimension (Bates et al., 2003; Condit, 2005). Either way, such message may not be perceived as believable or credible. Considering these issues and the findings of Cappella et al. (2005) our first goal was to examine whether the general public accepts genetic health messages as credible and believable compared to general health messages.

Besides issues of genetic health message's believability, the perceived personal relevance of the genetic health message may be an important factor that determines the effects of mass media genetic 
health messages on health cognitions and precautionary action. The primary driving force behind the positive effects of genetic testing and counselling is argued to lie in its ability to individualize risks by referring to individual differences in DNA structure (Guttmacher \& Collins, 2005; Janssens \& Van Duijn, 2008). However, the mass media inevitably lack such individuation qualities as it directs genetic health messages at the general public at large (i.e. it cannot definitively argue whether or not message recipients are a carrier of the predisposing gene). As such, genetic health message recipients may not be convinced of the personal relevance of this message. So, besides examining whether the general public accepts genetic health messages as credible and believable, our second goal was to investigate whether the general public perceives genetic health messages as personally relevant. Additionally, we were also interested in how information acceptance and personal relevance could explain the adverse effects of genetic health messages on perceived susceptibility as observed in previous research (Cappella et al., 2005; Smerecnik et al., in press), which was our third goal.

Concerning our first goal (i.e. examine whether genetic health messages communicating the existence of genetic risk factors for multifactorial disease are accepted by the general public as credible and believable), we formulated two hypotheses. We expected individuals who were unaware at the time of information exposure to be less inclined to accept a genetic health message as believable compared to a general health message (hypothesis 1) as the genetic health message contains new information with which they are not familiar (i.e. creates dissonance). The opposite effect was expected for aware individuals. Aware participants might view a general message with suspicion since it does not mention genetics as a cause for disease that they know to be true (cf. Frewer, Howard, Hedderley, \& Shepherd, 1999). As such, the general health message may be less likely to be perceived as credible or believable as compared to the genetic health message (hypothesis 2). Our second goal was to examine whether the general public perceives genetic health messages as personally relevant. We expected that among previously unaware participants, the general health message will be perceived to be more personally relevant compared with the genetic health message (hypothesis 3). Among previously aware participants, we did not expect differences between the genetic and general health message in terms of perceived personal relevance (hypothesis 4). Concerning our third goal, we explored the possible mediating or moderating effects of information acceptance and personal relevance in explaining the effects of genetic health messages on perceived susceptibility and intention. 


\section{Method}

\section{Participants}

We approached 2500 individuals for the present study through an Internet consumer panel. After completing each of the three questionnaires of this study (see procedure), participants were rewarded conform the norms of the consumer panel. They could obtain an additional bonus by completing all questionnaires.

\section{Procedure}

The Internet consumer panel sent e-mails to the 2500 individuals selected for the study. These individuals were selected to form a sample representative of the Dutch general population. The e-mail message contained an internet link to a login page, which expired after one week. After logging into their account, participants oould fill out the socio-demographics questionnaire, containing measures of several socio-demographic characteristics and awareness status of the genetic risk factors for salt sensitivity. When finished with the questionnaire participants were automatically relocated to the consumer panel's homepage. Two weeks later participants who filled out the socio-demographics questionnaire were sent a second e-mail inviting them for the baseline questionnaire. The baseline questionnaire contained (pretest) measures of susceptibility, severity, and intention to restrict salt intake. An additional two weeks later participants that filled out the baseline questionnaire were sent a thind e-mail inviting them to fill out the immediate follow-up questionnaire. This questionnaire started with either one of two health messages (communicating the existence of genetic risk factors for salt sensitivity or communicating general information about salt sensitivity without reference to genetic risk factors) followed by (post test) measures of information acceptance, personal relevance, susceptibility, severity, and intention.

\section{Materials}

The present scenarios and the questionnaires were adopted from previous research (Smerecnik et al., in press). One health message presented information on the existence of genetic risk factors for salt sensitivity whereas the other health message presented general information on salt sensitivity without reference to its genetic risk factors (see Appendix 1). Note that this does not entail providing personalized DNA risk information, but rather involves simply communicating the fact that salt sensitivity is partly caused by genetic factors. 


\section{Measures}

Socio-demographics questionnaire

In the socio-demographics questionnaire, participants were asked to report the following demographic characteristics: hypertension status ("Are you currently diagnosed with hypertension?" $1=$ no, $2=$ yes), whether they presently were on a salt-restricted diet ( $1=$ no, $2=$ yes), and whether they had a family history of cardiovascular disease (CVD) and family history of hypertension ("Are one or more members of your direct family diagnosed with cardiovascular disease / hypertension?" 1 =no, 2 = don't know, 3 =yes).

Awareness status was assessed using one forced-choice item (Have you ever heard of genetic risk factors for a salt-sensitive blood pressure? 1 =yes, $0=$ no). Participants' age, gender, and level of education were available through the Internet consumer panel.

\section{Baseline questionnaire}

Risk perception was operationalized by assessing perceived susceptibility to and perceived severity of salt sensitivity. Perceived susceptibility of having a salt-sensitive blood pressure was measured using three items assessing absolute perceptions of susceptibility (e.g., "I am vulnerable to a salt-sensitive blood pressure", $1=$ totally disagree to $7=$ totally agree) and three items assessing perceptions of risk relative to others (e.g., "Relative to your peer group, how large is your chance of having a salt sensitive blood pressure", $1=$ much smaller to $7=$ much larger). Exploratory factor analysis revealed one single underlying factor (Eigenvalue $=3.80 ; \mathrm{R}^{2}=0.76$ ). These six items were therefore combined into the susceptibility factor (Cronbach's $\alpha=.91, \mathrm{M}=3.29, \mathrm{SD}=1.20$ ). Severity was assessed by three items (e.g., "Salt sensitivity is a serious medical condition", $1=$ totally disagree - $7=$ totally agree; Cronbach's $\alpha=.87, \mathrm{M}=3.49$, SD $=2.17$ ). The intention to restrict salt intake was assessed using three items (e.g., "I intend to restrict my salt intake", $1=$ totally disagree to 7 =totally agree; Cronbach's $\alpha=.93, \mathrm{M}=4.40, \mathrm{SD}=1.70$ ).

\section{Posttest questionnaire}

In the immediate follow-up questionnaire, participants first read the health message and were then asked to fill out questions regarding information acceptance and perceived personal relevance. Information acceptance was assessed by four items (e.g., "The information in the message was believable", "The information in the message was accurate", $1=$ totally disagree $-7=$ totally agree; Cronbach's $\alpha=.77, \mathrm{M}=4.86, \mathrm{SD}=1.25)$. Perceived personal relevance was measured using two items (e.g., The information was 
personally relevant', The information is applicable to me personally', $1=$ totally disagree $-7=$ totally agree; Cronbach's $\alpha=.76, \mathrm{M}=3.66$, $\mathrm{SD}=1.48$ ). Afterwards participants answered the same questions on perceived susceptibility (Cronbach's $\alpha=.93, \mathrm{M}=3.39$, $\mathrm{SD}=1.24$ ), severity (Cronbach's $\alpha=.87, \mathrm{M}=2.75, \mathrm{SD}=1.29$ ), and intention (Cronbach's $\alpha=.94, \mathrm{M}=4.41, \mathrm{SD}=1.67$ ) as in the baseline questionnaire.

\section{Statistical analyses}

Initial analyses were conducted to examine whether the general health message versus the genetic health message groups and the aware versus unaware groups differed in terms of the sociodemographic variables. Possible confounding variables (i.e. those variables on which the experimental or the aware versus unaware groups differed) were added as covariates in all subsequent analyses. To examine the effects of the health messages on information acceptance and personal relevance, we conducted two regression analyses with information acceptance and personal relevance as the dependent variables and health message type, awareness status, and their interaction as independent variables. We first attempted to replicate previous findings that the effects of genetic health messages on intention was mediated by perceived susceptibility (Cappella et al., 2005; Smerecnik et al., in press) in order to establish the reliability of the data and to obtain a baseline model to test our hypotheses concerning information acceptance and personal relevance. To this end, we examined whether the effect of health message type on intention was mediated or moderated by susceptibility (see Figure 2) by performing the procedure outlined in Fairchild \& MacKinnon (2009), using the Mplus software package (Muthen \& Muthen, 2006). The same procedure for testing mediation and moderation was then used to examine the possible mediating or moderating effects of information acceptance and personal relevance on perceived susceptibility by adding these concepts to our baseline model.

\section{Results}

\section{Sample Characteristics}

In total, 1319 participants filled out all three questionnaires. Table 5.1 presents the demographic characteristics of the initial $(n=2500)$ and the final sample $(n=1319)$. The final sample seemed to be somewhat higher-educated than the general population but accurately reflects the general population in terms of gender and age.

We observed no differences between the genetic health message $(n=654)$ and general health message groups $(n=665)$ in terms of 
age, gender, level of education, hypertension status, family history of CVD, family history of hypertension, whether they were on a saltrestricted diet or not, and awareness status (ps >.11). The aware ( $\mathrm{n}=$ 235) versus the unaware group $(\mathrm{n}=1084)$ did not differ in terms of age, gender, hypertension status, and whether they were on a saltrestricted diet (ps > .23). However, aware participants were more likely to be higher educated ( $\mathrm{OR}=1.27, \mathrm{p}=.01$ ), and more likely to be aware of their family history of CVD (OR $=1.39, \mathrm{p}<.01)$. Consequently, all subsequent analyses were controlled for level of education, and family history of CVD.

Table 5.1. Demographic characteristics of the initial and final research sample.

\begin{tabular}{|c|c|c|c|c|c|}
\hline \multirow[t]{2}{*}{$\begin{array}{l}\text { Demographic } \\
\text { characteristics }\end{array}$} & \multicolumn{2}{|c|}{$\begin{array}{c}\text { Initial sample }(n= \\
2500)\end{array}$} & \multicolumn{2}{|c|}{$\begin{array}{c}\text { Final sample }(n= \\
1319)\end{array}$} & \multirow{2}{*}{$\begin{array}{l}\text { Dutch } \\
\text { population } \\
\text { data, \% a }\end{array}$} \\
\hline & $\%$ & $\mathbf{n}$ & $\%$ & $\mathbf{n}$ & \\
\hline \multicolumn{6}{|l|}{ Gender } \\
\hline Male & 48 & 1200 & 48.7 & 642 & 49.4 \\
\hline Female & 52 & 1300 & 51.3 & 677 & 50.6 \\
\hline \multicolumn{6}{|l|}{ Age } \\
\hline 20-39 years & 35 & 875 & 30.3 & 399 & 34.8 \\
\hline 40-64 years & 45 & 1125 & 51.4 & 714 & 46.2 \\
\hline$\geq 65$ years & 20 & 500 & 15.6 & 206 & 19.1 \\
\hline \multicolumn{6}{|l|}{ Level of education } \\
\hline Low & 30 & 750 & 31.8 & 419 & 33.4 \\
\hline Medium & 42 & 1050 & 38.9 & 513 & 41.0 \\
\hline High & 28 & 700 & 29.3 & 387 & 25.6 \\
\hline
\end{tabular}

a Statistics Netherlands (CBS), Voorburg/ Heerlen, 2007 (http:// www.cbs.nl). Data of Dutch population $\geq 20$ years for gender and age, and data $\geq 15$ years for level of education.

\section{Information acceptance}

Regression analysis did not reveal a significant effect of health message type, awareness or the health message type by awareness interaction effect on information acceptance $(\beta \mathrm{s}<.15$, ps $>.10$, see Table 5.2). In other words, the genetic health message was accepted as well as the general health message by both previously aware and previously unaware participants.

\section{Personal Relevance}

Regression analyses revealed a significant main effect of awareness on personal relevance, $\beta=-.09, \mathrm{p}=.01$ (see Table 5.2). However, this effect seemed to be qualified by a health message type by awareness 
interaction effect, $\beta=.28, \mathrm{p}=.04$ (see Figure 5.1). In depth analyses revealed a significant negative effect of health message type on personal relevance among previously unaware individuals, $\beta=-.14$, $\mathrm{p}$ $=.03$, but not among previously aware participants, $\beta=-.01, \mathrm{p}=.95$. Previously unaware participants perceived the general scenario information as more personally relevant $(\mathrm{M}=4.17, \mathrm{SD}=1.58)$ than the genetic scenario information $(\mathrm{M}=3.74, \mathrm{SE}=1.46)$. In addition, previously unaware participants reading the general health message also reported higher personal relevance than previously aware participants who read the general health message $(\mathrm{M}=3.60, \mathrm{SD}=$ $1.46, \mathrm{p}<.001)$ and previously aware participants who read the genetic health message $(\mathrm{M}=3.61, \mathrm{SD}=1.46, \mathrm{p}<.001)$. No other significant effects were observed on this measure.

\section{Mediation and moderation analyses}

Since we did not observe any effects of health message or awareness status on information acceptance, the mediation and moderation analyses were only conducted for personal relevance. To replicate previous findings of the effects of genetic health messages on intention (Cappella et al., 2005; Smerecnik et al., in press), we first explored whether the effects of health message type and awareness status on intention (see Tables 5.2 and 5.3) were mediated or moderated by perceived susceptibility (see Figure 5.2). We observed a significant effect of the health message by awareness status interaction on susceptibility $(\beta=0.30, \mathrm{p}=.03)$ and a significant effect of susceptibility on intention $(\beta=0.21, \mathrm{p}<.01)$. The direct effect of the health message type by awareness status interaction effect was not significant $(\beta=0.03, \mathrm{p}=.87)$, nor were the two two-way interaction effects between health message type and susceptibility $(\beta=$ $-0.06, \mathrm{p}=.34)$ and awareness status and susceptibility $(\beta=-0.07, \mathrm{p}=$ .30) or the three-way interaction effects between health message type, awareness status and susceptibility $(\beta=-0.17, \mathrm{p}=.17)$. These results seem to suggest a mediated-moderation effect in which the interaction effect of health message type and awareness status on intention is mediated by susceptibility. Performing Morgan-Lopez and MacKinnon's (2006) point estimator and standard error for the product of coefficients method, the estimate of the mediatedmoderation effect was .06 and its standard error .11. Since mediated effects based on normal theory may provide biased confidence intervals, we calculated an asymmetric distribution to accurately determine the confidence interval for our estimate of the mediatedmoderation effect (see MacKinnon, Lockwood, Hoffman, West, \& Sheets, 2002; MacKinnon, Lockwood, \& Williams, 2004). To this 
Chapter 5 | Personal relevance of genetic health messages

Table 5.2. Regression analyses of health message type and awareness on personal relevance, susceptibility, and intention.

\begin{tabular}{|c|c|c|c|c|c|c|c|c|c|c|}
\hline & \multicolumn{2}{|c|}{$\begin{array}{l}\text { Information } \\
\text { acceptance }\end{array}$} & \multicolumn{2}{|c|}{ Personal relevance } & \multicolumn{2}{|c|}{ Severity } & \multicolumn{2}{|c|}{ Susceptibility } & \multicolumn{2}{|c|}{ Intention } \\
\hline & $\beta$ & $\Delta \mathrm{R}^{2}$ & $\beta$ & $\Delta \mathrm{R}^{2}$ & $\beta$ & $\Delta \mathrm{R}^{2}$ & $\beta$ & $\Delta \mathrm{R}^{2}$ & $\beta$ & $\Delta \mathrm{R}^{2}$ \\
\hline $\begin{array}{l}\text { Step } 1 \\
\text { Health } \\
\text { Message type }\end{array}$ & -.03 & .002 & -.03 & $.010^{* *}$ & -.01 & $.190^{* *}$ & .03 & $.220 * *$ & .05 & $.410^{* *}$ \\
\hline $\begin{array}{l}\text { Awareness } \\
\text { Step } 2\end{array}$ & -.04 & .001 & $-.09 * *$ & $.003 *$ & .03 & .000 & & $.010 *$ & & $.003 *$ \\
\hline $\begin{array}{l}\text { Health } \\
\text { Message type }\end{array}$ & -.17 & & $-.29 *$ & & -.06 & & -.35 & & $-.25^{*}$ & \\
\hline $\begin{array}{l}\text { Awareness } \\
\text { Health } \\
\text { Message type } \\
* \text { Awareness }\end{array}$ & $\begin{array}{l}-.07 \\
.15\end{array}$ & & $\begin{array}{l}-.15^{* *} \\
.28^{*}\end{array}$ & & $\begin{array}{l}.02 \\
.05\end{array}$ & & $\begin{array}{l}-.21 * * \\
.50 *\end{array}$ & & $\begin{array}{l}-.08^{*} \\
.27^{*}\end{array}$ & \\
\hline
\end{tabular}


Chapter 5 | Personal relevance of genetic health messages

Table 5.3. Correlation matrix of information acceptance, personal relevance, severity, susceptibility and intention.

\begin{tabular}{|c|c|c|c|c|c|c|c|c|}
\hline & \multirow{2}{*}{$\begin{array}{c}\text { Information } \\
\text { acceptance }\end{array}$} & \multirow{2}{*}{$\begin{array}{l}\text { Personal } \\
\text { relevance }\end{array}$} & \multicolumn{2}{|c|}{ Severity } & \multicolumn{2}{|c|}{ Susceptibility } & \multicolumn{2}{|c|}{ Intention } \\
\hline & & & pretest & posttest & pretest & posttest & pretest & posttest \\
\hline Information acceptance & 1 & & & & & & & \\
\hline Personal relevance & $.28^{* *}$ & 1 & & & & & & \\
\hline Severity & & & & & & & & \\
\hline - pretest & $.17^{* *}$ & $-.17 * *$ & 1 & & & & & \\
\hline - posttest & $.20 * *$ & $-.20 * *$ & $.44 * *$ & 1 & & & & \\
\hline Susceptibility & & & & & & & & \\
\hline - pretest & .03 & -.03 & -.03 & .02 & 1 & & & \\
\hline - posttest & $-.66^{* *}$ & $.61^{* *}$ & $-.15^{* *}$ & $-.21 * *$ & -.03 & 1 & & \\
\hline Intention & & & & & & & & \\
\hline - pretest & $-.25^{* *}$ & $.27 * *$ & $-.17^{* *}$ & $-.17 * *$ & -.01 & $.18^{* *}$ & 1 & \\
\hline - posttest & $-.31 * *$ & $.33^{* *}$ & $-.17^{* *}$ & $-.21 * *$ & -.01 & $.23 * *$ & $.70^{* *}$ & 1 \\
\hline
\end{tabular}


end, we entered the estimatesand standard errors of the effects of the health message type by awareness interaction effect on personal relevance $(\beta=0.30, \mathrm{SE}=.14)$ and of personal relevance on perceived susceptibility $(\beta=0.21, \mathrm{SE}=.07)$ in the PRODCLIN programme (MacKinnon, Fritz, Williams, \& Lockwood, 2007). The resulting confidence interval ranged from 0.01

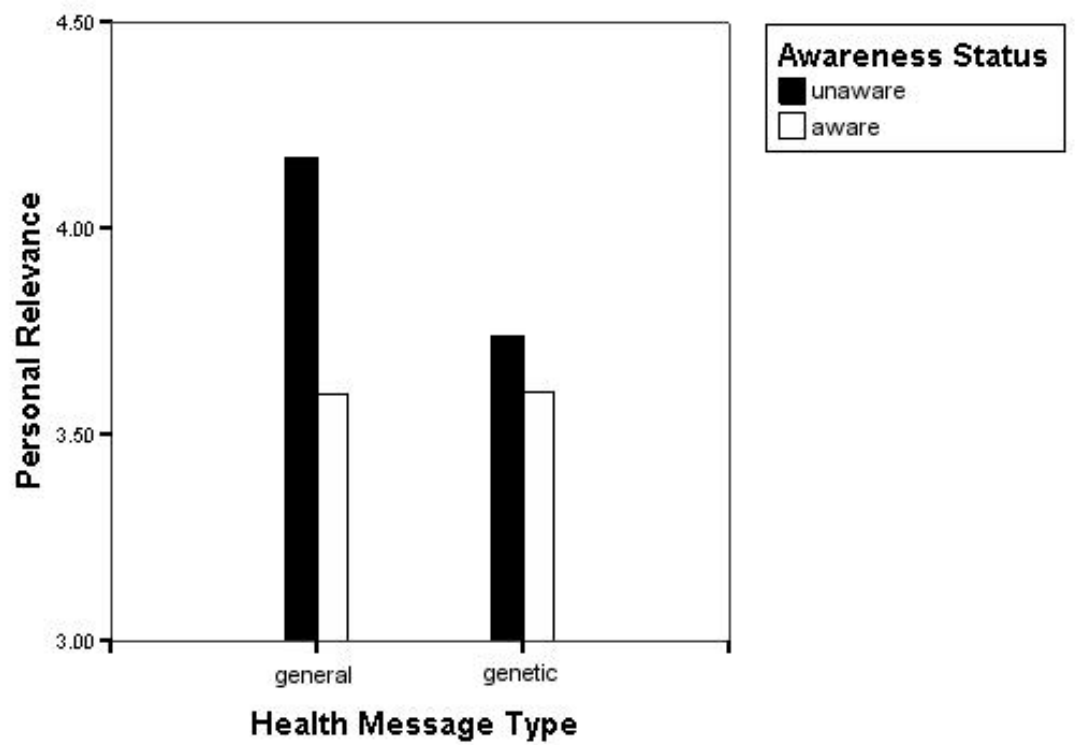

Figure 5.1. Personal relevance scores for previously aware versus previously unaware individuals categorized by health message type.

to 0.15 , indicating that the mediated-moderation effect was significant at the .05 level.

Concerning the role of personal relevance in explaining the effects of health message type on susceptibility (see Figure 5.3), we observed a significant health message type by awareness status interaction effect on personal relevance $(\beta=0.44, \mathrm{p}=.03)$ and a significant main effect of personal relevance on susceptibility $(\beta=0.66, \mathrm{p}<.0001)$. No interaction effect was observed between personal relevance and health message type or awareness. The results thus seem to suggest a mediated-moderation effect in which the interaction effect of health message type and awareness status on susceptibility is mediated by personal relevance. Performing Morgan-Lopez and MacKinnon's (2006) point estimator and standard error for the product of coefficients method, the estimate of the mediated-moderation effect 
was .29 and its standard error .32. After entering the estimates and standard errors of the effects of the health message type by awareness interaction effect on personal relevance $(\beta=0.44, \mathrm{SE}=.21)$ and of personal relevance on perceived susceptibility $(\beta=0.66, \mathrm{SE}=.06)$ in the PRODCLIN programme (MacKinnon et al., 2007), the resulting confidence interval ranged from 0.02 to 0.57 , indicating that the mediated-moderation effect was significant at the .05 level.

\section{Discussion}

The aims of this study were (1) to examine whether the general population accepts genetic health messages as well as the general health message, (2) to examine whether they perceived genetic health messages as personally relevant as general health message and (3) to explore the possible mediating or moderating effect of perceived personal relevance in the health message type - intention relationship. Concerning the first aim, the data do not support our hypotheses 1 and 2 . We observed no effect of health message type or its interaction with awareness status on information acceptance. The genetic health message was accepted as well as the general health message by both previously aware and previously unaware participants. We did observe a health message type by awareness status interaction effect on perceived personal relevance. Participants reporting to be unaware of the existence of genetic risk factors for salt sensitivity prior to reading the health message were more inclined to perceive the general health message as personally relevant than the genetic health message confirming our hypothesis 3 . The results also supported the hypothesis that aware participants would not be more inclined to perceive as personally relevant the genetic message than the general message (i. e. hypothesis 4).

In fact, our findings seems to suggest that participants who were aware of the genetic risk factors for salt sensitivity (either prior to the study or while reading the genetic health message) perceived the message about salt sensitivity to be less personally relevant than participants who were and remained unaware of these factors. A recently proposed materialist framework of lay knowledge of genetics (Condit et al., 2009) may shed some light on these results. According to this framework, people possess two mental models of disease causation: one describing genetic causation and the other describing behavioural causation. These two models are assumed to be unrelated and, as such, no mental model of gene-behaviour interaction causation exists. Importantly, for the present purpose, either one of these models can be activated upon proper cueing. The genetic health message may therefore have activated the 'genetic causation' mental model. Since the genetic causation model is not related to the 
Chapter 5 | Personal relevance of genetic health messages

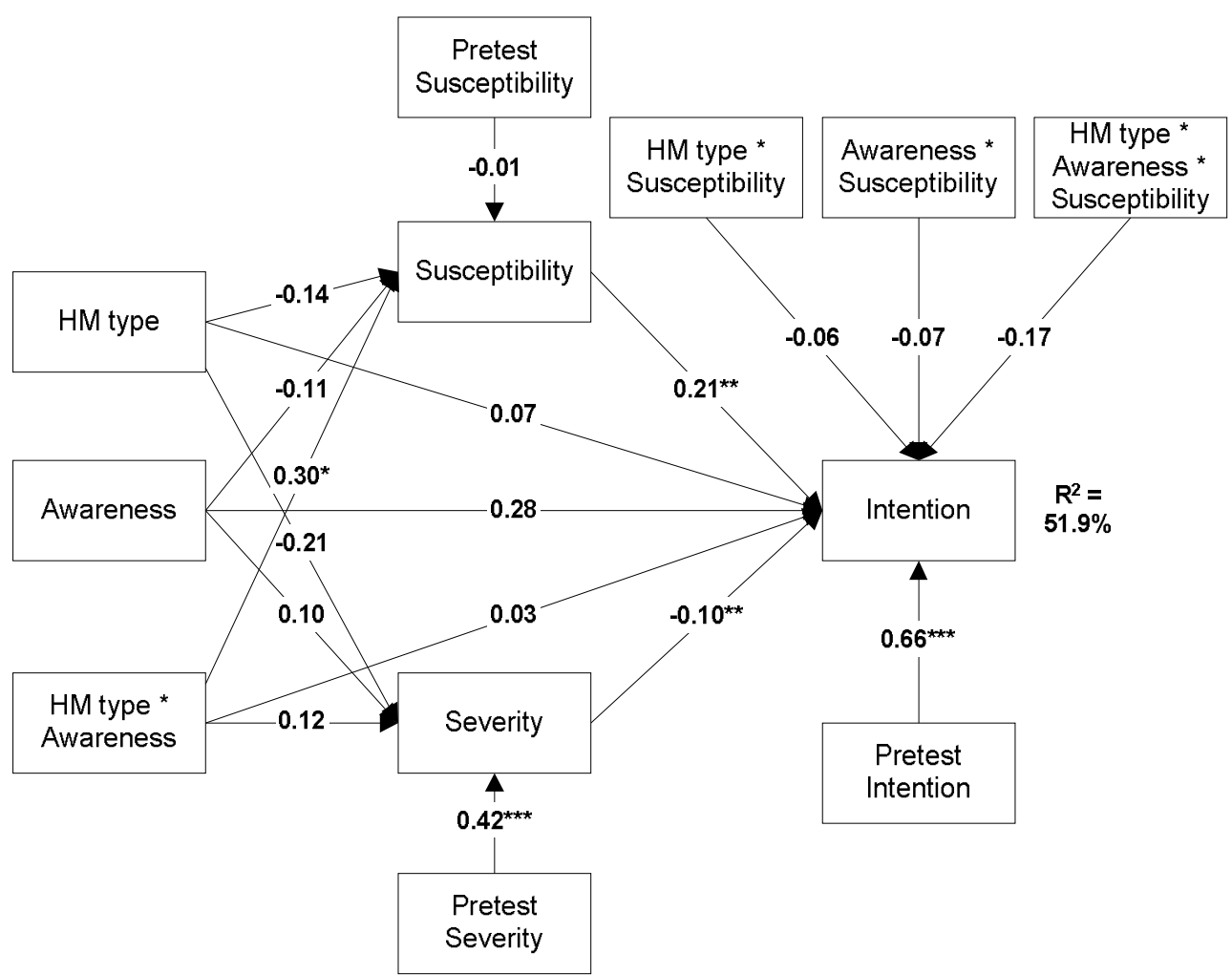

Figure 5.2. General model for testing mediation and moderation effects of susceptibility in the health message (HM) - intention relationship. 
Chapter 5 | Personal relevance of genetic health messages

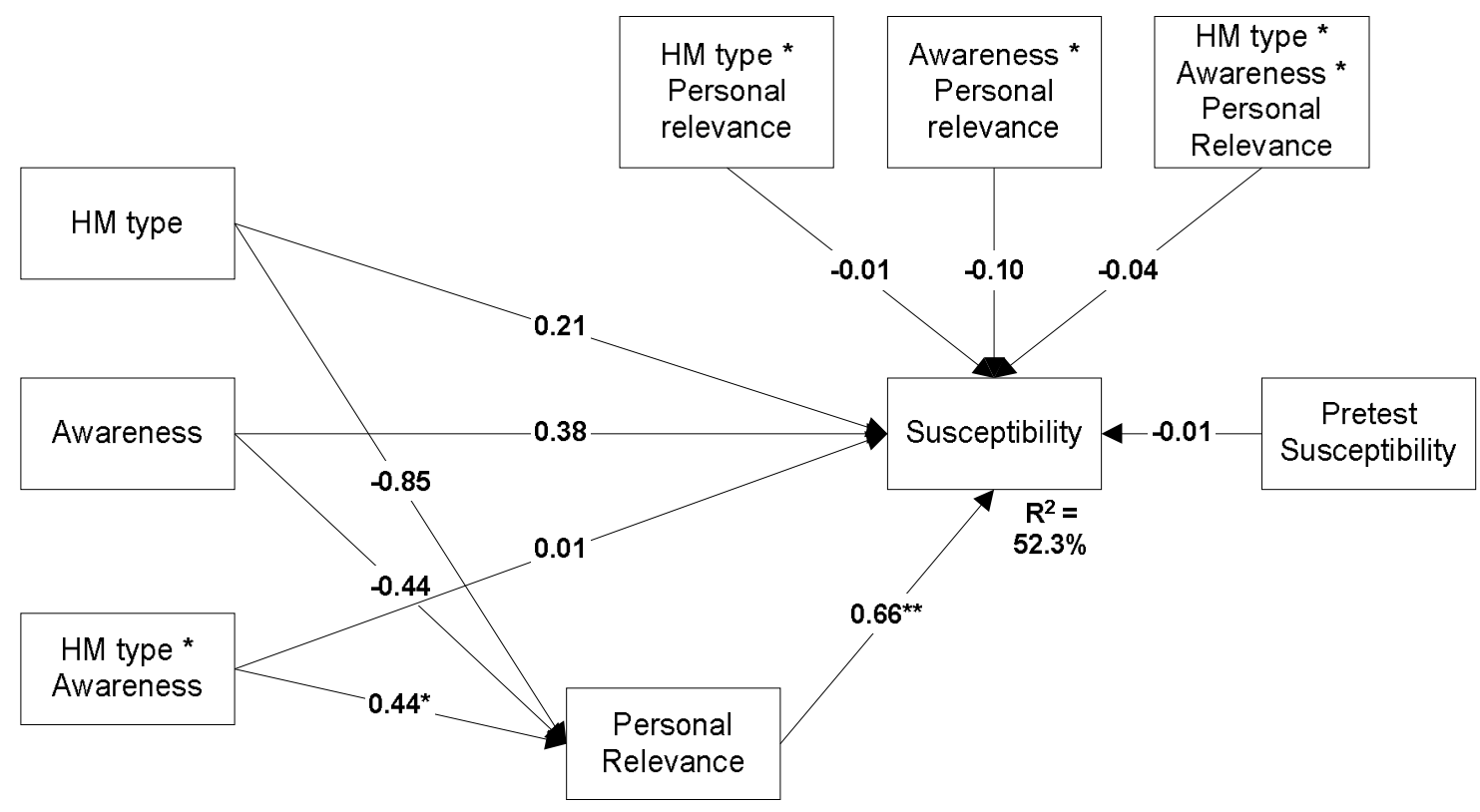

Figure 5.3. General model for testing mediation and moderation effects of personal relevance in the health message (HM) - susceptibility relationship. 
behavioural causation model, the genetic health message may not have elicited consideration of the gene-behaviour interaction. As such, message recipients may not be convinced that behaviour changes reduce their chance of developing hypertension as a result of salt consumption (Senior \& Marteau, 2007; Wright et al., 2006). This explanation is consistent with our finding that previously unaware individuals who read the genetic health message did not intend to restrict their salt consumption. However, knowing that the risk of having a genetic predisposition is, at least potentially, present may cause negative affect (J anoff-Bulman \& Lang-Gunn, 1988). Consequently, message recipients may use defensive coping strategies to reduce these feelings (Ruiter, Abraham, \& Kok, 2001), such as derogating personal relevance or underestimating personal susceptibility. Indeed, the observed effects of genetic health messages on intention were mediated by perceived susceptibility and personal relevance.

Notwithstanding the underlying cognitive processes, the results concerning our third aim showed that not perceiving the genetic health message to be personally relevant had an adverse influence on susceptibility and intention. Our results suggested the presence of a mediated-moderation effect, meaning that the health message type by awareness status interaction effect on perceived susceptibility was mediated by personal relevance. Our findings are largely consistent with the scarce previous research into the effects of genetic health messages, observing negative effects of genetic health messages on susceptibility and intention (Cappella et al., 2005; Smerecnik et al., in press). The present results suggest that these effects may be explained by differential perceived personal relevance between general and genetic health messages. Previous research examining the relationship between personal relevance and perceived susceptibility suggests that individuals who do not perceive a health problem to be personally relevant are more likely to use heuristic strategies to determine susceptibility (Rothman \& Schwarz, 1998). As such, they are more likely to perceive lower personal susceptibility than those who do perceive a health problem to be personally relevant and as such use systematic strategies to arrive at a judgement.

Several implications for future research and practice can be deduced from our results. The present findings confirm the concerns that media coverage of genetics may not be effective to promote precautionary action. However, as stated, public education may benefit the technological applications of genomics (e.g., genetic testing) and should not be underestimated. Our findings suggest that the 'adverse' effects of genetic health messages may be due to low perceived personal relevance of such messages. We may thus benefit 
from psychological research which has identified strategies to improve perceived personal relevance. According to the Heuristic Systematic Model (Chaiken, Liberman, \& Eagly, 1989; Chen \& Chaiken, 1999), so-called heuristics (e.g., 'an expert is always right' or 'consensus implies correctness') can result in higher perceived personal relevance or susceptibility judgments regardless of its content. This seems especially relevant considering our discussion on the use of heuristic strategies to arrive at judgments of susceptibility. A promising factor influencing persuasion is source credibility. Recent research on the effects of source credibility on the persuasiveness of a message (Pornpitakpan, 2004) suggest that different sources are needed based on individuals' current beliefs about the role of genes in health and disease development. Message frequency may also play a role. As exposure increases, the uncertainty of a stimulus decreases and relevant characteristics of the message are more readily available for processing (Berlyne, 1970).

In addition to source credibility and message frequency, message framing has also been shown to affect perceived personal relevance. Message framing refers to the phenomenon that the same content can be 'framed' differently (Rothman \& Salovey, 1997). For instance, communicating that restricting salt intake influences hypertension can be framed as a gain (i.e. "consuming little salt will decrease the blood pressure") or as a loss (i.e. "consuming a lot of salt will increase the blood pressure"). Research into the effects of message framing on information acceptance and personal relevance has shown that gainframed messages are more likely to be accepted as personally relevant than loss-framed messages (e.g., van 't Riet, Ruiter, Werrij, \& de Vries, 2008). If genetic health messages stress the gain of preventive behaviour in the face of genetic predispositions rather than (imply) the loss of personal control due to genetic predispositions (cf. Ugalde, Martin, \& Rees, 2008), such messages may prevent derogation of the personal relevance of the message. Although this suggestion does not exactly parallel the definition of message framing, future research is suggested to assess the value of message framing for genetic health messages.

Our conclusions and implications for future research and practice need to be interpreted with some caution. Firstly, we assessed awareness of genetic risk factors for salt sensitivity in the sociodemographics questionnaire. Consequently, participants may have already formed expectations about the goal of the study prior to the experimental manipulation which could have biased the effects. However, the socio-demographics questionnaire was presented one month before the experimental manipulation which probably decreased any potential bias. Moreover, the results are consistent 
with previous research which assessed awareness status after the experimental manipulation at the end of the experiment (Smerecnik et al., in press). Secondly, perceived susceptibility was assessed using absolute and relative measures. However, recent research has shown that conditional measures are better suited to predict risk-behaviour change (Brewer, Chapman, Gibbons, Gerrard, \& McCaul, 2007). Since we were primarily interested in differences in perceived susceptibility between the genetic and the general health message rather than predicting health behaviour, our measures may have sufficed for this goal.

In conclusion, participants who were aware of the genetic risk factors of salt sensitivity reported lower perceived personal relevance of salt sensitivity compared to unaware participants. Consequently, genetic health messages are likely to have adverse effects on susceptibility and intention. Communication strategies that increase the perceived personal relevance of the message may be able to effectively reduce these adverse effects. Future research may try to identify and develop strategies to enhance perceived personal relevance and thereby overooming these adverse effects. The potential of technological applications of genomics has long been recognized and with careful research into best practices of communicating such information this potential may be more fully utilised. 


\section{Chapter 6}

An empirical test of the materialist framework for understanding the general population's reaction to genetic health messages

Manuscript submitted as: Smerecnik, C. M. R., Mesters, I., De Vries, H., \& De Vries, N. K. (2009). An empirical test of the materialist framework for understanding the general population's reaction to genetic health messages 


\begin{abstract}
Purpose. Genetic health messages are increasingly prevalent in our society. The materialist framework of laypeople's genetic knowledge may provide a good basis for understanding the effects of such messages on preventive behaviour and related health cognitions. This study aimed to test the predictions of this framework using genetic versus general health messages about salt sensitivity.

Method. We presented 929 participants who were aware or unaware of the existence of genetic risk factors for salt sensitivity with either a genetic health message or a general health message about salt sensitivity. Baseline, immediate follow-up, 1 month follow-up and 6 month follow-up questionnaires assessed risk perception, intention and salt consumption.

Results. Compared to the general health message, previously unaware participants reported lower susceptibility to salt sensitivity, lower severity of salt sensitivity and lower intentions to restrict salt intake immediately after reading the genetic health message, but not at the 1 month and 6 months follow-ups. No such effects were observed for previously aware participants. Additionally, we observed no effect of health message type on self-reported salt consumption.

Conclusions. Our findings support the predictions of the materialist framework for understanding laypeople's knowledge of genetics. Based on the results several implications are discussed for public education of genetics.
\end{abstract}




\section{Introduction}

'Gene defect explains high blood pressure' (BBC News, 2003), Blood pressure gene affects 20\%' (BBC News, 2008) and 'Single gene link to heart health' (BBC News, 2004). Health messages linking the role of genes to health and disease development are increasingly prevalent in our society. Media coverage about genetics has substantially increased since the announcement of the Human Genome Project (cf. Bubela \& Caulfield, 2004; Tambor et al., 2002), which aimed at the complete mapping and understanding of all the genes of the human genome. Since its completion in 2003, the Human Genome Project has fuelled the discovery of nearly 2000 disease genes (National Institutes for Health, 2009). The mass media has eagerly reported such discoveries (Bubela \& Caulfield, 2004; Cappella et al., 2005).

The effect of such media coverage has been heavily debated with opponents arguing that it may lead to beliefs of genetic determinism (e.g., Katz Rothman, 1998) while proponents argue that beliefs about genetic causation have remained rather consistent despite massive media attention (e.g., Condit et al., 2009). In general, however, empirical research into the impact of mass media genetic health messages is scarce and a closer examination of how these messages affect health cognitions and behaviour change is warranted (Saab et al., 2004).

A recently proposed materialist framework of laypeople's knowledge of genetics (Condit et al., 2009) seems particularly important for this pursuit. According to this framework, the general public has constructed two main mental models of disease causation: a 'genetic causation' model which is highly deterministic and a behavioural causation' model which is primarily characterized by uncertainty. Links between these two models are rare and an accurate model of the gene-environment interaction seems to be lacking. Most people seem to have a bias toward the behaviour causation model but in response to contextual cues, personal motivations and understandings of a specific disease, they may switch to the genetic causation model.

Thus, when primed with a genetic health message in the mass media, people may use the genetic causation model to determine their reaction to the message. The scarce research into the effects of genetic health messages suggests that such messages may have adverse effects on the intention to get a genetic test (Cappella et al., 2005) or to engage in preventive behaviour (Smerecnik et al., in press) which seemed to be mediated by perceived susceptibility (Cappella et al., 2005; Smerecnik et al., in press). Interpreted in light of the materialist framework, these findings suggest that participants who 
received the genetic health message were primed to employ the genetic causation model. To guard against its deterministic implications, they may have felt the need to defend against this threat to health by underestimating personal susceptibility (see Ruiter et al., 2001). In addition, the materialist framework predicts that when people are not primed with the genetic causes of a disease, they are likely to employ the behavioral causation model although they may still be aware of the existence of genetic causes (Condit et al., 2009).

To test the predictions of the materialist framework, we presented participants with either a general health messages about salt sensitivity or with a genetic health message that presented the same information as the general health message but additionally communicated the existence of genetic risk factors for salt sensitivity. The term salt sensitivity refers to the fact that some individuals show a greater increase in blood pressure following similar amounts of salt intake compared to others (Weinberger, 1991). Recently, a number of different polymorphisms (i.e. genetic variants) have been discovered that seem to be causally involved in this phenomenon (Beeks et al., 2004; Sanada et al., 2006). Of these, the alpha-adducin polymorphism Gly 460 Trp has been suggested to be the most important (Beeks et al., 2004; Cusi et al., 1997). Prior to the message and immediately, 1 month, and 6 months after the message, we asked participants to report their risk perception toward salt sensitivity, their intention to restrict salt intake, and their salt consumption.

Following the materialist framework, we expected that the genetic health message would result in lower risk perception and intention compared to the general health message immediately after message exposure (i.e. when participants were cued with the genetic causation model), but not at the 1 month and 6 months follow-ups (i.e. when not cued with 'genetics'). We expected no effects of the genetic health message on salt consumption since most people tend to switch back to the behavioural causation model after a certain amount of time (Condit et al., 2009). No effects were expected at the immediate follow-up measurement since participants will have had no chance to change their salt consumption as a result of the message. In addition, they are expected to switch to the behavioural causation model prior to the 1 month follow-up and, as such, no difference between the general and genetic health messages will be expected at the 1 month and the 6 months follow-ups. 
Chapter 6 | Testing the materialist framework

\section{Methods}

\section{Overview and design}

The current study presents the long-term effects of genetic health messages (see Figure 6.1 for a flowchart of the study) testing the predictions of the materialist framework of laypeople's knowledge of genetics. We presented participants with either a general health message about salt sensitivity or with a genetic health message that presented the same information as the general health message but additionally communicated the existence of genetic risk factors for salt sensitivity (Smerecnik et al., in press). Note that the genetic health message does not provide personalized DNA risk information, but rather involves simply communicating the fact that salt sensitivity is partly caused by genetic factors.

\section{Participants}

We recruited 2500 individuals for the present study through an Internet consumer panel. After completing each of the five questionnaires of this study, participants were rewarded conform the norms of the research company. They could obtain an additional bonus by completing all questionnaires.

\section{Procedure}

The Internet research company sent e-mails to the 2500 panel members selected for the study. These individuals were selected to form a sample representative of the Dutch general population. The email message contained an Internet link to a login page, which expired after one week. After logging into their account, participants could fill out the socio-demographics questionnaire, containing measures of several socio-demographic characteristics and awareness status of the genetic risk factors for salt sensitivity. Two weeks later participants that filled out the socio-demographics questionnaire were sent a second e-mail inviting them for the baseline questionnaire. The baseline questionnaire contained (pre-test) measures of risk perception, intention to restrict salt intake, and salt consumption. An additional two weeks later participants that filled out the baseline questionnaire were sent a third e-mail. This questionnaire started with either one of two health messages (genetic versus general) followed by (post test) measures of risk perception, intention, and behaviour. A fourth and fifth questionnaire containing the same questions as the third questionnaire were sent to participants one month and six months after the immediate post-test questionnaire, respectively (see Figure 6.1). 
Chapter 6 | Testing the materialist framework

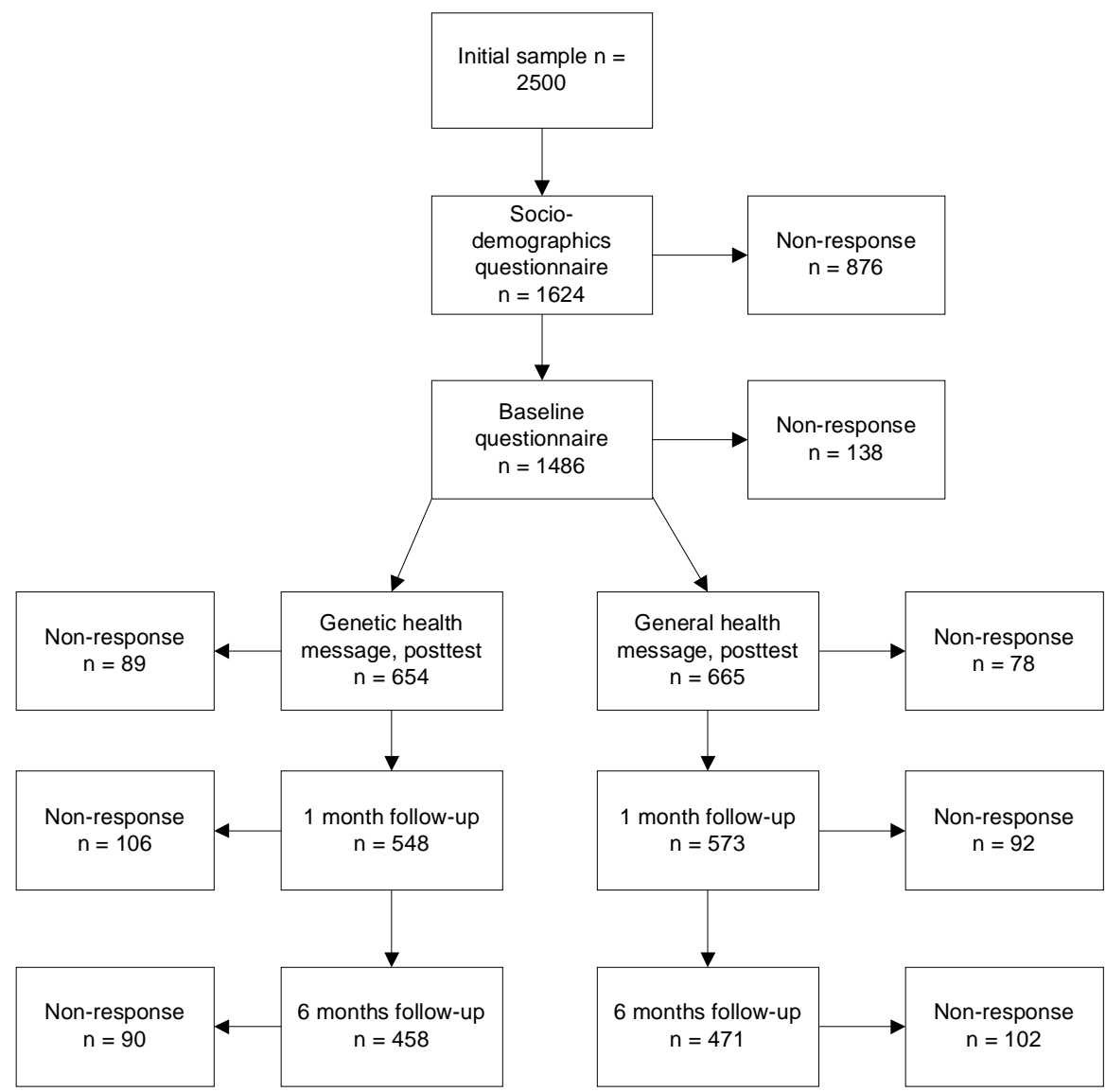

Figure 6.1. Flowchart of the study.

\section{Measures}

Socio-demographics questionnaire

Participants' age (in years), gender, and level of education (categorised in low, medium, and high level of education) were available through the Internet consumer panel. In the sociodemographics questionnaire, participants were asked to report their hypertension status ("Are you currently diagnosed with hypertension?" 1 = no, 2 =yes), whether they had a family history of cardiovascular disease (CVD) and family history of hypertension ("Are one or more members of your family diagnosed with 
cardiovascular disease $/$ hypertension?" $1=$ no, $2=$ don't know, $3=$ yes), and whether they were on a salt-restricted diet ( $1=$ no, $2=y e s)$.

We assessed participants' awareness status by using one forcedchoice item (Had you ever heard of genetic risk factors for a saltsensitive blood pressure prior to this study? $1=$ yes, $0=$ no).

Baseline questionnaire

Risk perception was assessed by measuring perceived susceptibility to, and perceived severity of salt sensitivity. Perceived susceptibility of having a salt-sensitive blood pressure was measured using three items assessing absolute perceptions of susceptibility (e.g., "I am vulnerable to a salt-sensitive blood pressure", 1 = totally disagree to 7 $=$ totally agree) and three items assessing perceptions of risk relative to others (e.g., "Relative to your peer group, how large is your chance of having a salt sensitive blood pressure", $1=$ much smaller to $7=$ much larger). Exploratory factor analysis revealed one single underlying factor (Eigenvalue $=3.80 ; \mathrm{R}^{2}=0.76$ ). These six items were therefore combined into the susceptibility factor (Cronbach's a $=.91, \mathrm{M}=4.63, \mathrm{SD}=1.24$ ). Severity was assessed by three items (e.g., "Salt sensitivity is a serious medical condition", $1=$ totally disagree $-7=$ totally agree; Cronbach's $\alpha=.87, \mathrm{M}=2.67, \mathrm{SD}=1.22$ ). The intention to restrict salt intake was assessed using three items (e.g., "I intend to restrict my salt intake", $1=$ totally disagree to $7=$ totally agree; Cronbach's $\alpha=.93, \mathrm{M}=3.17, \mathrm{SD}=1.52$ ). Additionally, they were asked to report their salt consumption using 3 items (e.g., 'On how many days in the week do you generally add (kitchen) salt to your meal?'; cf. Salonen, Tuomilehto, \& Tanskanen, 1983). These items were summed to form the behaviour index $(\mathrm{M}=11.97, \mathrm{SD}=$ 4.56). Higher scores on the behaviour index represent more salt consumption.

Follow-up questionnaires

In the immediate, 1 month and 6 months follow-ups, participants answered the same questions on perceived susceptibility (immediate: Cronbach's $\alpha=.93, \mathrm{M}=4.62, \mathrm{SD}=1.24 ; 1$ month: Cronbach's $\alpha=$ $.93, \mathrm{M}=4.65, \mathrm{SD}=1.24 ; 6$ months: Cronbach's $\alpha=.92, \mathrm{M}=4.73$, SD $=1.21$ ), perceived severity (immediate: Cronbach's $\alpha=.93, \mathrm{M}=2.75$, $\mathrm{SD}=1.31 ; 1$ month: Cronbach's $\alpha=.92, \mathrm{M}=2.74, \mathrm{SD}=1.25 ; 6$ months: Cronbach's $\alpha=.92, \mathrm{M}=2.83, \mathrm{SD}=1.31$ ), intention (immediate: Cronbach's $\alpha=.94, \mathrm{M}=3.53, \mathrm{SD}=1.67 ; 1$ month: Cronbach's $\alpha=.94, \mathrm{M}=3.37, \mathrm{SD}=1.57 ; 6$ months: Cronbach's $\alpha=$ $.93, \mathrm{M}=3.54, \mathrm{SD}=1.68$ ) and salt consumption (immediate: $\mathrm{M}=$ 11.98, $\mathrm{SD}=4.79 ; 1$ month: $\mathrm{M}=12.36$, $\mathrm{SD}=4.73$; 6 months: $\mathrm{M}=$ $12.19, \mathrm{SD}=4.51$ ) as in the pre-test questionnaire. 


\section{Statistical analyses}

Initial analyses were conducted to check whether randomization was successful. To this end, we performed a logistic regression with health message type and awareness status as the dependent variables and age, gender, level of education, family history of CVD, family history of hypertension, and salt-restricted diet as independent variables. Possible confounding variables were included in all subsequent analyses. A linear mixed model regression analyses was conducted to examine the long-term effects of genetic health messages on perceived susceptibility, attitude, intention, and salt consumption. After identifying the best fitting covariance structure, we performed the linear mixed model regression to examine the fixed effects.

\section{Results}

\section{Sample characteristics}

In total, 929 participants filled out all five questionnaires. Table 6.1 presents the demographic characteristics of the initial $(n=2500)$ and the final sample $(n=929)$. The final sample seemed to be somewhat higher-educated than the general population but accurately reflects the general population in terms of gender and age.

We observed no differences between the genetic health message ( $\mathrm{n}=458)$ and general health message groups $(\mathrm{n}=471)$ in terms of age, gender, level of education, hypertension status, family history of CVD, family history of hypertension, whether they were on a saltrestricted diet or not, and awareness status (ps >.22). The aware ( $\mathrm{n}=$ 154) versus the unaware group $(n=775)$ did not differ in terms of age, gender, hypertension status, family history of CVD, and whether they were on a salt-restricted diet (ps > .35). Aware participants were more likely to be higher educated ( $\mathrm{OR}=1.35, \mathrm{p}=.01$ ) and more likely to be unaware of their family history of hypertension (OR $=1.45, \mathrm{p}<.01)$. Consequently, all subsequent analyses were controlled for level of education and family history of hypertension.

\section{Attrition analysis}

Attrition analyses showed that dropout was not related to health message type, awareness status, gender, level of education, hypertension status, family history of hypertension, family history of CVD, or whether they were on a salt-restricted diet (ps > .13). However, participants that completed all five questionnaires were older $(\mathrm{M}=49.46, \mathrm{SD}=15.10)$ than those that dropped out $(\mathrm{M}=$ 45.96, $\mathrm{SD}=15.43), \mathrm{t}(927)=-4.59, \mathrm{p}<.001$. 
Table 6.1. Demographic characteristics of the initial and final research sample contrasted with the data from the entire Dutch population.

\begin{tabular}{|c|c|c|c|c|c|}
\hline \multirow{2}{*}{$\begin{array}{l}\text { Demographic } \\
\text { characteristics }\end{array}$} & \multicolumn{2}{|c|}{ Initial sample $(\mathrm{n}=2500)$} & \multicolumn{2}{|c|}{ Final sample $(\mathbf{n}=929)$} & \multirow{2}{*}{$\begin{array}{l}\text { Dutch } \\
\text { population } \\
\text { data, } \% \text { a }\end{array}$} \\
\hline & $\%$ & n & $\%$ & $\mathbf{n}$ & \\
\hline \multicolumn{6}{|l|}{ Gender } \\
\hline Male & 48 & 1200 & 52 & 483 & 49.4 \\
\hline Female & 52 & 1300 & 48 & 446 & 50.6 \\
\hline \multicolumn{6}{|l|}{ Age } \\
\hline $20-39$ years & 35 & 875 & 32 & 297 & 34.8 \\
\hline 40-64 years & 45 & 1125 & 54 & 502 & 46.2 \\
\hline$\geq 65$ years & 20 & 500 & 14 & 130 & 19.1 \\
\hline \multicolumn{6}{|l|}{ Level of education } \\
\hline Low & 30 & 750 & 32 & 298 & 33.4 \\
\hline Medium & 42 & 1050 & 38 & 357 & 41.0 \\
\hline High & 28 & 700 & 29 & 274 & 25.6 \\
\hline
\end{tabular}

\section{Risk perception}

Susceptibility. Mixed model linear regression analysis revealed a significant time by health message type by awareness status threeway interaction effect on susceptibility, $F(3,921)=2.65, p=.06$. In comparison with baseline, we observed a significant health message type by awareness effect on the immediate follow-up measurement, $\beta$ $=-.34, \mathrm{p}=.04$, but not for the 1 month or the 6 months follow-ups (ps $>$.10). In depth analyses revealed a significant time by health message type interaction effect for previously unaware participants ( $F$ $(3,824)=2.57, \mathrm{p}=.05)$ : in reference to baseline, previously unaware participants reported lower perceived susceptibility immediately after reading the genetic health message $(\mathrm{M}=4.58, \mathrm{SD}=1.21$ versus $\mathrm{M}=$ $4.72, \mathrm{SD}=1.22$ at baseline) compared to reading the general health message $(\mathrm{M}=4.72, \mathrm{SD}=1.21$ versus $\mathrm{M}=4.74, \mathrm{SD}=1.16$ at baseline), $\beta=-.12, \mathrm{p}=.05$, but not at the 1 month follow-up $(\mathrm{p}=.43)$ or the 6 month follow-up $(p=.58)$. Figure 6.2 presents an overview of the susceptibility scores among previously unaware participants on the four measurement moments categorised by health message type. No effects were observed for previously aware participants (ps >.23).

Severity. We observed a significant time by health message type by awareness status three-way interaction effect on severity, F (3, $926)=3.10, p=.03$. In comparison with baseline, we observed a signifcant health message type by awareness interaction effect at the immediate follow-up, $\beta=-.67, \mathrm{p}<.01$, but not for the 1 month and 6 months follow-ups (ps > .18). Analyses stratisfied for awareness 
status revealed a marginally significant time by health message type interaction effect, $\mathrm{F}(3,174)=2.30, \mathrm{p}=.07$ : in reference to baseline, previously unaware participants reported lower severity when reading the genetic health message $(\mathrm{M}=2.47, \mathrm{SD}=1.19$ versus $\mathrm{M}=2.87$, SD $=1.24$ at baseline) compared with the general health message $(\mathrm{M}$ $=2.55, \mathrm{SD}=1.13$ versus $\mathrm{M}=2.72, \mathrm{SD}=1.48$ at baseline), $\beta=-.59, \mathrm{p}=$ .02. No such effects were observed for previously aware participants (ps >.41).

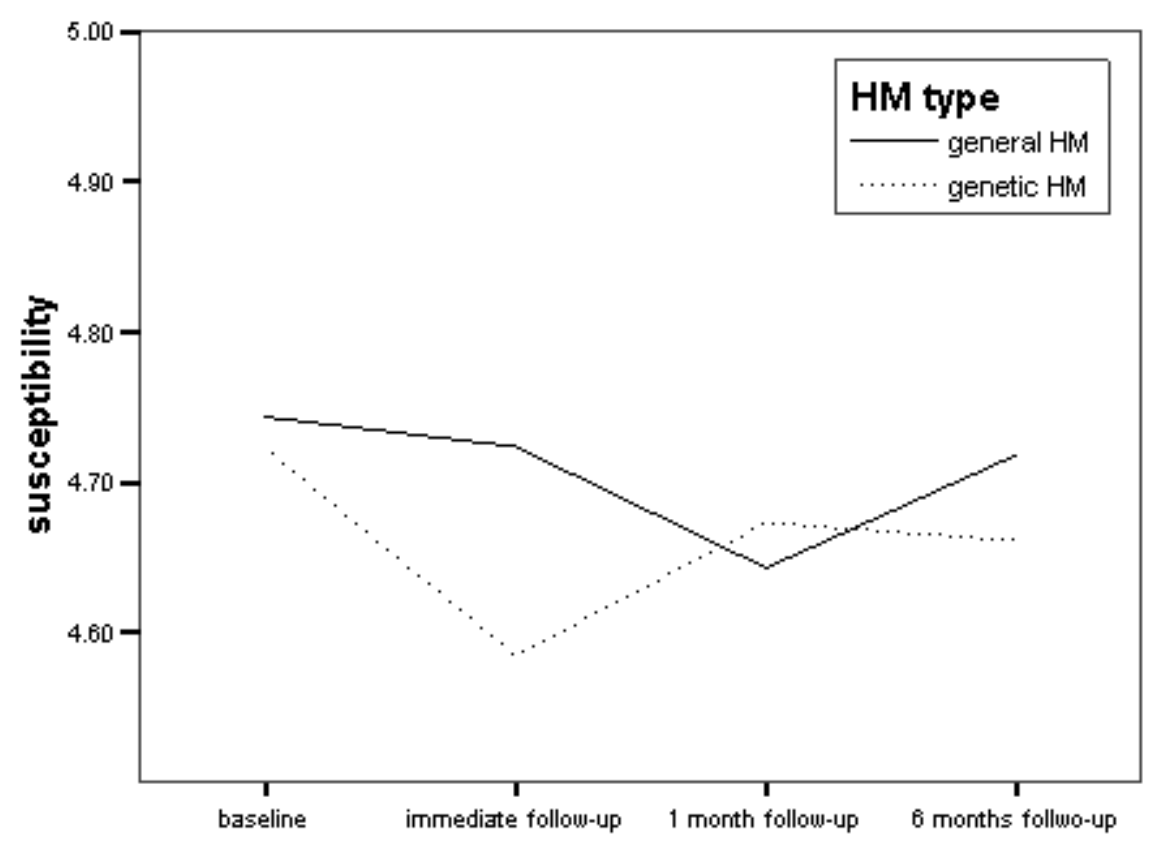

Figure 6.2. Perceived susceptibility scores for previously unaware participants on the four measurement moments categorised by health message (HM) type.

Intention

Although the analyses did not reveal an overall time by health message type by awareness status interaction effect on intention, $\mathrm{F}$ (3, $980)=1.09, p=.35$, in depth analyses did reveal a significant health message type by awareness status interaction effect at the immediate follow-up, $\beta=.42, \mathrm{p}=.05$. After stratifying on awareness status, we observed a significant time by health message type interaction effect, $\beta=.39, \mathrm{p}=.05$, among previously unaware participants. In reference 
to baseline, previously unaware participants reported lower intention to restrict salt intake after reading the genetic health message $(\mathrm{M}=$ 3.12 , $\mathrm{SD}=1.66$ versus $\mathrm{M}=3.63, \mathrm{SD}=1.52$ at baseline) than after reading the general health message $(\mathrm{M}=3.28, \mathrm{SD}=1.52$ versus $\mathrm{M}=$ $3.48, \mathrm{SD}=1.66$ at baseline). No such effect was observed for previously aware participants (ps $>.59$ ).

\section{Behaviour}

Mixed model linear regression revealed a significant main effect of awareness on salt consumption, $F(1,920)=3.87$, $p=.05$. Overall, previously unaware participants reported lower salt consumption (M $=12.02$, $\mathrm{SD}=4.59)$ than previously aware participants $(\mathrm{M}=12.69$, $\mathrm{SD}=4.90$ ). No other effects were found on this measure (ps $>.21$ ). Thus, although we observed no effect of the health messages on salt consumption, at all measurement moments previously unaware participants reported lower salt consumption than previously aware participants.

\section{Discussion}

In the present study, we used the materialist framework of laypeople's knowledge of genetics to predict the effects of genetic health messages. Our findings largely confirm our expectations. As predicted, we observed adverse immediate, but no longitudinal, effects of genetic health messages on perceived susceptibility and intention among previously unaware participants. Unexpectedly, these effects were not observed among previously aware participants. According to the materialist framework, people may switch between the mental models based on prior understanding of a given disease. Since previously aware participants had some prior understanding of salt sensitivity they may have switched back to the behavioural model relatively quickly after having read the genetic health messages. Concerning our hypothesis that the genetic health message would not affect salt consumption, the results seem to oonfirm this hypothesis: we did not observe any effects of health message type on salt consumption. We did however observe a main effect of awareness status on salt consumption. At all measurement moments, previously unaware participants had lower self-reported salt consumption than previously aware participants.

In general our findings are consistent with the little research that is available. Capella et al (2005) focused on the intention to obtain a genetic test for susceptibility genes for smoking addiction among smokers rather than preventive behaviour. They observed that a health message communicating the existence of smoking susceptibility genes resulted in lower intentions to get genetically 
tested. This effect seemed to be mediated by perceived susceptibility. Similarly, Smerecnik et al. (in press) observed that a genetic health message about salt sensitivity resulted in lower intentions to restrict salt intake, but only among participants who were unaware of the existence of genetic risk factors for salt sensitivity. Again, this adverse effect on intention seemed to be mediated by susceptibility. The present findings add to this literature by suggesting why people after being confronted by a genetic health message reported lower susceptibility and intention.

Indeed, our findings suggest that the materialist framework is a valuable tool for examining the effect of genetic health messages on preventive behaviour. In particular it suggests that genetic health messages elicit the genetic causation model which is highly deterministic. People may thus feel a need to protect themselves against such a health threat (Ruiter et al., 2001). Condit et al. (2009) have suggested that laypeople's usage of the two mental models may facilitate unrealistic optimism. According to Breznitz (1983), people defend themselves against recognition of threatening information by engaging in the least degree of denial necessary to adequately protect oneself from the (fear of the) threat. Low levels of denial (e.g., denial of vulnerability) are more likely to occur after ambiguous messages (e.g., mass media genetic health messages) than after unambiguous messages (e.g., genetic consultation after genetic testing). Note that participants did not read the health messages prior to filling out the 1 month and 6 months follow-ups. Thus, previously unaware participants in the genetic health message condition may not have felt the need to react defensively at the 1 month and 6 months follow-up as the genetic risk factors were not salient at that moment (i.e. the genetic causation model is not activated). Alternatively, the defensive reaction at the immediate follow-up may have served the purpose of bolstering previously unaware participants' initial beliefs about salt sensitivity (Blumberg, 2000).

Our findings have several important implications for practice and future research. First, if, as suggested by the materialist framework, our and previous findings may be explained by the priming of the genetic causation model after reading the genetic health message, then genetic health messages may elicit beliefs of genetic determinism and the need to defend against its implications. As such, genetic health messages may not be effective at all in motivating the general public to engage in preventive behaviour. As argued by Condit et al. (2009) this may imply that we need to instigate a 'gene-environment interaction' model rather than trying to strengthen one model or the other. However, such new models may not be easily accepted or assimilated into laypeople's mental models. Fortunately, several 
strategies are available to enhance assimilation of new information into existing mental models. For instance, multiple exposure to the same message has been shown to decrease its perceived complexity (Berlyne, 1970). Repeated exposure to the same gene-environment interaction message may therefore make more readily available for processing the relevant characteristics of the message (Berlyne, 1970), which may ultimately facilitate integration of the new genetic information into existing mental frameworks.

A second implication concerns possible defensive responses to the genetic health message. Several strategies that are available from social psychological research may prove useful for this end. According to the Self-Affirmation Theory (Steele, 1988), people are primarily motivated to defend their belief that they are adaptively and morally adequate (or their sense of self-integrity). Threatening health messages are assumed to compromise people's self-integrity resulting in the need to defend against information. The Self-Affirmation Theory has fuelled research into the use of self affirmation as a strategy to reduce defensiveness (e.g., Correll, Spencer, \& Zanna, 2004; Harris \& Napper, 2005; Reed \& Aspinwall, 1998; Sherman, Nelson, \& Steele, 2000). These and other strategies, such as elaboration (Block \& Williams, 2002) or message framing (Schneider, 2006), may be examined to reduce the defensive response to genetic health messages.

Our conclusions and implications for future research need to be interpreted with some caution. We assessed awareness of genetic risk factors of salt sensitivity in the socio-demographics questionnaire. Consequently, participants may have already formed expectations about the goal of the study prior to the experimental manipulation which could have biased the effects. However, the sociodemographics questionnaire was presented one month before the experimental manipulation which probably decreased any potential bias. Moreover, the results are consistent with previous research which assessed awareness status after the experimental manipulation at the end of the experiment (Smerecnik et al., in press).

In general, we may conclude that the adverse effects of genetic health messages may be due to the priming of the genetic causation model. Further research is warranted to examine the effects of genetic health messages more closely and to identify the cognitive processes responsible for these effects. By gaining more insight into these effects, future health messages about the role of genes in health and disease may be more effective in accomplishing desired changes in health cognitions and behaviour. 
114 


\section{Chapter 7}

General discussion 


\section{Introduction}

The aim of the present dissertation was to examine the effects of genetic health messages on preventive behaviour in the general population. In Chapters 2 and 3, a knowledge framework was presented to understand the general population's knowledge of the role of genetics in a vide variety of multifactorial diseases. Following this framework, creating public awareness of genetic risk factors of a given disease is the first step in educating the general population about multifactorial disease. As such, in the following chapters, the effect of genetic health messages alerting the general population to the genetic risk factors for a given medical condition (i.e. salt sensitivity) was examined in the remainder of the dissertation (Chapters 4, 5, and 6).

In this chapter, the results are discussed and integrated with existing literature. First, the results of all the studies presented in this dissertation are summarised and discussed in terms of this dissertation's aims. Subsequently, the role of awareness in the effects of genetic health messages will be discussed. Third, a theoretical framework is presented to explain the results and integrate them with existing literature. And finally, several conclusions will be presented.

\section{Aims revisited}

\section{Examining genetic knowledge}

Concerning our first aim, examining the current level of genetic knowledge among the general population, Chapters 2 and 3 show that genetic knowledge is still limited despite growing media attention. In these chapters, E. M. Rogers' knowledge framework was presented as a sophisticated tool for understanding genetic knowledge among the general population. This framework distinguishes three increasingly complex types of knowledge: awareness knowledge, how-to knowledge and principles knowledge. By applying Rogers' knowledge framework, Chapters 2 shows that the public's awareness knowledge of genetic risk factors for a variety of diseases (from hypercholesterolemia to breast cancer) is reasonable but nevertheless in need of improvement; approximately $59 \%$ is aware of genetic risk factors. How-to knowledge of genetic risk factors was limited, especially when compared to knowledge of other risk factors. Finally, principles knowledge was observed to be largely insufficient and superficial. The results from the systematic review seem to extend to the Dutch general population as well (see Chapter 3). These two chapters highlight the value of Rogers' framework for cataloguing and investigating public understanding of genetics. More importantly, the 
results showed that the general public's knowledge of genetics is poor. According to the Hierarchy of Effects (McGuire, 1985; 1999), if the first step in behaviour change (i.e. knowledge, or more specifically, awareness knowledge) is not adequately accomplished, the likelihood of behaviour change is dramatically reduced. Indeed, several authors have suggested that the general population's knowledge of genetics needs to be improved if future genetics-based public health campaigns are to succeed (e.g., Khoury et al., 2000).

One important assumption inherent in the knowledge framework is that awareness knowledge alone is not sufficient for relevant changes in health cognitions and behaviours. Rather, awareness knowledge should be accompanied by adequate how-to knowledge and preferably with principles knowledge. Unfortunately, current attention to genetics and its role in health and disease seems to focus on communicating the existence of genetic risk factors and, as such, attempts to impart awareness knowledge in its recipients. Considering that approximately $75 \%$ of the Dutch population was unaware of the existence of genetic risk factors for multifactorial diseases, this is an important and necessary step in educating the general population. However, following the predictions of Rogers' knowledge framework, health messages that only alert the general population to the existence of genetic risk factors without communicating how-to (and preferably principles) knowledge are not likely to successfully change relevant health cognitions and subsequent behaviours. Considering the avalanche of health messages communicating the existence of genetic risk factors in the mass media (Bubela \& Caulfield, 2004), the effects of health messages aiming to diffuse awareness knowledge by alerting the general population to genetic risks were central to our second and third aim. Although the importance of how-to and principles knowledge is recognized, the remaining chapters of the dissertation focused on the reality that the mass media is primarily concerned with diffusing awareness knowledge. As empirical research into the effects of such communication is scarce (Saab et al., 2004), this research is considered the first, and important, step in examining the effects of educating the general population about multifactorial diseases and developing effective strategies to do so.

\section{Assessing the effectiveness of genetic health messages}

The second aim was to examine the ability of genetic health messages to motivate the general public to engage in preventive behaviour, while the third aim investigated whether this ability was moderated by awareness knowledge of the genetic risk factors at the moment of information exposure. In line with expectations, the results from 
Chapters 4, 5 and 6, seem to suggest that for previously unaware participants, genetic health messages resulted in lower perceived susceptibility to salt sensitivity. These effects were not observed for previously aware participants. In studies $4.1 \mathrm{~A}, 4.1 \mathrm{~B}$, and 4.2 genetic health messages were also observed to result in lower intention to engage in preventive behaviour among previously unaware participants but not among previously aware participants. The negative effects on intention, however, were mediated by perceived susceptibility. These adverse results on susceptibility and intention among previously unaware participants were replicated in studies 5 and 6, suggesting that genetic health messages do not necessarily motivate the general population to engage in preventive behaviour. Instead, they may result in decreased perceived susceptibility, intention and eventually preventive behaviour depending on whether message recipients are aware or unaware of the existence of genetic risk factors at the moment of information exposure.

Several possible cognitive mechanisms may be responsible for these effects. These possibilities will be integrated in a comprehensive theoretical framework later in this chapter. For now, the genetic mass media health message's lack of ability to individualize genetic risks by referring to DNA-based risk information (i.e. definitively argue whether or not the recipient possesses the predisposing gene) may be the primary cause for the observed results. As a result of this inability, individuals will have no decisive answer concerning their personal predisposition. This uncertainty may cause anxiety instigating defensive coping strategies, such as underestimating personal susceptibility. Later in this chapter, the role of defensive coping and strategies to reduce defensiveness are discussed in more detail. Alternatively, the genetic health message's inability to individualise risks (i.e., to definitively show whether or not the predisposing genetic variant is present) may have caused participants to not perceive the genetic health message as personally relevant which could also explain the effects on perceived susceptibility.

\section{The role of personal relevance}

Personal relevance is an important factor in persuasion as it determines how people process a health message. Personal relevance has been heavily used to promote careful and detailed examination of a target message. Rothman and Schwarz (1998) showed that individuals who do not perceive the topic under consideration as personally relevant make use of simple inferential rules to arrive a judgment of susceptibility rather than more elaborate scrutiny of available information. Therefore, the role of perceived personal relevance of genetic health messages in explaining the messages' 
effects on perceived susceptibility and intention was examined in Study 5. Participants who were aware of the genetic risk factors for salt sensitivity (either prior to the experiment or as a result of reading the genetic health message presented to them) perceived the genetic health message as less personally relevant than unaware participants. These differences in perceived personal relevance was observed to mediate the health message by awareness interaction effect on perceived susceptibility as observed in Chapter 4 . Previously unaware participants thus reported lower levels of personal relevance after reading the genetic versus the general health message and, consequently, lower perceived susceptibility. This is to be expected since the genetic health message did not (indeed could not) give decisive personal evidence of susceptibility in the way that a genetic test would. As such, participants may have found it easy to refute the personal relevance of the genetic health message.

These results cannot be attributed to differences in acceptance of the genetic risk factors of salt sensitivity. That is, health message type and awareness status were not observed to affect information acceptance. Thus, the genetic health message and the general health message were equally accepted by previously aware and previously unaware participants. These findings suggest that while genetic health messages may increase awareness of genetic risk factors as such, they were observed to be less effective in motivating the general public to engage in preventive behaviour than general health messages. Moreover, the low perceived personal relevance among aware participants (either prior to the experiment or as a result of reading the genetic health message) may result in less attention to and low motivation to process future health messages about salt sensitivity (Bernhardt et al., 2004; Wiebe \& Black, 1997). This may prove a serious barrier to future attempts to persuade (individual members of) the general population to engage in preventive behaviour in order to prevent hypertension as a result of salt sensitivity.

Personal relevance is an important factor in persuasion as it determines how people process a health message. Personal relevance has been heavily used to promote careful and detailed examination of a target message. Rothman and Schwarz (1998) showed that individuals who do not perceive the topic under consideration as personally relevant make use of simple inferential rules rather than more elaborate scrutiny of available information to arrive at a judgment of susceptibility. The role of information processing will be further discussed in the Theoretical framework' section. A second consequence of the results of Chapter 5 concerns practical issues concerning the communication regarding genetic risk factors. Since 
such communications are accepted but not perceived as personally relevant by the general population, several strategies (such as source characteristics and framing) may be applied to counteract these negative effects (see Chapter 5).

\section{The materialist framework and genetic health messages}

The results observed in Chapters 4 and 5 seem to be short-lived. When examining the longitudinal effects of genetic health messages (see Chapter 6), the immediate post-test effects seemed to disappear at the 1 month and 6 months follow-up. This suggests that although a genetic health message has adverse effects on perceived susceptibility, these effects are temporary. These findings are consistent with the predictions of the materialist framework for understanding laypeople's knowledge of genetics (Condit et al., 2009). This framework proposes that laypeople possess two models of disease causation: the 'genetic causation' model and the 'behavioural causation model'. People generally bias towards the behavioural causation model, but, when primed, may employ the genetic causation model. In light of this framework, when participants were primed by reading the genetic health message, they may have employed the genetic causation model to determine their reaction to the message. Since the genetic causation model is highly deterministic, participants may have felt the need to defend against this threat by perceived low personal susceptibility (Ruiter et al., 2001). However, at the 1 and 6 months follow-up participants were no longer primed by reading the health messages and they habitually employed the behavioural causation model to estimate their personal relevance. As such, no effect of health message type was observed. The fact that previously unaware participants who read the genetic health message had similar susceptibility scores as previously unaware participants reading the general health message at the 1 month and 6 months follow-ups should not be interpreted as evidence for the fact that previously participants have not yet fully integrated the existence of genetic risk factors for salt sensitivity in their illness representation. Rather, it may reflect the laypeople's general bias towards the behavioural causation model in explaining disease occurrence.

\section{Awareness}

The observed differences between aware and unaware participants warrant attention. The differential effects of previously aware and previously unaware participants in the studies presented in Chapters 4, 5 and 6 highlight the importance of awareness knowledge and the lack of empirical insight into its role in explaining the effects of 
genetic health messages. That is, the results of the studies presented in these chapters consistently show interactive effects between health message type and awareness status on perceived susceptibility. Among previously aware participants, no differences were observed between the general and the genetic health message. However, among previously unaware participants reading the genetic health message resulted in lower perceptions of susceptibility compared to the general health message. Similarly, findings presented in Chapters 4, 5 and 6 suggest that health message type and awareness status interact to affect intention. Additionally, a main effect of awareness status on behaviour was observed in Study 6 with aware participants reporting more salt consumption than unaware participants.

In Chapter 4 it was argued that the genetic health message would only lead to persuasion if it is perceived to be correct, new, and relevant to the topic under consideration (Vinokur \& Burnstein, 1978). As such, the genetic health message was expected to only affect individuals who were unaware of their existence for salt sensitivity or heightened cholesterol levels at the moment of information exposure (i.e., for whom the information is new). Although it could be argued that information about the existence of genetic risk factors could also influence previously aware individuals by being newly considered (i.e., an aocessibility effect), the discrepancy between prior knowledge and information is likely to be larger among the previously unaware individuals. Moreover, a health message's impact on risk perception and intention is probably related to individuals' confidence in reaching a decision in accordance with their current motivational concerns (Eagly \& Chaiken, 1993). Upon learning about the existence of genetic risk factors, previously unaware individuals may perceive their existing knowledge as insufficient and are therefore probably more likely to be influenced by the health message.

Considering the differential results on aware and unaware participants, it is surprising how little attention awareness has received in the health psychology literature. Of course, awareness is not a sufficient prerequisite for behaviour change. It may nevertheless prove an important determinant of behaviour change or an important factor for target population segmentation. Although more models may have employed similar concepts, such as susceptibility (e.g., Rogers, 1975; 1983) and prior knowledge (e.g., J anz \& Becker, 1984), only a handful of health psychology models have paid attention to awareness as conceptualised by Rogers. These models include the Precaution Adoption Process Model (Weinstein, 1988) and the Integrated Change Model (De Vries et al., 2003). Unfortunately, these models lack a comprehensive description of the importance of awareness in behaviour change and how awareness relates to other 
cognitive determinants of health behaviour. Moreover, effective strategies to communicate the existence of health problems are lacking.

\section{Theoretical framework}

The fact that genetic health messages result in lower perceived susceptibility and intention to engage in preventive behaviour among previously unaware, but not among previously aware participants warrants further discussion. In this section, an attempt will be made to explain these results using a theoretical framework. First, this framework is presented. Subsequently, the results will be discussed in light of this framework. And finally, a tentative explanation of the observed results will be described and directions for future research will be provided.

According to an important school of thought in cognitive social psychology, persuasive message have their effect via two mediational paths: namely systematic processing and heuristic processing. In the Heuristic-Systematic Model (HSM), systematic processing is conceptualised as "a comprehensive, analytic orientation in which perceivers access and scrutinize all informational input for its relevance and importance to their judgment task, and integrate all useful information in forming their judgments" (Chaiken et al., 1989, p. 212). When processing information systematically, people thus make an effort to understand the information and how it relates to decision-making. As such, systematic processing requires cognitive ability and capacity on the side of the individual. In contrast, when processing information heuristically, people exert relatively little effort in processing the information. Instead, heuristic processing refers to focusing "on that subset of available information that enables them to use simple inferential rules, schemata, or cognitive heuristics to formulate their judgments or decisions" (Chaiken et al., 1989, p. 213). In general, persuasion and subsequent changes in health cognitions and behaviour based on systematic processing are assumed to be more resistant to change, more stable over time and more predictive of behaviour than changes based on heuristic processing (Chaiken et al., 1989).

The HSM is based on the principles of least effort and of information sufficiency: that is, people generally try to arrive at a judgement using as little effort as possible (i.e. least effort), while these judgements should be associated with a sufficient level of (subjective) confidence (i.e. information sufficiency). In a sense, people will attempt to find a balance between minimizing effort and maximising confidence that their judgment will satisfy their motives or goals (Chen, Duckworth, \& Chaiken, 2000). The sufficiency 
principle reflects a continuum along which two critical points are situated: one representing a person's level of current confidence and one representing that person's desired level of confidence for a given motive and judgmental context. The sufficiency threshold represents the point on this continuum at which a person feels subjectively confident enough that their judgment will satisfy their current motives or goals in the current context (Chen \& Chaiken, 1999). Since systematic processing takes more effort than heuristic processing, people will usually first employ heuristic processing to arrive at a judgment with sufficient confidence. Only when this is unsuccessful will they use systematic processing.

Whether systematic processing occurs is further dependent upon two conditions. First, people need to have the required cognitive ability and opportunity to elaborate on the message (Chaiken et al., 1989). Second, people should be motivated to engage in systematic processing. Two important influences of motivation are assumed in the HSM (Chen et al., 2000). First, the level of motivation determines whether a person will predominantly use systematic or heuristic processing strategies in a given context. Second, the type of motivation determines the direction or nature of whatever processing strategy is used. The HSM distinguishes three types of general motivations. People may be motivated to arrive at an accurate judgement (i.e. accuracy motivation), or to defend a certain position (i.e. defence motivation) or they may be motivated to develop or maintain socially-acceptable positions (i.e. impression motivation).

Whereas a similar dual-process model, the Elaboration Likelihood Model (Petty \& Cacioppo, 1986), assumes that systematic (or central) processing and heuristic (or peripheral) processing are independent and qualitatively different processes, the HSM assumes a continuum ranging from heuristic processing at one end of the continuum to systematic processing at the other end. That is, although systematic and heuristic processing can occur alone, they may also oo-occur in a given context (Chaiken et al., 1989) in either an additive manner (one type of processing complements the other (Maheswaran \& Chaiken, 1991)) or in a biasing manner (one type of processing biases the other type (Chaiken \& Maheswaran, 1994)). Under the influence of the recent focus on automaticity (e.g., Bargh \& Chartrand, 1999), this continuum is often reinterpreted to include automatic processing at one end of the continuum going via heuristic processing to systematic processing at the other end at the continuum.

This theoretical framework seems fit to explain our results and shed some light on the cognitive mechanisms that have caused the 'adverse' effects of genetic versus general health messages. Of 
particular importance is the sufficiency threshold which determines how a person processes a health message. Importantly, the confidence a person has in his or her opinion may be influenced by aspects of a persuasive (health) message and the context in which this message is received. Whether people are motivated to process a persuasive (health) message systematically depends at least in part on whether a person's current level of confidence exceeds or falls short of the sufficiency threshold. Thus, when previously unaware participants read the genetic health message, their current level of confidence may have decreased and fallen below their sufficiency threshold. After all, the message contains new information (i.e. creates dissonance). This is not the case for the previously unaware participants that read the general health message or for the previously aware participants (regardless of which health message they read). These groups may thus not have experienced a (large) drop in their level of confidence and may not have been motivated to attend to the health message.

Depending on the difference between previously unaware participants' level of confidence after having read the health message and their sufficiency threshold (or desired level of confidence), three possibilities arise. Following the least effort principle, previously unaware participants reading the genetic health message will first try to achieve their desired level of confidence (the sufficiency threshold) by using heuristic processing. If this does not boost their current level of confidence beyond their sufficiency threshold, they are likely to engage in systematic processing. However, if participants felt they would not be able to reach the desired level of confidence at all, they are likely not to invest any effort in processing the message. In such cases of insufficient confidence to reach a judgement through information processing, 'gut feelings' (or implicit cognitions) may play an important role.

These three possibilities deserve some detailed attention. If participants felt they were not able to achieve the desired level of confidence and thus engaged in automatic processing, they are likely to base their judgements on their gut feelings. The scarce research available suggests that these gut feelings regarding genetics are likely to be negative. For instance, Condit and colleagues (2002; 2004) observed that while having adequate knowledge of the meaning of the word 'mutation', people experienced strong negative associations with this term. They suggested that public communications employing genetic words with negative connotations may lead to unexpected effects and may even do more harm than good. In an unpublished Implicit Association Test study (Smerecnik, Mesters, De Vries, \& De Vries, 2009), these negative associations with genetics 
were confirmed: people seem to hold negative implicit associations with 'genetics'. As such, perceiving themselves unable to achieve their desired level of confidence, previously unaware participants may have resorted to their implicit negative associations with genetics to arrive at a relatively lower susceptibility judgement.

Alternatively, if previously unaware participants perceive themselves capable of achieving the desired level of confidence they may first try to achieve the sufficiency threshold by using less effortful heuristic processing. Only if this did not result in the desired level of confidence would participants have had to engage in systematic processing. At this point, it is important to note that information processing style is not necessarily related to the (objective) correctness of an individual's judgement, decision, or behavioural response. Rather it focuses on the manner in which individuals arrive at their judgement, decision, or behavioural response which may be governed by self-serving motives.

In a first attempt, previously unaware participants are thus likely to try to reach the sufficiency threshold by applying simple if-then rules or heuristics. Heuristics can, however, only be used if they are available, accessible and applicable (Higgins, 1989; 1996). In other words, a heuristic must be stored in memory, activated when needed and must be appropriate for the task at hand. The nature of processing thus depends on whether the appropriate heuristics can be activated, for instance by the presence of heuristic-cue information. Other factors may also play a role as these factors may facilitate coping (Chen \& Chaiken, 1999). Prior knowledge, for instance, may facilitate message derogation. Furthermore, prior knowledge may be relevant in so far they may serve as heuristics. Consider the example used in the studies presented in this dissertation in which previously unaware individuals are alerted to the existence of genetic risk factors of salt sensitivity. Flawed how-to or principles knowledge of genetics and the gene-environment interaction may serve as a heuristic which could be activated by the message's mention of genetics. This heuristic may then be used to defensively process the message to arrive at the conclusion of low personal susceptibility.

The results of the studies presented in this dissertation provide some suggestions as to which type of processing is most likely to have occurred. That is, previously unaware participants may have heuristically processed the genetic health message. First, previously unaware participants reported lower personal relevance for the genetic health message compared to the general health message (see Chapter 5). Personal relevance is a factor that has been heavily used to manipulate processing style. In general, researchers assume that messages that are personally relevant are processed systematically 
and those that are not perceived to be personally relevant are processed heuristically if at all. For instance, Rothman and Schwarz (1998) asked participants to recall either three or eight CVD riskdecreasing and either three or eight CVD risk-increasing behaviours. When participants considered CVD to be personally irrelevant, they relied more on the 'ease-of-recall' heuristic to form judgements concerning their susceptibility. That is, these participants reported higher susceptibility after recalling three rather than eight riskincreasing behaviours and lower susceptibility after having to recall three rather than eight risk-decreasing behaviours. Since three riskincreasing factors are easier to recall than eight, this ease of recall seems to suggest that CVD is more common and participants may have felt more susceptible. In contrast, when recalling three rather than eight risk-decreasing factors, participants may have used the ease-of-recall heuristic to judge the likeliness of risk-decreasing factors and may thus have felt less susceptible after easily recalling three risk-decreasing factors. When CVD was perceived to be personally relevant, participants used a systematic strategy to arrive at judgments of susceptibility. That is, when considered relevant, judgments of susceptibility were higher after recalling eight rather than three risk-increasing behaviours and lower after recalling eight rather than three risk-decreasing behaviours. The authors conclude that individuals draw on the specific content of the message only when this is considered sufficiently relevant, motivating them to use a systematic strategy to arrive at judgments.

Second, the 'adverse' effects on risk perception were observed at the immediate follow-up and were absent at the 1 month and 6 months follow-ups (see Chapter 6). This is consistent with a heuristic processing explanation. Indeed, judgements that are reached using heuristic processing are assumed to be less resistant to change and less stable over time. As such, it is likely but not certain that previously unaware participants have heuristically processed the genetic health message, which may have resulted in lower perceived susceptibility.

\section{Implications for future research}

The theoretical framework presented in this section has two broad implications for future research. That is, research may investigate the role of (1) information processing in genetic health messages; and (2) defence motivation in processing genetic health messages and how to decrease it.

Information processing. Concerning the role of information processing in genetic health messages several issues need to be investigated. First and foremost, future research may examine 
whether and when (i.e. under which circumstances) genetic health messages are processed automatically, heuristically or systematically and how this relates to health cognitions and behaviour outcome measures, such as risk perception, intention, and preventive behaviour. To this end, participants could be administered an Implicit Association Test (e.g., Greenwald, MoGhee, \& Schwartz, 1998) after which participants will be randomly assigned to receive a genetic or a general health message which either contain strong arguments or weak arguments. Additionally, to enable assessment of potentially differential effects of awareness status, participants' awareness status will be assessed as well. This experiment will thus employ a 2 (health message: genetic versus general) * 2 (arguments: strong versus weak) $* 2$ (awareness status: aware versus unaware) design. Such a design would enable the assessment of (1) automatic processing of genetic health messages by analysing the contribution of IAT scores on selected outcome measures (e.g., perceived susceptibility) stratified for health message type and awareness status; and (2) heuristic versus systematic processing by analysing whether aware versus unaware participants discriminate between strong versus weak arguments stratified for health message type. If previously unaware participants reading the genetic health messages process this message heuristically, we would expect that they fail to discriminate between strong and weak arguments. If they do discriminate between strong and weak arguments they are likely to have processed the genetic health message systematically. Alternative methods to manipulate processing style concern procedures that prevent people from processing a message systematically by: (1) diverting participants by having them perform a secondary task, or (2) overloading participants by placing a limit on the time available for processing.

Secondly, we would want to know how automatic, heuristic or systematic processing influences the outcome measures. A first step would be to conduct qualitative research to examine what heuristics people use when reading genetic health messages. Think-aloud or thought-listing procedures would be suitable for this endeavour. Afterwards experimental studies may manipulate the use of these heuristics and examine the effects of use on the outcome measures.

Thirdly, applied research may develop strategies to efficiently communicate genetic health messages to the general public for maximum benefit. The development of these strategies could be guided by three distinct approaches: 1) needs and capacity assessment (e.g., vocabulary, health literacy) to investigate the public's needs in terms of genetic information and their capacity to process such information; 2) think aloud procedures where people 
are asked to verbalise their thoughts while reading genetic health messages to identify problems that are generally encountered; and 3) cognitive-ergonomical considerations (e.g., decision aids, advance organizers, visual aids) to select relevant strategies to remedy the problem identified in the think aloud procedure using a Delphi procedure. Finally, experimental and field research should then examine the efficacy of these strategies in practice.

Besides these main issues, future research can expand the horizon and examine the influence of affect or emotions on processing style in general and for genetic health messages specifically (see Das \& Fennis, 2008). Several other factors have been suggested to influence information processing, such as vividness (Smith \& Shaffer, 2000), fit with regulatory focus (Lee \& Aaker, 2004), and negative affect (Burke-Beckjord, Finney-Rutten, Arora, Moser, \& Hesse, 2008). However, more research is needed on how these factors influence processing of information in general and specifically how these factors can be applied to genetic health messages to increase systematic processing of these messages.

Defence motivation. Defence motivation seems to be a default when people consider (threatening) health information (e.g., Greenberg, Arndt, Simon, Pyszczynski, \& Solomon, 2000; Harris \& Napper, 2005). People like to believe that they are healthy and messages that imply otherwise may be perceived or experienced as a threat to the self (or self-integrity). Consequently, people are likely to engage in defensive processing or coping especially if they believe that they cannot decrease or avert the threat. Acconding to Breznitz (1983), people defend themselves against recognition of a health threat by engaging in the least degree of defence necessary to adequately protect themselves against the (fear of the) threat. Moreover, as message ambiguity decreases the level of defence increases. That is, for ambiguous messages (e.g., mass media health messages) simple defence measures, such as decreasing personal relevance or perceived susceptibility, will suffice. However, less ambiguous messages (e.g., personalised DNA-risk information) require more sophisticated defence measures, such as counterargumentation. Moreover, once the need for defence has been satisfied, other opportunities for defence will not be needed and thus not utilised (see also Starzyk, Fabrigar, Soryal, \& Fanning, 2009). Breznitz's ideas of levels of defence may be an interesting concept for future research. To this end, previously unaware and aware participants may be presented with a genetic versus a general health message. Half the genetic health messages (and also half the general health messages) will be ambiguous (e.g., universally communicating that there is a gene for a given disease) the other half will be less 
ambiguous (e.g., communicating that the target population is at increased risk of inheriting that gene). This 2 (health message type: genetic versus general) $* 2$ (ambiguity: high versus low) $* 2$ (awareness status: aware versus unaware) design will examine the influence of the independent variables on level of defence outcome measures varying from low levels of defence (e.g., susceptibility) to higher levels of defence (e.g., counter argumentation). Interestingly, the lower levels of defence seem to be available during heuristic processing and the higher levels of defence probably require systematic processing as these require more elaborate understanding of the message and its implications.

Another aspect that warrants future research concerns potential strategies that reduce defensiveness. For instance, a large body of literature attests to the fact that people have the tendency to defend against (threatening) health messages (e.g., Blumberg, 2000; Goldenberg \& Arndt, 2008; Harris \& Napper, 2005; Ruiter et al., 2001). That is, people tend to interpret health messages in a selfserving manner (Ditto \& Lopez, 1992). According to the SelfAffirmation Theory (Steele, 1988), people are primarily motivated to defend the belief that they are adaptively and morally adequate (or their sense of self-integrity). Threatening health messages are assumed to compromise people's self-integrity resulting in the need to defend against information. The Self-Affirmation Theory has fuelled research into the use of self affirmation as a strategy to reduce defensiveness. These and other strategies, such as elaboration and message framing, may be examined to reduce the defensive response to genetic health messages.

\section{Limitations}

The studies presented in this dissertation have several methodological limitations and the results and conclusions need to be interpreted with these limitations in mind.

\section{Self-report measures}

Throughout the present studies, self-report measures were used. Although such measures are commonly used to assess psychological concepts such as perceived susceptibility, these measurement techniques have some disadvantages. First and foremost is the disadvantage that self-report measures are subject to social desirability bias. Second, participants may not be aware of the complex cognitive processes that they are asked to report on. Third, memory biases may influence reporting. However, recent advances in computer science have spawned the creation of so-called implicit measures of psychological concepts. These measures are assumed to 
be less sensitive to social desirability and less under the control of participants. Originally, such assessments were restricted to evaluations or associations with a target object. Visschers (2007), however, has adapted an assessment for risk perception purposes. The use of such assessments measures may prove to be more reliable than self-report measures. However, decades of research have used self-report measures for these concepts and they seem to reliably assess psychological concepts.

Self-report measures of salt consumption may be more problematic. One problem is that people may not know that most products inherently contain salt. Moreover, this is usually indicated as sodium on the food label. People need to know that sodium is salt and that the ratio of sodium to salt is $1: 2.5$, meaning that $1 \mathrm{~g}$ of sodium is $2.5 \mathrm{~g}$ of salt. As such, people may report lower salt intake than they in fact consume. A better, but much more intensive, alternative is urine excretion. This method is however also not $100 \%$ bias-proof. Additionally, self-reported salt consumption has been used in previous research and has been found to yield reliable results (Parkington \& Roussos, 2008; Salonen et al., 1983). For our purposes self reports probably sufficed. That is, we were not interested in the exact amount of salt consumed, but rather in relative (subjective) differences between the health message groups.

\section{Operationalisation of concepts}

A related limitation concerns the operationalization of the outcome measures. For instance, perceived susceptibility was assessed concerning salt sensitivity and not concerning having the predisposing gene. Although both measures would have provided valuable information, the aim of the studies was to examine how communicating the existence of genetic risk factors influenced perceived susceptibility to the disease. However, susceptibility of having the gene may prove to be a mediator of the effects of genetic health messages on perceived susceptibility to the disease.

Moreover, susceptibility was measured in absolute and relative terms and not conditional on having the genetic predisposition or not. Recent research suggests that conditional measures may be better able to assess risk perception and to predict intention and behaviour (Brewer et al., 2007). However, since the primary interest was in difference between genetic versus general health messages rather than predicting intention and behaviour from susceptibility, absolute and relative measures provided enough information to test our hypotheses. 


\section{Generalisation to other diseases}

Except for study 4.2, all studies used salt sensitivity as the medical condition under investigation. As such, the generalisability of the results to other medical conditions remains to be examined. As mentioned in the introduction, the medical condition under consideration (i.e. salt sensitivity) was chosen for several reasons. First, the general population is already largely aware of the relationship between salt consumption and increased blood pressure and the risk this carries for cardiovascular disease. Second, and related, the genetic polymorphism for salt sensitivity has been discovered fairly recently. Consequently, the genetic risk factors for salt sensitivity are relatively unknown among the general population. As such, using salt sensitivity in our studies may provide a good approximation to mass media messages reporting the discovery of new disease genes. Third, the Dutch general population has been shown to consume approximately 9 grams of salt each day, which is about $50 \%$ over the recommended 6 grams (Van den Hooven et al., 2007). Fourth, an estimated $40 \%$ of the population has the alphaadducin polymorphism which predisposes for salt sensitivity. As such, a large portion of the general population may gain additional benefits from this knowledge. Nevertheless, future research should try to replicate our results using a wide variety of other medical conditions with a wide variety of severity.

\section{Risk presentation}

A large body of research has documented that different presentations of risks elicit different responses (for an overview see Visschers, Meertens, Passchier, \& de Vries, 2009). The genetic health messages that were used in the present studies conveyed the additional risk due to genetic predispositions as a verbal risk presentation (i.e. those having a genetic predisposition run a greater risk of having a saltsensitive blood pressure). However, research has shown that verbal risk descriptions have large between-subjects variability (Theil, 2002). That is, being at greater risk due to having a genetic predisposition to salt sensitivity may not have meant the same for every individual participant. Moreover, the meaning of verbal risk descriptions seemed to be influenced by the context in which it is presented (Visschers et al., 2009). Consequently, Karelitz and Budesco suggested tailoring verbal risk descriptions to the target individual's personal lexicon (Karelitz \& Budesco, 2004). Although this did indeed result in conveying accurate risks, such tailoring to a person's lexicon may not be easily achieved for mass media health messages. 
Numerical risk descriptions seem to be better understood (Knapp, Raynor, \& Berry, 2004) and more trusted (Gurmankin, Baron, \& Armstrong, 2004) than verbal risk descriptions. Presenting the risk of developing a salt sensitive blood pressure due to a genetic predisposition in numeric form may have elicited different results than those that were observed in this dissertation. This may be especially likely since verbal risk descriptions seem to result in more variability in risk perception (Gurmankin et al., 2004). However, verbal risk descriptions do have their value. For instance, individuals have been shown to more readily use verbal information when describing their risk to others (Erev \& Cohen, 1990) and when deciding on treatment (Teigen \& Brun, 2003). Visschers et al. (2009) therefore suggested using both numerical and verbal risk descriptions in a risk message. Future research may vary verbal and numerical risk descriptions to examine possible differential effects.

\section{Who's in control?}

Research has shown that attributing a disease to genetic causes may affect perceived control over prevention of that disease. For instance, individuals attributing a disease to genetic causes may be less likely to belief that their behaviour can influence or prevent disease development. According to Marteau and Weinman (2006), people use the heuristic of symmetry to infer the best coping strategy for a particular threat. If the threat representation of a disease includes genes as a cause, then people are likely to look for symmetry when determining the best possible coping strategy. This is likely to result in the use of inferential "if-then" rules. As such, people may belief that "TF [a disease] is caused by genes, THEN there is nothing that can be done" (Marteau \& Weinman, 2006, p. 1365). But this rule will most likely not satisfy their need for control over threats in their environment (DeCharms, 1968; Malinowski, 1955), and may even evoke negative affect. Consequently, Marteau and Weinman (2006) have argued that attributing a disease to genetic causes will not inevitably result in fatalism but is likely to result in the belief that biologically-based actions are more effective in reducing the threat than behaviour-based actions. In other words, rather than believing that nothing can be done if a disease is genetically determined, people may believe that "IF [a disease] is caused by genes, THEN biologically based interventions are more effective to reduce the risk" (Marteau \& Weinman, 2006, p. 1365).

Several studies have investigated this possibility, suggesting that presenting people with (hypothetical) information about the absence or presence of a genetic predisposition to, for instance, smoking results in lower confidence in will power and higher confidence in 
bupoprion when attempting to quit smoking (Wright, Aveyard, Guo, Murphy, Brown, \& Marteau, 2007; Wright, Weinman, \& Marteau, 2003). Other studies have not observed such effects (Wright et al., 2006). Moreover, recent longitudinal studies have shown that attributing smoking (Wright et al., 2007) or obesity (Hilbert et al., 2008; Rief et al., 2007) to genes did not influence quit attempts and quit attempt success or weight regulation and longer-term weight outcome respectively.

In short, the role of perceived control in the efficacy of genetic information to motivate people to engage in preventive behaviour (which also includes getting a genetic test and choosing for biologically-based preventive action) is currently not clear-cut. An interesting avenue for future research is to examine the role of perceived control in more detail. For instance, the literature distinguishes two types of perceived control: volition, which is defined as having control over the exposure to the risk itself, and control, which is defined as having command over the outcome (Nordgren, Van der Pligt, \& Van Harreveld, 2007). This distinction may be particularly interesting to genetic risk communication. Multifactorial genetic diseases are assumed to preventable by improving healthy lifestyle and, as such, are under a person's control. However, exposure to a given genetic polymorphism is not under that person's volition. While control has been shown to decrease risk perception, volition increases risk perception (Nordgren et al., 2007). Disentangling these two types of control may prove a fruitful pursuit for future research in genetic risk communication.

Other issues which need clarification are how genetic information affects threat appraisals and coping appraisals. For instance, research so far has primarily investigated the cause dimension of threat appraisals. Other aspects such as disease timeline may also play an important role in genetically determined multifactorial diseases. Additionally, more research is needed on which dimensions of threat appraisal are important for multifactorial genetic diseases and how these dimensions influence coping appraisal. Also, how coping appraisal affects preventive behaviour and decision-making related to genetic risk remains largely unclear. These issues may prove to be additional avenues of interest for future research.

\section{Conclusions}

The studies presented in this dissertation illustrate the value of Rogers' knowledge framework for public education of multifactorial genetic diseases and genetic risk communication. Following this framework, alerting the general population to the genetic risk factors for a given disease was shown to not necessarily result in adequate 
preventive behaviour. The studies have consistently shown that current genetic health messages may not be effective in changing the general public's health cognitions and health behaviour. Among previously unaware participants reading the genetic health message resulted in lower perceptions of susceptibility to salt sensitivity and consequently in lower intention to restrict salt intake. These effects on susceptibility and intention were not observed among previously aware participants. The genetic health message's inability to individualize risk may be the primary cause for these findings. Indeed, participants who were aware of genetic risk factors for salt sensitivity did not perceive the health message to be personally relevant. Several strategies, such as source credibility or message framing, may be effective in enhancing perceived personal relevance of the genetic health message. Alternatively, previously unaware participants may have used defensive strategies to defend against the negative emotions associated with induced dissonance between their current knowledge and the genetic health message. Strategies such as self-affirmation, elaboration, and message framing may prove useful strategies to decrease defensive responses to genetic health messages. Alternatively, following Rogers' knowledge framework, genetic health message may incorporate relevant how-to knowledge and principles knowledge. The theoretical framework presented in this chapter has proven useful to integrate the present findings into one coherent theory and may prove a valuable framework for future research into the effects of genetic health messages on preventive behaviour among the general population. 


\section{References}

Abifadel, M., Varret, M., Rabès, J . P., Allard, D., Ouguerram, K., Devillers, M., et al. (2003). Mutations in pcsk9 cause autosomal dominant hypercholesterolemia. Nature Genetics, 34, 154-156.

Ackermann, S., Renner, S. P., Fasching, P. A., Poehls, U., Bender, H. G., \& Beckmann, M. W. (2005). Awareness of general and personal risk factors for uterine cancer among healthy women. European Journal of Cancer Prevention, 14, 519-524.

Allum, N., Sturgis, P., Tabourazi, D., \& Brunton-Smith, I. (2008). Science knowledge and attitudes across cultures: A meta-analysis. Public Understanding of Science, 17, 35-54.

Baars, M., Henneman, L., \& ten Kate, L. P. (2005). Deficiency of knowledge of genetics and genetic tests among general practitioners, gynecologists, and pediatricians: A global problem. Genetics in Medicine, 7, 605-610.

Baars, M., Scherpbier, A. J .J . A., Schuwirth, L. W., Henneman, L., Beemer, F. A., Cobben, J. M., et al. (2005). Deficient knowledge of genetics relevant for daily practice among medical students nearing graduation. Genetics in Medicine, 7, 295-301.

Bargh, J. A., \& Chartrand, T. L. (1999). The unbearable automaticity of being. American Psychologist, 54, 462-479.

Barnoy, S., Bar-Tal, Y., \& Treister, L. (2003). Effect of unrealistic optimism, perceived control over disease, and experience with female cancer on behavioral intentions of israeli women to undergo screening tests. Cancer Nursing, 26, 363-369.

Baron, R. M., \& Kenny, D. A. (1986). The moderator-mediator variable distinction in social psychological research: Conceptual, strategic, and statistical considerations. J ournal of Personality and Social Psychology, 51, 1173-1182.

Bates, B. R., Templeton, A., Achter, P. J., Harris, T. M., \& Condit, C. M. (2003). What does 'a gene for heart disease' mean? A focus group study of public understandings of genetic risk factors. American Journal of Medical Genetics: Part A, 119, 156-161.

BBC News. (2003). Gene defect explains high blood pressure. Retrieved April 8, 2009, from http:// news.bbc.co.uk/ 1/ hi/ health/2760843.stm.

BBC News. (2004). Single gene link to heart health. Retrieved April 8, 2009, from http:// news.bbc.co.uk/ 1/ hi/ health/3762664.stm

BBC News. (2008). 'blood pressure gene' affects 20\%. Retrieved April 8, 2009, from http://news.bbc.co.uk/1/hi/health/7802743.stm

Beeks, E., Kessels, A. G. H., Kroon, A. A., Van der Klauw, M. M., \& De Leeuw, P. W. (2004). Genetic predisposition to salt-sensitivity: A systematic review. J ournal of Hypertension, 22, 1243-1249.

Berlyne, D. E. (1970). Novelty complexity and hedonic value. Perception and Psychophysics, 8, 279-286.

Bernhardt, B. A., McClain, J., \& Parrott, R. L. (2004). Online health communciation about human genetics: Perceptions and preferences of internet users. CyberPsychology \& Behavior, 7, 728-733.

Block, L. G., \& Williams, P. (2002). Undoing the effects of seizing and freezing: Decreasing defensive processing of personally relevant messages. J ournal of Applied Social Psychology, 32, 803-830. 
Blumberg, S. J. (2000). Guarding against threatening hiv prevention messages: An information-processing model. Health Education \& Behaviour, 27, 780795.

Bottorff, J. L., Ratner, P. A., Balneaves, L. G., Richardson, C. G., McCullum, M., Hack, T., et al. (2002). Women's interest in genetic testing for breast cancer risk: The influence of socidemographics and knowledge. Cancer Epidemiology Biomarkers \& Prevention, 11, 89-95.

Brand, A. (2005). Public health and genetics--a dangerous combination? European J ournal of Public Health, 15, 114-116.

Brand, A., Brand, H., \& Schulte in den Baumen, T. (2007). The impact of genetics and genomics on public health. European J ournal of Human Genetics, 16, 513.

Brewer, N. T., Chapman, G. B., Gibbons, F. X., Gerrard, M., \& McCaul, K. D. (2007). Meta-analysis of the relationship between risk perception and health behavior: The example of vaccination. Health psychology 26, 136-145.

Breznitz, S. (1983). The seven kinds of denial. In S. Breznitz (Ed.), The denial of stress (pp. 257-280). New York: International Universities Press.

Bruno, M., Tommasi, S., Stea, B., Quaranta, M., Schittulli, F., Mastropasqua, A., et al. (2004). Awareness of breast cancer genetics and interest in predictive genetic testing: A survey of a southern italian population. Annals Oncologica, 15 (supplement 1), i48-i54.

Bubela, T. M., \& Caulfield, T. A. (2004). Do the print media "Hype" Genetic research? A comparison of newspaper stories and peer-reviewed research papers. Canadian Medical Association J ournal, 170, 1399-1407.

Bunn, J. Y., Bosompra, K., Ashikaga, T., Flynn, B. S., \& Worden, J. K. (2002). Factors influencing intention to obtain a genetic test for colon cancer risk: A population-based study. Preventive Medicine, 34, 567-577.

Burke-Beckjord, E., Finney-Rutten, L. J., Arora, N. K., Moser, R. P., \& Hesse, B. W. (2008). Information processing and negative affect: Evidence from the 2003 health information national trends survey. Health Psychology, 27, 249-257.

Burke, W., Atkins, D., Gwinn, M., Guttmacher, A., Haddow, J., Lau, J., et al. (2002). Genetic test evaluation: Information needs of clinicians, policy makers, and the public. American J ournal of Epidemiology, 156, 311-318.

Butow, P. N., Lobb, E. A., Meiser, B., Barratt, A., \& Tucker, K. M. (2003). Psychological outcomes and risk perception after genetic testing and counselling in breast cancer: A systematic review. Medical Journal of Australia, 178, 77-81.

Cappella, J. N., Lerman, C., Romantan, A., \& Baruh, L. (2005). News about genetics and smoking: Priming, family smoking history, and news story believability on inferences of genetic susceptibility to tobacco addiction. Communication Research, 32, 478-502.

Catz, D. S., Green, N. S., Tobin, J. N., Lloyd-Puryear, M. A., Kyler, P., Umemoto, A., et al. (2005). Attitudes about genetics in underserved, culturally diverse populations. Community Genetics, 8, 161-172.

Center for Disease Control. (2006). Genetic information presents many new opportunities to improve health and prevent disease. Http:// www.cdc.gov/genomics/population/file/print/opportunity.pdff Accessed 19 April 2007.

Chaiken, S., Liberman, A., \& Eagly, A. (1989). Heuristic and systematic information processing within and beyond the persuasion context. In J. S. 
Uleman \& J . A. Bargh (Eds.), Unintended thought (pp. 212-252). New York: The guilford Press.

Chaiken, S., \& Maheswaran, D. (1994). Heuristic processing can bias systeamtic processing: Effects of source credibility, argument ambiguity, and task importance on attitude judgment. Journal of Personality and Social Psychology, 66, 460-473.

Chapple, A., May, C., \& Campion, P. (1995). Lay understanding of genetic disease: A british study of families attending a genetic counseling service. J ournal of Genetic Counseling, 4, 281-300.

Chen, L. S., \& Goodson, P. (2007). Public health genomics knowledge and attitudes: A survey of public health educators in the united states. Genetics in Medicine, 9, 496-503.

Chen, S., \& Chaiken, S. (1999). The heuristic-systematic model in its broader context. In S. Chaiken \& Y. Trope (Eds.), Dual-process theories in social psychology (pp. 73-96). New York: The Guilford Press.

Chen, S., Duckworth, K., \& Chaiken, S. (2000). Motivated heuristic and systematic processing. Psychological Inquiry, 10, 44-49.

Clark, J. K., Wegener, D. T., \& Fabrigar, L. R. (2008). Attitudinal ambivalence and message-based persuasion: Motivated processing of proattitudinal information and avoidance of counterattitudinal information. Personality and Social Psychology Bulletin, 34, 565-577.

Collins, F. S., Green, E. D., Guttmacher, A. E., \& Guyer, M. S. (2003). A vision for the future of genomics research. Nature, 422, 835-847.

Condit, C. M. (2001). What is 'public opinion' about genetics? Nature reviews: Genetics, 2, 811-815.

Condit, C. M. (2005). Lay people actively process messages about genetic research. In E. F. Einsiedel \& F. Timmermans (Eds.), Crossing over: Genomics in the public arena (pp. 131-156). Calgary: University of Calgary Press.

Condit, C. M., Achter, P. J., Lauer, I., \& Sefcovic, E. (2002). The changing meaning of "mutation": A contextualized discourse study. Human Mutation, 19, 69-75.

Condit, C. M., Dubriwny, T., Lynch, J., \& Parrott, R. (2004). Lay people's understanding of and preference against the word "mutation". American J ournal of Medical Genetics Part A, 130A, 245-250.

Condit, C. M., Ferguson, A., Kassel, R., Thadhani, C., Gooding, C., \& Parrott, R. (2001). An exploratory study of the impact of news headlines on genetic determinism. Science Communication, 22, 379-395.

Condit, C. M., Gronnwoll, M., Landau, J., Shen, L., Wright, L., \& Harris, T. M. (2009). Believing in both genetic determinism and behavioral action: A materialist framework and implications. Public Understanding of Science, DOI: $10.1177 / 0963662508094098$.

Conrad, P. (1997). Uses of expertise: Sources, quotes and voices in the reporting of genetics in the news. Public Understanding of Science, 8, 285-302.

Correll, J ., Spencer, S. J ., \& Zanna, M. P. (2004). An affirmed self and an open mind: Self-affirmation and sensitivity to argument strength. Journal of Experimental Social Psychology, 40, 350-356.

Cusi, D., Barlassina, C., Azzani, T., Casari, G., Citterio, L., \& Devoto, M. (1997). Polymorphisms of alpha-adducin and salt sensitivity in patients with essential hypertension. The Lancet, 349, 1353-1357. 
Das, E., \& Fennis, B. M. (2008). In the mood to face the facts: When a positive mood promotes systematic processing of self-threatening information. Motivation and Emotion, 32, 221-230.

Das, E. H. H. J., de Wit, J. B. F., \& Stroebe, W. (2003). Fear appeals motivate acceptance of action recommendations: Evidence for a positive bias in the processing of persuasive messages. Personality and Social Psychology Bulletin, 29, 650-664.

De Hoog, N., Stroebe, W., \& de Wit, J. B. F. (2005). The impact of fear appeals on processing and acceptance of action recommendations. Personality and Social Psychology Bulletin, 31, 24-33.

De Vries, H., Mesters, I., Van de Steeg, H., \& Honing, C. (2005). The general public's information needs and perceptions regarding hereditary cancer: An application of the integrated change model. Patient Education \& Counseling, 56, 154-165.

De Vries, H., Mudde, A., Leijs, I., Charlton, A., Vartiainen, E., Buijs, G., et al. (2003). The european smoking prevention framework approach (esfa): An example of integral prevention. Health Education Research, 3, 611-626.

DeCharms, R. (1968). Personal causation. New York: Academic Press.

Ditto, P. H., \& Lopez, D. F. (1992). Motivated skepticism: Use of differential decison criteria for preferred and nonpreferred conclusions. Journal of Personality and Social Psychology, 63, 568-584.

Donovan, K. A., \& Tucker, D. C. (2000). Knowledge about genetic risk for breast cancer and perceptions of genetic testing in a sciodemgraphically diverse sample. J ournal of Behavioural Medicine, 23, 15-36.

Eagly, A. H., \& Chaiken, S. (1993). The psychology of attitudes. Fort Worth, TX: Harcourt Brace College Publishers.

Einsiedel, E. F. (2006). The challenges of translating genomic knowledge. Clinical Genetics, 70, 433-437.

Emery, J., Kumar, S., \& Smith, H. (1998). Patient understanding of genetic principles and their expectations of genetic services within nhs: A qualitative study. Community Genetics, 1, 78-83.

Erev, I., \& Cohen, B. L. (1990). Verbal versus numerical probabilities: Efficiency, biases, and the preference paradox. Organizational Behavior and Human Decision Processes, 45, 1-18.

Etchegary, H., Cappelli, M., Potter, B., Vloet, M., Graham, I., Walker, M., et al. (2009). Attitude and knowledge about genetics and genetic testing. Public Health Genomics, e-pub ahead of print, DOI: 10.1159/000220034.

Fairchild, A. J., \& MacKinnon, D. P. (2009). A general model for testing mediation and moderation effects. Prevention Science, 10, 87-99.

Festinger, L. (1962). A theory of cognitive dissonance. Stanford: Stanford University Press.

Frewer, L. J., Howard, C., Hedderley, D., \& Shepherd, R. (1999). Reactions to information about genetic engineering: Impact of source characteristics, perceived personal relevance, and persuasiveness. Public Understanding of Science, 8, 35-50.

Frosch, D. L., Mello, P., \& Lerman, C. (2005). Behavioral consequences of testing for obesity risk. Cancer Epidemiology Biomarkers \& Prevention, 14, 14851489.

Geibert, R. C. (2006). Using diffusion of innovation concepts to enhance implementation of an electronic health record to support evidence-based practice. Nursing Administration Quarterly, 30, 203-210. 
Geller, G., Bernhardt, B. A., \& Holtzman, N. A. (2002). The media and public reaction to genetic research. J ournal of the American Medical Association, 287, 773-.

Godin, G., \& Kok, G. (1996). The theory of planned behavior: A review of its applications to health-related behaviors. American Journal of Health Promotion, 11, 87-98.

Goldenberg, J. L., \& Arndt, J . (2008). The implications of death for health: A terror management health model for behavioral health promotion. Psychological Review, 115, 1032-1053.

Gooding, H. C., Linnenbringer, E. L., Burack, J., Roberts, J. S., Green, R. C., \& Biesecker, B. B. (2006). Genetic susceptibility testing for alzheimer disease: Motivation to obtain information and control as precursors to coping with increased risk. Patient Education and Counseling, 64, 259-267.

Gooding, H. C., Organista, K., Burack, J., \& Biesecker, B. B. (2006). Genetic susceptibility testing from a stress and coping perspective. Social Science \& Medicine, 62, 1880-1890.

Greenberg, J., Arndt, J., Simon, L., Pyszczynski, T., \& Solomon, S. (2000). Proximal and distal defenses in response to reminders of one's mortality: Evidence of a temporal sequence. Personality and Social Psychology Bulletin, 26, 91-99.

Greenwald, A. G., McGhee, D. E., \& Schwartz, J. L. K. (1998). Measuring individual differences in implicit cognition: The implicit association test. J ournal of Personality and Social Psychology, 74, 1464-1480.

Gurmankin, A. D., Baron, J., \& Armstrong, K. (2004). The effect of numerical statements of risk on trust and comfort with hypothetical physician risk communication. Medical Decision Making, 24, 265-271.

Guttmacher, A. E., \& Collins, F. S. (2005). Realizing the promise of genomics in biomedical research. J ournal of the American Medical Association, 294, 1399-1402.

Hahn, S., Letvak, S., Powell, K., Christianson, C., Wallace, D., Speer, M., et al. (2008). A community's awareness and perceptions of genomic medicine. Public Health Genomics, e-pub ahead of print, DOI: 10.1159/ 000218712.

Hailey, B. J., Carter, C. L., \& Burnett, D. R. (2000). Breast cancer attitudes, knowledge, and screening behavior in women with and without a family history of breast cancer. Health Care for Women International, 21, 701-715.

Harris, P. R., \& Napper, L. (2005). Self-affirmation and the biased processing of threatening health-risk information. Personality and Social Psychology Bulletin, 31, 1250-1263.

Health Council of the Netherlands. (2003). Public awareness about genetics. (2003/ 05). The Hague: Health Council of the Netherlands.

Hendriks, J. J. J., \& De Vries, H. (2002). Erfelijkheid en kanker: Focusgroep interviews naar opvattingen van nederlands [heredity and cancer: Focusgroup interviews of dutch opinions]. Maastricht: University of Maastricht.

Henneman, L., Timmermans, D. R. M., \& Van der Wal, G. (2004). Public experiences, knowledge and expectations about medical genetics and the use of genetic information. Community Genetics, 7, 33-43.

Higgins, E. T. (1989). Knowledge accessibility and activation: Subjectivity and suffering from unconscious sources. In J. S. Uleman \& J. A. Bargh (Eds.), Unintended thought (pp. 75-123). New York: The Guilford Press. 
Higgins, E. T. (1996). Knowledge activation: Accessibility, applicability, and salience. In E. T. Higgins \& A. W. Kruglanski (Eds.), Social psychology: Handbook of basic principles (pp. 133-168). New York: The Guilford Press.

Hilbert, A., Dierk, J --M., Conradt, M., Schlumberger, P., Hinney, A., Hebebrand, J., et al. (2008). Causal attributions of obese men and women in genetic testing: Implications of genetic/ biological attributions. Psychology \& Health, $24,749-762$.

Holtzman, N. A., \& Marteau, T. M. (2000). Will genetics revolutionize medicine? New England J ournal of Medicine, 343, 141-144.

Honda, K. (2003). Who gets the information about genetic testing for cancer risk? The role of race/ ethnicity, immigration status, and primary care clinicians. Clinical Genetics, 64, 131-136.

Hunt, K., Emslie, C., \& Watt, G. (2001). Lay constructions of a family history of heart disease: Potential for misunderstandings in the clinical encounter? Lancet, 357, 1168-1171.

Ikeda, W. (2008). The public's attitudes towards the use of genetic information for medical purposes and its related factors in japan. Community Genetics, $11,18-25$.

Inoue, M., Iwasaki, M., Otani, T., Sasazuki, S., \& Tsugane, S. (2006). Public awareness of risk factors for cancer among the japanese general population: A population-based survey. BMC Public Health, 6, 2.

Jallinoja, P., \& Aro, A. R. (2000). Does knowledge make a difference? The association between knowledge about genes and attitudes toward gene tests. J ournal of Health Communication, 5, 29-39.

J anoff-Bulman, R., \& Lang-Gunn, L. (1988). Coping with disease, crime, and accidents: The role of self-blame attributions. In L. Y. Abramson (Ed.), Social cognition and clinical psychology: A synthesis (pp. 116-147). New York: Guilford.

Janssens, A. C. J. W., \& Van Duijn, C. M. (2008). Genome-based prediction of common diseases: Advances and prospects. Human Molecular Genetics, 17, R166-R173.

J anz, N., \& Becker, M. H. (1984). The health belief model: A decade later. Health Education Quarterly, 11, 1-47.

Kaptein, A. A., van Korlaar, I. M., Cameron, L. D., Vossen, C. Y., van der Meer, F. J. M., \& Rosendaal, F. R. (2007). Using the common-sense model to predict risk perception and disease-related worry in individuals at increased risk for venous thrombosis. Health Psychology, 26, 807-812.

Kardia, S. L., \& Wang, C. (2005). The role of health education and behavior in public health genetics. Health Education \& Behaviour, 32, 583-588.

Karelitz, B. M., \& Budesco, D. V. (2004). You say "probable" And I say "likely": Improving interpersonal communication with verbal probability phrases. J ournal of Experimental Psychology: Applied, 10, 24-41.

Katz Rothman, B. K. (1998). Genetic maps and human imaginations: The limits of science in understanding who we are. New York: W. W. Norton.

Kautz, K., \& Larsen, E. A. (2000). Diffusion theory and practice. Disseminating quality management and software process improvement innovations. Information, Technology, \& People, 13, 11-26.

Keighley, M. R. B., O'Morain, C., Giacosa, A., Ashorn, M., Burroughs, A., Crespi, M., et al. (2004). Public awareness of risk factors and screening for colorectal cancer in europe. European J ournal of Cancer Prevention, 13, 257-262. 
Khoury, M. J. (2003). Genetics and genomics in practice: The continuum from genetic disease to genetic information in health and disease. Genetics in Medicine, 5, 261-268.

Khoury, M. J., Thrasher, J. F., Burke, W., Gettig, E. A., Fridinger, F., \&J ackson, R. (2000). Challenges in communicating genetics: A public health approach. Genetics in Medicine, 2, 198-202.

Kirscht, J. P., Haefner, D. P., Kegeles, F. S., \& Rosenstock, I. M. (1966). A national study of health beliefs. J ournal of Health \& Human Behaviour, 7, 248-254.

Knapp, P., Raynor, D. K., \& Berry, D. C. (2004). Comparison of two methods of presenting risk information to patients about side effects of medicines. Quality and Safety in Health Care, 13, 176-180.

Lanie, A. D., Epstein J ayaratne, T., Sheldon, J. P., Kardia, S. L. R., Anderson, E. S., Feldbaum, M., et al. (2004). Exploring the public understanding of basic genetic concepts. J ournal of Genetic Counseling, 13, 305-320.

Lee, A. Y., \& Aaker, J. L. (2004). Bringing the frame into focus: The influence of regulatory fit on processing fluency and persuasion. J ournal of Personality and Social Psychology, 86, 205-218.

Lerman, C., Narod, S., Schulman, K., Hughes, C., Gomez-Caminero, A., Bonney, G., et al. (1996). Brca1 testing in families with hereditary breast-ovarian cancer. A prospective study of patient decision making and outcomes. J ournal of the American Medical Association, 275, 1885-1892.

Lipkus, I. M., Iden, D., Terrenoire, J., \& Feaganes, J. R. (1999). Relationships among breast cancer concern, risk perceptions, and interest in genetic testing for breast cancer susceptibility among african-american women with and without a family history of breast cancer. Cancer Epidemiology Biomarkers \& Prevention, 8, 533-539.

Ludwig, E. H., Hopkins, P. N., Allen, A., Wu, L. L., Williams, R. R., Anderson, J. L., et al. (1997). Association of genetic variations in apolipoprotein $\mathrm{b}$ with hypercholesterolemia, coronary artery disease, and receptor binding of low density lipoproteins. J ournal of Lipid Research, 38, 1361-1373.

MacKinnon, D. P., Fritz, M. S., Williams, J., \& Lockwood, C. M. (2007). Distribution of the product confidence limits for the indirect effect: Program prodclin. Behavior Research Methods, 39, 384-389.

MacKinnon, D. P., Lockwood, C. M., Hoffman, J. M., West, S. G., \& Sheets, V. (2002). A comparison of methods to test the significane of mediation and other intervening variables. Psychological Methods, 7, 83-104.

MacKinnon, D. P., Lockwood, C. M., \& Williams, J . (2004). Confidence limits for the indirect effect: Distribution of the product and resampling methods. Multivariate Behavioral Research, 39, 99-128.

Maheswaran, D., \& Chaiken, S. (1991). Promoting systematic processing in lowmotivation settings: Effects of incongruent information on processing and judgment. J ournal of Personality and Social Psychology, 61, 13-25.

Malinowski, B. (1955). Magic, science, and religion. New York: Anchor Books.

Marteau, T. M. (1999). Communicating genetic risk information. British Medical Bulletin, 55, 414-428.

Marteau, T. M., \& Lerman, C. (2001). Genetic risk and behavioural change. British Medical J ournal, 322, 1056- 1059.

Marteau, T. M., Senior, V., Humphries, S. E., Bobrow, M., Cranston, T., Crook, M. A., et al. (2004). Psychological impact of genetic testing for familial hypercholesterolemia within a previously aware population: A randomized 
controlled trial. American J ournal of Medical Genetics: Part A, 128, 285293.

Marteau, T. M., \& Weinman, J. (2006). Self-regulation and the behavioural response to DNA risk information: A theoretical analysis and framework for future research. Social Science \& Medicine, 62, 1360-1368.

McGuire, W. J . (1985). Attitudes and attitude change. In G. Lindzey \& E. Aronson (Eds.), The handbook of social psychology (Vol. 2, pp. 233-346). New York: Random House.

McGuire, W. J. (1999). Constructing social psychology. Creative and constructive processes. Cambridge: Cambrigde University Press.

McMenamin, Barry, Lennon, Purcell, Baum, Keegan, et al. (2005). A survey of breast cancer awareness and knowledge in a western population: Lots of light but little illumination. European J ournal of Cancer, 41, 393-397.

McQuail, D., \&Windahl, S. (1993). Communication models for the study of mass communication. New York: Longman Publishing.

Meiser, B., \& Halliday, J . L. (2002). What is the impact of genetic counseling in women at increased risk of developing hereditary breast cancer? A metaanalytic review. Social Science \& Medicine, 54, 1463-1470.

Mendel, J . G. (1865). Versuche über plflanzenhybriden [Experiments in plant hybridization]. Paper presented at the Verhandlungen naturforschenden Vereines Brünn, Brünn.

Mesters, I., Ausems, A., \& De Vries, H. (2005). General public's knowledge, interest and information needs related to genetic cancer: An exploratory study. European J ournal of Cancer Prevention, 14, 69-75.

Mogilner, A., Otten, M., Cunningham, J . D., \& Brower, S. T. (1998). Awareness and attitudes concerning brca gene testing. Annals of Surgery \& Oncology, $5,607-612$.

Molster, C., Charles, T., Samanek, A., \& O'Leary, P. (2009). Australian study on public knowledge of human genetics and health. Public Health Genomics, 12, 84-91.

Morgan-Lopez, A. A., \& MacKinnon, D. P. (2006). Demonstration and evaluation of a method for assessing mediated moderation. Behavior Research Methods, 89, 852-863.

Morgan, M. G., Fischhoff, B., Bostrom, A., \& Atman, C. J. (2002). Risk communication: A mental models approach. Cambrigde: Cambridge University Press.

Morris, J., Gwinn, M., Clyne, M., \& Khoury, M. J. (2003). Public knowledge regarding the role of genetic susceptibility to environmentally induced health conditions. Community Genetics, 6, 22-28.

Muthen, B., \& Muthen, L. (2006). Mplus 4.2: Statistical software.

National Institutes for Health. (2009). Human genome project - fact sheet (Vol. 2009).

NCBI. (2009). Genetests-geneclinics. Retrieved 11-08-2009, from http:// www.geneclinics.org.

Nordgren, L. F., Van der Pligt, J., \& Van Harreveld, F. (2007). Unpacking perceived control in risk perception: The mediating role of anticipated regret. J ournal of Behavioral Decision Making, 20, 533-544.

Parkington, S. R., \& Roussos, S. (2008). Measuring salt consumption to guide behavior change in applied settings: A critical review. . American J ournal of Health Promotion, 23, 101-107.

Petty, R. E., \& Cacioppo, J . T. (1986). Communication and persuasion: Central and peripheral routes to attitude change. New York: Springer-Verlag. 
Pornpitakpan, C. (2004). The persuasiveness of source credibility: A critical review of five decades' evidence. J ournal of Applied Social Psychology, 34, 243-281.

Porter, C. E., \& Donthu, N. (2006). Using the technology acceptance model to explain how attitudes determine internet usage: The role of perceived access barriers and demographics. J ournal of Business Research, 59, 999-1007.

Prochaska, J. O., \& DiClemente, C. C. (1984). The transtheoretical approach: Crossing traditional boundaries of therapy. Homewood, IL: Dow J onesIrwin.

Prochaska, J. O., \&DiClemente, C. C. (1992). Stages of change in the modification of problem behaviors. Progession in Behaviour Modification, 28, 184-218.

Reed, M., \& Aspinwall, L. (1998). Self-affirmation reduces biased processing of health-risk information. Motivation and Emotion, 22, 99-132.

Renner, B., Panzer, M., Oeberst, A., \& Hartung, F.-M. (2007). Risk perceptions and behavior change related h5n1 avian influenza. Health Psychology Review, 1, S297-S297.

Renner, C. H., \& Renner, M. J. (2001). But I thought I knew that: Using confidence estimation as a debiasing technique to improve classroom performance. Applied Cognitive Psychology, 15, 23-32.

Richards, M. (1996). Lay and professional knowledge of genetics and inheritance. Public Understanding of Science, 5, 217-230.

Richards, M., \& Ponder, M. (1996). Lay understanding of genetics: A test of a hypothesis. J ournal of Medical Genetics, 33, 1032-1036.

Rief, W., Conradt, M., Dierk, J .-M., Rauh, E., Schlumberger, P., Hinney, A., et al. (2007). Is information on genetic determinants of obesity helpful or harmful for obese people? - a randomized clinical trial. J ournal of General Internal Medicine, 22, 1553-1559.

Rogers, E. M. (2003). Diffusion of innovations. New York (NY): Free Press.

Rogers, R. W. (1975). A protection motivation theory of fear appeals and attitude change. The J ournal of Psychology, 91, 93-114.

Rogers, R. W. (1983). Cognitive and physiological processes in fear appeals and attitude change: A revised theory of protection motivation. In T. Cacioppo \& R. E. Petty (Eds.), Social psychophysiology: A sourcebook (pp. 153-176). New York: Guilford Press.

Rosenstock, I. M. (1974). The health belief model and preventive health behaviour. Health Education Monographs, 2, 354-356.

Rosenthal, R. (1991). Meta-analysis: A review. Psychosomatic Medicine, 53, $247-$ 271.

Rothman, A. J., \& Salovey, P. (1997). Shaping perceptions to motivate healthy behavior: The role of message framing. Psychological Bulletin, 121, 3-19.

Rothman, A. J ., \& Schwarz, N. (1998). Constructing perceptions of vulnerability: Personal relevance and the use of experiential information in health judgments. Personality and Social Psychology Bulletin, 24, 1053-1064.

Ruiter, R. A. C., Abraham, C., \& Kok, G. (2001). Scary warnings and rational precautions: A review of the psychology of fear appeals. Psychology and Health, 16, 613-630.

Saab, P. G., McCalla, J. R., Coons, H. L., Christensen, A. J., Kaplan, R., Bennet J ohnson, S., et al. (2004). Technological and medical advances: Implications for health psychology. Health Psychology, 23, 142-146.

Salonen, J . T., Tuomilehto, J ., \& Tanskanen, A. (1983). Relation of blood pressure to reported intake of salt, saturated fats, and alcohol in healthy middle-aged population. J ournal of Epidemiology \& Community Health, 37, 32-37. 
Sanada, H., Yatabe, J., Midorikawa, S., Hashimoto, S., Watanabe, T., Moore, J. H., et al. (2006). Single-nucleotide polymorphisms for diagnosis of saltsensitive hypertension. Clinical Chemistry, 52, 352-360.

Sanderson, S. C., Humphries, S. E., Hubbart, C., Hughes, E., J arvis, M. J., \& Wardle, J . (2008). Psychological and behavioural impact of genetic testing smokers for lung cancer risk: A phase ii exploratory trial. J ournal of Health Psychology, 13, 481-494.

Schneider, T. R. (2006). Getting the biggest bang for your health education buck: Message framing and reducing health disparities. American Behavioral Scientist, 49, 812-822.

Seemann, K. (2003). Basic principles of holistic technology education. J ournal of Technology Education, 14, 28-39.

Senior, V., \& Marteau, T. M. (2007). Causal attributions for raised cholesterol and perceptions of effective risk-reduction: Self-regulation strategies for an increased risk of coronary heart disease. Psychology \& Health, 22, 699 - 717.

Sherif, M., \& Hovland, C. I. (1961). Social judgment. New Haven, CT: Yale University Press.

Sherman, D. A. K., Nelson, L. D., \& Steele, C. M. (2000). Do messages about health risks threaten the self? Increasing the acceptance of threatening health messages via self-affirmation. Personality and Social Psychology Bulletin, 26, 1046-1058.

Shiloh, S., Rashuk-Rosenthal, D., \& Benyamini, Y. (2002). Illness causal attribution: An exploratory study of their structure and associations with other illness cognitions and perceptions of control. J ournal of Behavioral Medicine, 25, 373-394.

Siegel, S., \& Castellan Jr., N. J. (1988). Nonparametric statistics for the behavioral sciences.: MoGraw-Hill.

Smerecnik, C. M. R., Mesters, I., De Vries, N. K., \& De Vries, H. (2008). Educating the general public about multifactorial genetic disease: Applying a theory-based framework to understand current public knowledge. Genetics in Medicine, 10, 251-258.

Smerecnik, C. M. R., Mesters, I., De Vries, N. K., \& De Vries, H. (2009). Implicit versus explicit attitudes toward genetics and their influence on responses to genetic health messages. Maastricht: Unpublished manuscript.

Smerecnik, C. M. R., Mesters, I., De Vries, N. K., \& De Vries, H. (in press). Alerting the general public to genetic risks: The value of health messages communicating the existence of genetic risk factors for public health promotion. Health Psychology.

Smerecnik, C. M. R., Mesters, I., Verweij, E., de Vries, N., \& de Vries, H. (2009). A systematic review of the impact of genetic counseling on risk perception accuracy. J ournal of Genetic Counseling, 18, 217-228.

Smith, S. M., \& Shaffer, D. R. (2000). Vividness can undermine or enhance message processing: The moderating role of vividness congruency. Pers Soc Psychol Bull, 26, 769-779.

Starzyk, K. B., Fabrigar, L. R., Soryal, A. S., \& Fanning, J. J . (2009). A painful reminder: The role of level and salience of attitude importance in cognitive dissonance. Personality and Social Psychology Bulletin, 35, 126-137.

Steele, C. M. (1988). The psychology of self-affirmation: Sustaining the integrity of the self. In L. Berkowitz (Ed.), Advances in experimental social psychology (Vol. 21, pp. 261-302). New York: Academic Press.

Sturgis, P., \& Allum, N. (2004). Science in society: Re-evaluating the deficit model of public attitudes. Public Understanding of Science, 13, 55-74. 
Tambor, E. S., Bernhardt, B. A., Rodgers, J., Holtzman, N. A., \& Geller, G. (2002). Mapping the human genome: An assessment of media coverage and public reaction. Genetics in Medicine, 4, 31-36.

Tambor, E. S., Rimer, B. K., \& Strigo, T. S. (1997). Genetic testing for breast cancer susceptibility: Awareness and interest among women in the general population. American J ournal of Medical Genetics, 68, 43-49.

Teigen, K. H., \& Brun, W. (2003). Verbal probabilities: A question of frame? J ournal of Behavioral Decision Making, 16, 53-72.

Theil, M. (2002). The role of translations of verbal to numerical probaility expressions in risk managemant: A meta-analysis. J ournal of Risk Research, 5, 177-186.

Ugalde, A., Martin, P., \& Rees, G. (2008). Psychological impact of receiving genetic risk information for breast cancer, with and without lifestyle information. Australian J ournal of Psychology, 60, 1- 9.

van 't Riet, J., Ruiter, R. A. C., Werrij, M. Q., \& de Vries, H. (2008). Self-efficacy moderates message-framing effects: The case of skin-cancer detection. Psychology \& Health, epub ahead of print, DOI: $10.1080 / 08870440802530798$.

Van Cuilenberg, J. J., \& Noomen, W. (1984). Communicatiewetenschappen [communication sciences]. Amsterdam: Coutinho.

Van den Hooven, C., Fransen, H., J ansen, E., \& Ocke, M. (2007). 24-uurs urineexcretie van natrium. Voedingsstatusonderzoek bij volwassen nederlanders [24 hour urine-excretion of sodium. Food status research among dutch adults] (350050004/2007). Bilthoven: RIVM.

Van den Nieuwenhoff, H. W. P., Mesters, I., Gielen, C., \& De Vries, N. K. (2007). Family communication regarding inherited high cholesterol: Why and how do patients disclose genetic risk? Social Science \& Medicine, 65, 1024-1037.

Van den Nieuwenhoff, H. W. P., Mesters, I., \& De Vries, N. K. (2006). Public awareness of the existence of inherited high cholesterol. European J ournal of Cardiovascular Prevention \& Rehabilitation, 13, 990-992.

Vinokur, A., \& Burnstein, E. (1978). Novel argumentation and attitude change: The case of polarization following group discussion. European J ournal of Social Psychology, 8, 335-348.

Visschers, V. H. M. (2007). Gut feeling versus common sense. The role of associative and cognitive processes in risk perception and oommunication. University Maastricht, Maastricht.

Visschers, V. H. M., Meertens, R. M., Passchier, W. F., \& de Vries, N. K. (2009). Probability information in risk communication: A review of the research literature. Risk Analysis, 29, 267-287.

Vural, B. K., Tomatir, A. G., Kurban, N. K., \& Taspinar, A. (2009). Nursing students' self-reported knowledge of genetics and genetic education. Public Health Genomics, 12, 225-232.

Waller, J., McCaffery, K., \& Wardle, J. (2004). Beliefs about the risk factors for cervical cancer in a british population sample. Preventive Medicine, 38, 745753.

Wang, C., Bowen, D. J., \& Kardia, S. L. R. (2005). Research and practice opportunities at the intersection of health education, health behavior, and genomics. Health Education \&Behaviour, 32, 686-701.

Wardle, J., Waller, J., Brunswick, N., \& J arvis, M. J. (2001). Awareness of risk factors for cancer among british adults. Public Health, 115, 173-174.

Watson, J. D., \& Crick, F. H. (1953). Letter to the editor; molecular structure of nucleic acids. Nature, 171, 737-738. 
Watson, J . D., \& Crick, F. H. (1953). The structure of DNA. Cold Spring Harbour Symposia on Quantitative Biology, 18, 123-131.

Weinberger, M. H. (1991). Salt sensitive human hypertension. Endocrine research, 17, 43-51.

Weingardt, K. R., \& Villafranca, S. W. (2005). Translating research into practice: The role of web-based education. . Journal of Technology in Human Services 23, 259-273

Weinstein, N. D. (1980). Unrealistic optimism about future life events. J ournal of Personality and Social Psychology, 39, 806-820.

Weinstein, N. D. (1982). Unrealistic optimism about susceptibility to health problems. J ournal of Behavioural Medicine, 5, 441-460.

Weinstein, N. D. (1987). Unrealistic optimism about susceptibility to health problems: Conclusions from a community-wide sample. Journal of Behavioural Medicine, 10, 481-500.

Weinstein, N. D. (1988). The precaution adoption process. Health Psychology, 7, 355-386.

Welkenhuysen, M., Evers-Kiebooms, G., Decruyenaere, M., Claes, E., \& Denayer, L. (2001). A community based study on intentions regarding predictive testing for hereditary breast cancer. J ournal of Medical Genetics, 38, 540547.

Wiebe, D. J., \& Black, D. (1997). Illusional beliefs in the context of risky sexual behaviors. J ournal of Applied Social Psychology, 27, 1727-1749.

Wonkam, A., Njamnshi, A. K., \& Angwafo, F. F. I. (2006). Knowledge and attitudes concerning medical genetics amongst physicians and medical students in cameroon (sub-saharan africa). Genetics in Medicine, 8, 331-338.

World Health Organization. (2002). Genomics and world health. Geneva: World Health Organization.

Wright, A. J., Aveyard, P., Guo, B., Murphy, M., Brown, K., \& Marteau, T. M. (2007). Is attributing smoking to genetic causes associated with a reduced probability of quit attempt success? A cohort study. Addiction, 102, 16571664.

Wright, A. J ., French, D. P., Weinman, J ., \& Marteau, T. M. (2006). Can genetic risk information enhance motivation for smoking cessation? An analogue study. Health Psychology, 25, 740-752.

Wright, A. J ., Weinman, J., \& Marteau, T. M. (2003). The impact of learning of a genetic predisposition to nicotine dependence: An analogue study. Tobacco Control, 12, 227-230.

Zimmern, R., Emery, J., \& Richards, T. (2001). Putting genetics in perspective. British Medical J ournal, 322, 1005-1006. 


\section{Appendix 1: Stimulus materials for studies 4.1A and B.}

\section{Genetic information scenario}

Researchers have announced that blood pressure responses to salt intake vary between individuals. Until fairly recently, salt intake was assumed to cause elevated blood pressure. The research team, however, has identified a gene which contributes to elevated blood pressure in response to salt intake.

Hypertension is an important risk factor for cardiovascular disease. In other words, if you are hypertensive, your risk of cardiovascular disease will increase. Hypertension is caused by lifestyle and environmental factors. The relationship between elevated blood pressure and salt intake, a lifestyle factor, is well known. However, researchers have announced that this relationship does not apply to everyone. "Not everyone is sensitive to salt intake", according to the project leader. "People without a genetic predisposition to salt-sensitive blood pressure may consume salt as usual."

The research team advises people with salt-sensitive blood pressure to restrict their salt intake in order to reduce their risk of cardiovascular disease.

\section{General information scenario}

Researchers have announced that blood pressure responses to salt intake vary between individuals. Until fairly recently, salt intake was assumed to cause elevated blood pressure.

Hypertension is an important risk factor for cardiovascular disease. In other words, if you are hypertensive, your risk of cardiovascular disease will increase. Hypertension is caused by lifestyle and environmental factors. The relationship between elevated blood pressure and salt intake is well known. However, researchers have announced that this relationship does not apply to everyone. "Not everyone is sensitive to salt intake", according to the project leader. "People without salt-sensitive blood pressure may consume salt as usual."

The research team advises people with salt-sensitive blood pressure to restrict their salt intake in order to reduce their risk of cardiovascular disease. 


\section{Appendix 2: Stimulus material for study 4.2}

\section{Genetic information scenario}

Scientists agree that high cholesterol levels are a risk factor for cardiovascular diseases. A 10\% elevation of cholesterol levels results in a 20$30 \%$ higher risk of cardiovascular diseases.

Cholesterol is a greasy substance found in the blood and cells and is a necessary component of hormones and gall. It can be divided into two types: low-density lipoprotein (LDL) and high-density lipoprotein (HDL)

LDL is also referred to as 'bad' cholesterol because it attaches to the walls of blood vessels. Consequently, blood vessels can become 'silted up', which could ultimately cause a stroke. HDL, on the other hand, maintains the discharge of cholesterol in the feces. It protects the body against cardiovascular diseases.

Several factors contribute to cholesterol levels. Overweight individuals and those who do not exercise regularly usually have high cholesterol. The consumption of fat also particularly contributes to high cholesterol. However, certain people may also have a genetic predisposition to developing high cholesterol and are thus at increased risk.

\section{General information scenario}

Scientists agree that high cholesterol levels are a risk factor for cardiovascular diseases. A $10 \%$ elevation of cholesterol levels results in a 20$30 \%$ higher risk of cardiovascular diseases.

Cholesterol is a greasy substance found in the blood and cells and is a necessary component of hormones and gall. It can be divided into two types: low-density lipoprotein (LDL) and high-density lipoprotein (HDL)

LDL is also referred to as 'bad' cholesterol because it attaches to the walls of blood vessels. Consequently, blood vessels can become 'silted up' which could ultimately cause a stroke. HDL, on the other hand, maintains the discharge of cholesterol in the feces. It protects the body against cardiovascular diseases.

Several factors contribute to cholesterol levels. Overweight individuals and those who do not exercise regularly usually have high cholesterol levels. The consumption of fat also particularly contributes to high cholesterol levels. 


\section{Summary}

Professional knowledge of genetics has increased vastly since the completion of the Human Genome Project (Collins et al., 2003; National Institutes for Health, 2009). Since then, approximately 200 o disease genes have been discovered and genetic tests are available for 350 diseases (National Institutes for Health, 2009). Several authors have suggested that the ultimate and immediate value of such technological applications of genetics can be greatly enhanced by public education of genetics (Burke et al., 2002; Wang et al., 2005).

The mass media has eagerly reported on the announcement of the Human Genome Project (Tambor et al., 2002) and resulting discoveries of disease genes (Bubela \& Caulfield, 2004). However, the mass media lack the ability to individualize risks for individual members of the general population by referring to individual differences in DNA structure (Guttmacher \& Collins, 2005; J anssens $\&$ Van Duijn, 2008). As such, the mass media may not be suitable for promoting precautionary action based on genetic information.

The aims of the dissertation were to examine (1) the current level of genetic knowledge among the general population; (2) the ability (or lack thereof) of mass media genetic health messages to enhance preventive behaviour among the general population; (3) whether the effects of genetic health messages differ according to whether message recipients are aware or unaware of the existence of these genetic risk factors at the moment of information exposure; (4) the role of information acceptance and perceived personal relevance of the health message; (5) the delayed effects of genetic health messages.

Using a diffusion of innovations approach, this dissertation will first present an overview of current public knowledge of genetics. Afterwards, the effects of genetic health messages on risk perception, intention to engage in preventive behaviour and preventive behaviour were examined. In Chapters 2 and 3, the first step of the innovationdecision process (i.e. knowledge) is examined while Chapters 4, 5, and 6 focus on the persuasion, decision and implementation steps.

Chapter 2 introduces Rogers' knowledge framework and argues that is a sophisticated tool to understand current public knowledge of genetic risk factors of multifactorial diseases. This framework distinguishes three increasingly complex forms of knowledge: "awareness knowledge", "how-to knowledge", and "principles knowledge". The value of this framework was illustrated by a systematic review of current research into the general public's knowledge of genetics. Based on this review, Rogers' knowledge framework may be a useful tool for assessing different types of public 
knowledge and pinpointing flaws or caveats in public knowledge with more precision and subsequently develop public health campaigns to remedy these flaws.

The knowledge framework was then applied to understand the Dutch general population's knowledge of genetics (in Chapter 3). A sample representative of the Dutch general population was asked questions regarding awareness knowledge, how-to knowledge and principles knowledge. The results suggest that the general public is moderately aware of genetic risk factors for multifactorial diseases. In general, how-to knowledge seems somewhat limited, whereas principles knowledge is limited and superficial.

Based on the results from Chapters 2 and 3 combined with the assumptions of the knowledge framework, alerting the general population to the existence of genetic risks is a necessary first step in public education of genetics. Chapter 4 describes three experiments examining the effects of genetic versus general health messages on risk perception and the intention to engage in preventive behaviour. The results revealed lower perceived susceptibility among participants who received information on genetic risk factors, which is associated with lowered intentions to engage in preventive behaviour. In Studies 4.1A and 4.1B, these effects were only observed for previously unaware individuals, whereas in Study 4.2 they were observed for the entire sample.

The study presented in Chapter 5 remedied several limitations of the studies presented in Chapter 4 (e.g., the lack of pre-test assessments of the dependent measures) while also examining the role of information acceptance and perceived personal relevance. The results showed that participants who were aware of genetic risk factors for salt sensitivity (either at the moment of information exposure or because they read the genetic health message) were less inclined to perceive the genetic health message as personally relevant compared to the general health message. Consequently, these participants reported lower perceived susceptibility and a negative attitude towards salt restriction, which was associated with a lower intention to restrict salt intake and more salt consumption.

Finally, in Chapter 6 the longitudinal effects of genetic health messages were examined. Health messages communicating the role of genes in health and disease are increasingly prevalent in our society. Immediate adverse effects of genetic health messages on perceived susceptibility were observed, but only among previously unaware participants. However, these adverse effects were not observed on the 1 month and 6 months follow-up measurements.

The results from these Chapters were discussed in the light of this dissertation's aim in the general discussion. A theoretical framework 
is presented that may shed light on the cognitive mechanisms responsible for the observed results. This framework may simultaneously inform future research into the diffusion of genetic knowledge to the general population. 


\section{Samenvatting}

Sinds de voltooiing van het Human Genome Project is de professionele kennis over de relatie tussen genetica en ziekte enorm toegenomen Sindsdien zijn ongeveer 2000 ziektegenen ontdekt en zijn genetische test voor meer dan 350 ziektes beschikbaar. Verschillende auteurs hebben gesuggereerd dat de uiteindelijke en onmiddellijke maatschappelijke waarde van dergelijke technologische toepassingen van genetica enorm kan worden verbeterd door het algemene publiek voor te lichten over genetica. Wanneer de doelgroep het algemeen publiek betreft geniet een massamediale aanpak vaak de voorkeur onder gezondheidsvoorlichters vanwege diens grote reikwijdte.

De massa media hebben veelvuldig gerapporteerd over het Human Genome Project en de daaruit volgende ontdekkingen van ziekte genen. Massacommunicatie is echter ongericht en heeft niet het vermogen om risico's te individualiseren en kan hooguit in zijn algemeenheid wijzen op mogelijke individuele verschillen in DNA structuur. De massa media lijken door het ontbreken van persoonlijk relevantie dientengevolge niet het ideale communicatiekanaal om preventieve actie te bevorderen op basis van genetische informatie. Desalniettemin dient deze veronderstelling te worden onderzocht.

Een eerste stap in het formuleren van een communicatie-uiting is af te tasten wat de doelgroep al weet. Vervolgens is het van belang te onderzoeken welke detaillering aan informatie al bekend is bij het publiek teneinde het gewenste preventieve response te kunnen vertonen. Indien de gewenste inhoud van de boodschap bekend is, zal de voorlichtingsboodschap op zijn effecten dienen te worden onderzocht en dienen de parameters waaronder een effect al dan niet optreedt te worden achterhaald.

De doelen van deze dissertatie waren derhalve:

(1) het vaststellen van het huidige niveau van kennis van genetica onder het algemene publiek;

(2) het onderzoeken van het vermogen van genetische gezondheidsboodschappen om preventief gedrag te bevorderen;

(3) nagaan of de effecten van genetische gezondheidsboodschappen verschillen tussen ontvangers die bewust dan wel onbewust waren van deze informatie ten tijde van blootstelling aan de genetische gezondheidsboodschap;

(4) het onderzoeken van de rol van de geloofwaardigheid en de waargenomen persoonlijke relevantie van de genetische gezondheidsboodschap onder het algemene publiek; en

(5) het onderzoeken of een theoretisch gefundeerd raamwerk, in dezen het 'materialistische' raamwerk, een mogelijke verklaring kan 
zijn voor de geobserveerde resultaten die voortkomen uit onderzoek verricht ten behoeve van doelen 2 en 3 . Volgens dit raamwerk zullen personen na het lezen van een genetische boodschap denken dat de desbetreffende aandoening volkomen genetisch is bepaald. Als gevolg hiervan kunnen personen defensief reageren en een lagere vatbaarheidinschatting maken. Echter als men geen genetische boodschap leest zal het eigen gedrag als belangrijkste oorzaak voor een aandoening worden aangemerkt. Dit zal waarschijnlijk niet leiden tot een defensieve lage vatbaarheidinschatting.

In de diverse hoofdstukken van dit proefschrift kwamen de volgende aspecten naar voren. Gebruikmakend van een Diffusie van Innovaties benadering, werd eerst een overzicht van de huidige publieke kennis van genetica gepresenteerd. Vervolgens werden de effecten van genetische gezondheidsboodschappen op risico perceptie, intentie en preventief gedrag beschreven. In hoofdstukken 2 en 3 werd over de eerste stap van Rogers innovatie-besluit proces gerapporteerd. Hoofdstukken 4, 5 en 6 richtten zich op de beschrijving van de overtuiging, besluit en implementatie fasen van dit zelfde proces.

$\mathrm{Nu}$ volgende de hoofdstukken beschreven in iets meer detail. Hoofdstuk 2 introduceerde het kennis raamwerk van E.M. Rogers en beargumenteerde dat dit raamwerk een waardevol hulpmiddel zou kunnen zijn om de huidige publieke kennis van genetische risicofactoren voor multifactoriële ziekten te begrijpen. Dit raamwerk onderscheidt drie soorten kennis: 'awareness' (bewustzijn) kennis, 'how-to' (hoe te handelen) kennis en principles (werkingsmechanismen) kennis. De waarde van het raamwerk werd geillustreerd door het uitvoeren van een systematische literatuurstudie van bestaand onderzoek naar publieke kennis van genetica. Op basis van dit literatuuronderzoek werd geconcludeerd dat het kennis raamwerk van Rogers een waardevol hulpmiddel was voor het vaststellen van verschillende soorten publieke kennis. Bovendien bleek het meer precieze informatie over de aard van beperkingen in publieke kennis te geven en als basis te kunnen dienen om deze beperkingen te verhelpen.

Het kennis raamwerk van Rogers werd in hoofdstuk 3 toegepast om een beeld te krijgen over de drie typen kennis van genetica onder het algemene Nederlandse publiek. Een representatieve steekproef van de Nederlandse bevolking werd via Internet een vragenlijst over genetica voorgelegd met als doel de kennis over genetica te meten. Deze vragenlijst was gebaseerd op het kennis raamwerk van Rogers en bevatte dus vragen over awareness kennis, how-to kennis en principles kennis. De resultaten suggereerden dat het algemene publiek slecht tot redelijk bewust was van het bestaan van genetische 
risicofactoren voor multifactoriële ziekten. Over het algemeen bleek dat how-to kennis over genetica beperkt was en dat priniciples kennis ook gebrekkig en oppervlakkig was.

Op basis van de bevingen in hoofdstukken 2 en 3 én de aanname van het kennis raamwerk dat awareness kennis een eerste belangrijke stap is in het verspreiden van kennis over genetica, lijkt het waarschuwen van het algemene publiek voor het bestaan van genetische risicofactoren voor multifactoriële ziekten een belangrijke eerste stap in publieke voorlichting over genetica.

Hoofdstuk 4 beschreef drie experimentele studies naar de effecten van genetische versus algemene gezondheidsboodschappen op risicoperceptie en de intentie om preventief gedrag te vertonen. De resultaten lieten zien dat onder personen die onbewust waren van het bestaan van genetische risicofactoren voor zoutgevoeligheid ten tijde van blootstelling aan de boodschap, de genetische boodschap resulteerde in een lagere vatbaarheidinschatting en dientengevolge een lagere intentie om het zoutgebruik te gaan beperken vergeleken met personen die de algemene boodschap ontvingen. Onder personen die bewust waren van het bestaan van genetische risicofactoren voor zoutgevoeligheid werden dergelijke verschillen tussen de genetische en algemene gezondheidsboodschappen niet gevonden.

De studie die beschreven werd in hoofdstuk 5 hield rekening met enkele methodologische tekortkomingen van de studies uit hoofdstuk 4 (zoals het meten van de afhankelijke variabelen voor en na de experimentele manipulatie). Tevens werd in deze studie de rol van de geloofwaardigheid en waargenomen persoonlijke relevantie van de genetische gezondheidsboodschap onderzocht, en hun mogelijk rol in het verklaren van de bevindingen uit de eerdere studies. Gebruikmakend van dezelfde materialen en procedure toonden de resultaten aan dat personen die zich bewust zijn van de genetische risicofactoren voor zoutgevoeligheid (zowel voorafgaand aan het experiment als door blootstelling aan de genetische gezondheidsboodschap) minder vaak aangaven de gezondheidsboodschap als persoonlijk relevant te ervaren dan personen die zich niet bewust waren van deze factoren. Als gevolg van een lagere inschatting van de persoonlijke relevantie, hadden onbewuste proefpersonen een lagere vatbaarheidinschatting en indirect een lagere intentie om het zout te beperken na het lezen van een genetische boodschap.

Tot slot werd in hoofdstuk 6 onderzocht of het materialistische raamwerk een goede verklaring kon bieden voor de resultaten uit hoofdstukken 4 en 5. In overeenstemming met deze studies werd meteen na het lezen van de genetische gezondheidsboodschap een lagere vatbaarheidinschatting geobserveerd onder onbewuste 
personen. Deze effecten waren echter niet meer aanwezig bij de twee nametingen van, respectievelijk, 1 en 6 maanden later. Deze bevindingen kwamen overeen met de voorspellingen van het materialistische raamwerk voor publieke kennis van genetica.

In de algemene discussie werden de resultaten van de studies bediscussieerd aan de hand van de doelen van deze dissertatie. Een theoretisch kader werd geschetst dat enig licht kon werpen op de cognitieve mechanismen die verantwoordelijk zouden kunnen zijn voor de huidige bevindingen. Dit kader zou als basis kunnen dienen voor toekomstig onderzoek naar de diffusie van genetische kennis onder de algemene bevolking. 


\section{Dankwoord}

Gelukkig heb ik de gelegenheid om hier een aantal mensen te bedanken voor hun, al dan niet wetenschappelijke, bijdrage aan mijn proefschrift. Het cliché wil dat zonder jullie hulp dit proefschrift niet tot stand was gekomen. Wat haat ik het toch als clichés waar blijken te zijn!

Mijn begeleiders, Ilse, Hein en Nanne: Bedankt voor de motivatie, vrijheid en wetenschappelijke discussies. Ik heb veel van jullie geleerd en hoop nog veel van jullie te mogen leren.

Collega's, vrienden: bedankt voor de gezellige tijd! (gezelligheid kent geen tijd)

Mijn moeder en zusjes: jullie onvoorwaardelijke acceptatie is het grootste geschenk dat jullie mij hebben gegeven (ja, ik weet het: alweer een cliché).

Zo, genoeg tegeltjeswijsheden. Rest mij alleen nog te zeggen:

J anaica: mijn alles, mij niets. 'Your existence is all I need.' 


\section{Curriculum Vitae}

Chris Smerecnik was born on Novermber $15^{\text {th }} 1980$ and grew up in Brunssum in the South of Limburg. After having graduated high school in 1998, he reluctantly started studying Psychology at Maastricht University.

He quickly fell in love with its intricacies and uncertainties. He chose cognitive ergonomics as his major subject. During the last year of his study he focused his efforts on health psychology as a studentassistant and intern at the department of Work and Social Psychology. He graduated in 2006.

On August 15th 2006, Chris started as a PhD student at the Department of Health Promotion of Maastricht University, where he completed his dissertation in three years.

Publications

Kok, G., Gottlieb, N., Commers, M., \& Smerecnik, C. (2008). The ecological approach in health promotion programs: A decade later. American J ournal of Health Promotion, 22, 437-442.

Smerecnik, C. M. R. \& Mesters, I. (2007). Validating the Medical Data Interpretation Test in a Dutch population. Patient Education and Counseling, 68, 287-290.

Smerecnik, C. M. R., Mesters, I., De Vries, N. K., \& De Vries, H. (2009). Alerting the general population to genetic risks: The value of health messages communicating the existence of genetic risk factors for public health promotion. Health Psychology, 28, 734-745.

Smerecnik, C. M. R., Mesters, I., De Vries, N. K., \& De Vries, H. (in press). Applying a theory-based framework to understand public knowledge of genetic risk factors: A case for the distinction between how-to knowledge and principles knowledge. Public Health Genomics.

Smerecnik, C. M. R., Mesters, I., De Vries, N. K., \& De Vries, H. (2008). Educating the general population about multifactorial genetic disease: Applying a theory-based framework to understand current public knowledge. Genetics in Medicine, $10,251-258$.

Smerecnik, C. M. R., Mesters, I., Van Keulen, H., Scheffers, I., Beeks, E., De Leeuw, P. W., De Vries, N. K., \& De Vries, H. (2007). Should individuals be informed about their salt sensitivity status? First indications of the value of testing for genetic predispositions to low-risk conditions. Genetic Testing, 11, 307-314. 
Smerecnik, C. M. R., Mesters, I., Verweij, E., De Vries, N. K., \& De Vries, H. (2009). A systematic review of the impact of genetic counseling on risk perception accuracy. J ournal of Genetic Counseling, 18, 217-228.

Van 't Riet, J., Ruiter, R. A. C., Smerecnik, C., \& De Vries, H. (in press). Examining the influence of self-efficacy on messageframing effects: Reducing salt consumption in the general population. Basic and Applied Social Psychology.

Submitted manuscripts

Smerecnik, C. M. R., Mesters, I., Candel, M. J . J . M., De Vries, H. \&De Vries, N. K.

Genetic health messages in the mass-media: Do the general public perceive non-personalised genetic health message as personally relevant?

Smerecnik, C. M. R., Mesters, I., De Vries, H. \&De Vries, N. K. An empirical test of the materialist framework for understanding the general population's reaction to genetic health messages.

Smerecnik, C. M. R., Mesters, I., Kessels, L. T. E., Ruiter, R. A. C., De Vries, H. \& De Vries, N. K.

Understanding the positive effects of graphical risk information on comprehension: Measuring attention to written, tabular and graphical risk information.

Smerecnik, C. M. R \& Ruiter, R. A. C.

Fear appeals in HIV prevention: The role of anticipated regret.

Smerecnik, C. M. R., Schaalma, H., Kok, G., Meijer, S., Poelman, J . Muslim adolescents and their views on sexuality: Using Internet forums as a means of qualitative research.

Smerecnik, C. M. R., Schutte, L., \& Van `t Riet, J .

Gain- and loss-framed messages affect intention through distinct pathways: The role of information processing, risk perception and attitude.

Smerecnik, C. M. R.

Media coverage of genetics and genetic determinism: Effects of genetic health messages on the perceived impact of genetic versus lifestyle factors. 